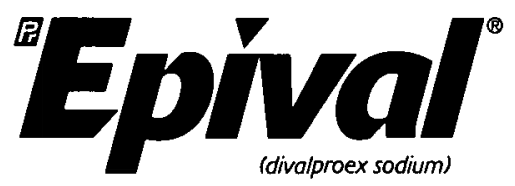

\section{PRESCRIBING INFORMATION}

NAME OF DRUG: EPIVAL ${ }^{\circ}$ (divalproex sodium)
Enteric-Coated Tablets

\section{THERAPEUTIC CLASSIFICATION: Anticonvulsant}

ACTION AND CLINICAL PHARMACOLOGY: EPIVAL ${ }^{\circ}$ divalproex sodium) has anticonvulsant properties, and is chemically related to valproic acid. Although its mechanism of action has not yet been established, it has been suggested that its activity is related to increased brain levels of gamma-aminobutyric acid (GABA). The effect on the neuronal membrane is unknown. EPIVAL ${ }^{\circ}$ dissociates into valproic acid in the gastrointestinal tract.

Peak serum levels of valproic acid occur in 3 to 4 hours.

The serum half-life $(\mathrm{t} / \mathrm{s})$ of valproic acid is typically in the range of 6 to 16 hours. Half-lives in the lower part of the above range are usually found in patients taking other drugs capable of enzyme induction. Enzyme induction may result in enhanced clearance of valproic acid by glucuronidation and microsomal oxidation. Because of these changes in valproic acid clearance, monitoring of valproate and concomitant drug concentrations should be intensified whenever enzyme-inducing drugs are introduced or withdrawn. A slight delay in absorption occurs when the drug is administered with meals but this does not affect the total absorption. Valproic acid is rapidly distributed throughout the body and the drug is strongly bound $(90 \%)$ to human plasma proteins. Increases in doses may result in decreases in the extent of protein binding and variable changes in valproic acid clearance and elimination. In epilepsy, the therapeutic plasma concentration range is believed to be from 50 to $100 \mu \mathrm{g} / \mathrm{mL}$. Occasional patients may be controlled with serum levels lower or higher than this range. A good correlation has not been estabtished between daily dose. serum level and therapeutic effect. In placebo-controlled clinical studies in acute mania, $79 \%$ of patients were dosed to a plasma concentration between $50 \mu \mathrm{gg} / \mathrm{mL}$ and $125 \mathrm{\mu g} / \mathrm{mL}$. Protein binding of valproate is saturable ranging from $90 \%$ at $50 \mu \mathrm{g} / \mathrm{mL}$ to $82 \%$ at $125 \mu \mathrm{g} / \mathrm{mL}$.

Elimination of valproic acid and its metabolites occurs principally in the urine, with minor amounts in the teces and expired air. Very little unmetabolized parent drug is excreted in the urine. The principat metabolite formed in the liver is the glucuronide conjugate. Other metabolites in the urine are products of $\mathrm{C}-3, \mathrm{C}-4$ and $\mathrm{C}-5$ oxidation. The major oxidative metabolite in the urine is 2-propyl-3-keto-pentanoic acid; minor metabolites are 2-propyl-glutaric acid, 2-propyl5-hydroxy-pentanoic acid, 2-propy-3-hydroxy-pentanoic acid and 2-propyl-4-hydroxy-pentanoic acid.

(See WARNINGS regarding statement on fatal hepatic dystunction.) INOICATIONS AND CLINICAL USE:

Epilepsy: EPIVAL ${ }^{\circ}$ (divalproex sodium) is indicated for use as sote or adjunctive therapy in the treatment of simple or complex absence seizures, including petit mal and is useful in primary generalized seizures with tonic-clonic manifestations. Divalproex sodium may also be used adjunctively in patients with multiple seizure types which include either absence or tonic-clonic seizures.

Acute Mania: EPIVAL ${ }^{\circ}$ (divalproex sodium) is indicated in the treatment of the manic episodes associated with bipolar disorder (DSMIII-R).

The effectiveness of EPIVAL ${ }^{\circ}$ in long-term use, that is for more than 3 weeks, has not been systematically evaluated in controlled trials. EPIVAL ${ }^{\circ}$ is not indicated for use as a mood stabilizer in patients under 18 years of age.

CONTRAINDICATIONS: EPIVAL ${ }^{\circ}$ (divalproex sodium) should not be administered to patients with hepatic disease or significant dysfunction; it is contraindicated in patients with known hypersensitivity to the drug.

WARNINGS: Hepatic failure resulting in fatalities has occurred in patients receiving valproic acid and its derivatives. These incidences usually occurred during the first six months of treatment with valproic acid. Experience has indicated that children under the age of two years are at a considerably increased risk of developing fatal hepatotoxicity, especially those on multiple anticonvulsants, those with congenital metabolic disorders, those with severe seizure disorders accompanied by mental retardation, and those with organic brain disease.

The risk in this age group decreased considerably in patients receiving valproate as monotherapy. Similarly, patients aged 3 to 10 years were at somewhat greater risk if they received multiple anticonvul. sants than those who received only valproate. Risk generally declined with increasing age. No deaths have been reported in patients over 10 years of age who received valproate alone.

If EPIVAL ${ }^{\circ}$ is to be used for the control of seizures in children two years old or younger, it should be used with extreme caution and as a sole agent. The benefits of therapy should be weighed against the risks.

Serious or fatal hepatotoxicity may be preceded by non-specific symptoms such as malaise, weakness, lethargy, facial edema, anorexia, vomiting, and in epileptic patients, loss of seizure control. Patients and parents should be instructed to report such symptoms. Because of the non-specific nature of some of the early signs, hepatotoxicity should be suspected in patients who become unwell, other than through obvious cause, while taking EPIVAL ${ }^{\circ}$ (divalproex sodium).
Ler function tesis should be performed prior to therapy and at freuent intervals thereafter especially during the first 6 months. However, physicians should not rely totally on serum biochemistry since these tests may not be abnormal in all instances, but should also consider the results of careful interim medical history and physical examination. Caution should be observed when administering EPIVAL ${ }^{\circ}$ to patients with a prior history of hepatic disease. Patients with various unusual congenital disorders, those with severe seizure disorders accompanied by mental retardation, and those with organic brain disease may be at particular risk.

In high-risk patients, it might also be useful to monitor serum fibrinogen and albumin for decreases in concentration and serum ammonia for increases in concentration. If changes occur divalproex sodium should be discontinued. Dosage should be titrated to and maintained at the lowest dose consistent with optimat seizure control.

The drug should be discontinued immediately in the presence of significant hepatic dysfunction, suspected or apparent. In some cases, hepatic dysfunction has progressed in spite of discontinuation of drug. The frequency of adverse effects (particularly elevated liver enzymes) may increase with increasing dose. The benefit of improved symptom control at higher doses should therefore be weighed against the possibility of a greater incidence of adverse effects.

Use in pregnancy: According to recent reports in the medical literature, valproic acid may produce teratogenicity in the offspring of human females receiving the drug during pregnancy. The incidence of neural tube defects in the fetus may be increased in mothers receiving valproic acid during the first trimester of pregnancy. Based upon a single report, It was estimated that the risk of valproic acidexposed women having children with spina bifida is approximately $1-2 \%$. This risk is similar to that which applies to non-epileptic women who have had children with neural tube defects (ANENCEPHALY AND SPINA BIFIDA).

Animal studies have demonstrated valproic acid-induced teratogenicity (see Reproduction and Teratology under TOXICOLOGY) and studies in human females have demonstrated placental transfer of the drug.

Multiple reports in the clinical literature indicate an association between the use of antiepileptic drugs and an elevated incidence of birth defects in children born to epileptic women taking such medication during pregnancy. The incidence of congenital malformations in the general population is regarded to be approximately $2 \%$ in children of treated epileptic women, this incidence may be increased 2 to 3-fold. The increase is largely due to specific defects, e.g. congenital malformations of the heart, cleft lip and/or palate, craniofacial abnormalities and neural tube defects. Nevertheless, the great majority of mothers receiving antiepileptic medications deliver normal infants.

Data are more extensive with respect to diphenylhydantoin and phenobarbital, but these drugs are also the most commonly prescribed antiepileptics. Some reports indicate a possible simila association with the use of other antiepileptic drugs, including trimethadione, paramethadione, and valproic acid. However, the possibility also exists that other factors, e.g. genetic predisposition or the epileptic condition itself may contribute to or may be mainly responsible for the higher incidence of birth defects.

Patients taking valproic acid may develop clotting abnormalities. I valproic acid is used in pregnancy, the clotting parameters should be monitored carefully.

Antiepileptic drugs should not be discontinued in patients to whom the drug is administered to prevent major seizures, because of the strong possibility of precipitating status epilepticus with attendant hypoxia and risks to both the mother and the unborn child. With regard to drugs given for minor seizures, the risks of discontinuing medication prior to or during pregnancy should be weighed against the risk of congenital defects in the particular case and with the particular family history.

Epileptic women of childbearing age should be encouraged to seek the counsel of their physician and should report the onset of pregnancy promptly to him. Where the necessity for continued use of antiepileptic medication is in doubt, appropriate consultation is indicated.

Risk-benefit must be carefully considered when treating women of childbearing age tor bipolar disorder.

Tests to detect neural tube and other defects using current accepted procedures should be considered a part of routine prenatal care in childbearing women receiving valproate.

Use in Nursing Mothers: Valproic acid is excreted in breast milk. Concentrations in breast milk have been reported to be 1 to $10 \%$ of serum concentrations. As a general rule, nursing should not be undertaken while a patient is receiving EPIVAL ${ }^{\circ}$ (divalproex sodium). It is not known what effect this may have on a nursing infant. Fertility: The effect of valproate on testicular development and on sperm production and fertility in humans is unknown. (See TOXICOLOGY: Fertility, for results in animal studies.

Long-term animal toxicity studies indicate that valproic acid is a weak carcinogen or promoter in rats and mice. The significance of these findings for man is unknown at present.

PRECAUTIONS:

Hepatic dysfunction: See CONTRAINDICATIONS and WARNINGS.

General: Because of reports of thrombocytopenia, inhibition of the second phase of platelet aggregation, platelet counts and coagulation tests are recommended before instituting therapy and at periodic intervals. It is recommended that patients receiving EPIVAL (divalproex sodium) be monitored for platelet count and coagula tion parameters prior to planned surgery.

Clinical evidence of hemorrhage, bruising or a disorder of hemostasis/coagulation is an indication for reduction of EPIVAL ${ }^{\circ}$ (dival- tion.

Hyperammonemia with or without lethargy or coma has been reported and may be present in the absence of abnormal liver function tests; if elevation occurs the divalproex sodium should be discontinued.

EPIVAL ${ }^{\circ}$ (divalproex sodium) is partially eliminated in the urine as a ketone-containing metabolite which may lead to a false interpretation of the urine ketone test.

There have been reports of altered thyroid function tests associated with valproic acid: the clinical significance of these is unknown.

Renal Impairment: Renal impairment is associated with an increase in the unbound fraction of valproate. In several studies, the unbound fraction of valproate in plasma from renally impaired patients was approximately double that for subjects with normal renal function. Hemodialysis in renally impaired patients may remove up to $20 \%$ of the circulating valproate.

Use in the Elderly: The safety and efficacy of EPIVAL ${ }^{\circ}$ in elderly patients with epilepsy and mania has not been systematically evaluated in clinical trials. Caution should thus be exercised in dose selection for an elderly patient, recognizing the more frequent hepatic and renal dysfunctions, and limited experience with EPIVAL ${ }^{\circ}$ in this population.

Driving and Hazardous Occupations: EPIVAL ${ }^{\circ}$ (divalproex sodium) may produce CNS depression, especially when combined with another CNS depressant, such as alcohol. Therefore, patients should be advised not to engage in hazardous occupations, such as driving a car or operating dangerous machinery, until it is known that they do not become drowsy from the drug.

Drug Interactions: EPIVAL ${ }^{\circ}$ (divalproex sodium) may potentiate the CNS depressant action of alcohol.

The concomitant administration of valproic acid with drugs that exhibit extensive protein binding (e.g., aspirin, carbamazepine and dicumarol) may result in alteration of serum drug levels.

Aspirin and Warfarin: Caution is recommended when EPIVAL ${ }^{\circ}$ is administered with drugs affecting coagulation (e.g., aspirin and warfarin). (See ADVERSE REACTIONS.)

Phenobarbital: There is evidence that valproic acid may cause an increase in serum phenobarbital levels, by impairment of non-renal clearance. This phenomenon can result in severe CNS depression. The combination of valproic acid and phenobarbital has also been reported to produce CNS depression without significant elevations of barbiturate or valproic acid serum levels. Patients receiving concomitant barbiturate therapy should be closely monitored for neurological toxicity. Serum barbiturate drug levels should be obtained, if possible, and the barbiturate dosage decreased, if indicated. Primidone: Primidone is metabolized into a barbiturate, and therefore, may also be involved in a similar or identical interaction.

Phenytoin: There is conflicting evidence regarding the interaction of valproic acid with phenytoin. It is not known if there is a change in unbound (free) phenytoin serum levels. The dosage of phenytoin should be adjusted as required by the clinical situation. There have been reports of breakthrough seizures occurring with the combination of valproic acid and phenytoin.

Because EPIVAL ${ }^{\circ}$ (divalproex sodium) may interact with concurrently administered drugs which are capable of enzyme induction. periodic serum level determinations of these drugs are recommended during the eariy part of therapy.

Clonazepam: The concomitant use of valproic acid and clonazepam may produce absence status in patients with a history of absencetype seizures.

Oral contraceptives: Evidence suggests that there is an association between the use of certain drugs capable of enzyme induction and failure of oral contraceptives. One explanation for this interaction is that enzyme-inducing antiepileptic drugs effectively lower plasma concentrations of the relevant steroid hormones, resulting in unimpaired ovulation. However, other mechanisms, not related to enzyme induction, may contribute to the failure of oral contraceptives. Valproic acid is not a significant enzyme inducer and would not be expected to decrease concentrations of steroid hormones. However, clinical data about the interaction of valproic acid with oral contraceptives are minimal.

Seizures: In addition to enhancing central nervous system (CNS) depression when used concurrently with valproic acid, tricyclic antidepressants, MAO Inhibitors, and antipsychotics may lower the seizure threshold. Dosage adjustments may be necessary to control seizures.

Carbamazepine: Concomitant use of carbamazepine with valproic acid may result in decreased serum concentrations and hali-life of valproate due to increased metabollsm induced by hepatic microsomal enzyme activity. Valproate causes an increase in the active 10,11 -epoxide metabolite of carbamazepine by inhibition of its breakdown. Monitoring of serum concentrations is recommended when either medication is added to or withdrawn from an existing regimen. Changes in the serum concentration of the 10,11-epoxide metabolite of carbamazepine, however, will not be detected by routine serum carbamazepine assay.

Cimetidine: Cimetidine may decrease the clearance and increase the half-life of valproic acid by altering its metabolism. In patient receiving valproic acid, serum valproic acid levels should be monitored when treatment with cimetidine is instituted, increased decreased, or discontinued. The valproic acid dose should be adjusted accordingly.

Chlorpromazine: A single study has shown that the concomitan use of chlorpromazine with valproic acid may result in a decrease in valproic acid clearance Valproic acid serum concentrations and effects should be monitored when valproic acid is co-administered 
with chlorpromazine due to possible inhibition of valproic acid metabolism.

Selective serotonin re-uptake inhibitors (SSR/s): Some evidence suggests that SSRIs inhibit the metabolism of valproate, resulting in higher than expected levels of valproate.

Tricyclic antidepressants: The metabolism of amitriptyline and nortriptyline after a single dose of amitriptyline $(50 \mathrm{mg})$ was inhibited by multiple dosing with valproic acid ( $500 \mathrm{mg}$ twice daily) in sixteen healthy male and female volunteers. For the sum of amitriptyline and nortriptyline plasma concentrations, in the presence of valproic acid, the mean $C_{\max }$ and AUC were increased by $19 \%$ and $42 \%$, respectively.

Lithium: in a double-blind, placebo-controlled, multiple dose crossover study in 16 healthy male volunteers, pharmacokinetic parameters of lithium were not altered by the presence or absence of EPIVAL ${ }^{\circ}$. The presence of lithium, however, resulted in an $11 \%$. $12 \%$ increase in the AUC and $\mathrm{C}_{\max }$ of valproate. $\mathrm{T}_{\max }$ was also reduced. Although these changes were statistically significant, they are not likely to have clinical importance.

Benzodiazepines: Valproic acid may decrease oxidative liver metabolism of some benzodiazepines, resulting in increased serum concentrations. In two small studies in healthy volunteers, valproate produced a $17 \%$ decrease in the clearance of lorazepam, and $26 \%$ decrease in the clearance of unbound diazepam. Displacement of diazepam from plasma protein binding sites may also occur. During valproate administration the unbound fraction of diazepam in the serum increased approximately twofold.

\section{ADVERSE REACTIONS:}

Epilepsy: The most commonly reported adverse reactions are nausea vomiting and indigestion. Since valproic acid has usually been used with other antiepileptics, it is not possible in most cases to determine whether the adverse reactions mentioned in this section are due to valproic acid alone or to the combination of drugs.

Gastrointestinal: Nausea, vomiting and indigestion are the most commonly reported side effects at the initiation of therapy. These effects are usually transient and rarely require discontinuation of therapy. Diarrhea, abdominal cramps and constipation have also been reported. Anorexia with some weight loss and increased appetite with some weight gain have also been seen.

CNS Effects: Sedative effects have been noted in patients receiving valproic acid alone but are found most often in patients on combination therapy. Sedation usually disappears upon reduction of other antiepileptic medication. Ataxia, headache, nystagmus, diplopia, asterixis, "spots before the eyes", tremor (may be dose-related) dysarthria, dizziness, and incoordination have rarely been noted. Rare cases of coma have been reported in patients receiving valproic acid alone or in conjunction with phenobarbital.

Dermatologic: Transient increases in hair loss have been observed. Skin rash, photosensitivity, generalized pruritus, erythema multiforme, Stevens-Johnson syndrome and petechiae have rarely been noted.

Endocrine: There have been reports of irregular menses and secondary amenorrhea, breast enlargement, galactorrhea and parotid gland swelling in patients receiving valproic acid. Abnormal thyroid function tests have been reported (see PRECAUTIONS)

Psychiatric: Emotional upset, depression, psychosis, aggression, hyperactivity and behavioral deterioration have been reported.

\section{Musculoskeletal: Weakness has been reported.}

Hematopoietic: Thrombocytopenia has been reported. Valproic acid inhibits the second phase of platelet aggregation (see PRECAUTIONS). This may be reflected in altered bleeding time. Petechiae, bruising, hematoma formation and frank hemorrhage have been reported. Relative lymphocytosis, macrocytosis and hypofibrinogenemia have been noted. Leukopenia and eosinophilia have also been reported. Anemia, including macrocytic with or without folate deficiency, bone marrow suppression and acute intermittent porphyria have been reported.

Hepatic: Minor elevations of transaminases (e.g. SGOT and SGPT) and $\mathrm{LDH}$ are frequent and appear to be dose-related. Occasionally. laboratory tests also show increases in serum bilirubin and abnormal changes in other liver function tests. These results may reflect potentially serious hepatotoxicity (see WARNINGS).

Metabolic: Hyperammonemia (see PRECAUTIONS), hyponatremia and inappropriate $A D H$ secretion. Hyperglycinemia has been reported and associated with a fatal outcome in a patient with preexisting non-ketotic hyperglycinemia.

\section{Genitourinary: Enuresis}

Pancreatic: There have been reports of acute pancreatitis occurring in association with therapy with valproic acid.

Special Senses: Hearing loss, either reversible or irreversible, has been reported; however, a cause and effect relationship has not been established.

\section{Other: Edema of the extremities has been reported.}

Blpolar D|sorder: The incidence of adverse events has been ascertained based on data from two short-term (21 day) placebo-controlled clinical trials of divalproex sodium in the treatment of acute mania, and from two long-term (up to 3 years) retrospective open trials.

Most Commonly Ooserved: During the short-term placebo-controlled trials, the six most commonly reported adverse events in patients $(\mathrm{N}=89)$ exposed to divalproex sodium were nausea $(22 \%)$. headache $(21 \%)$, somnolence $(19 \%)$, pain $(15 \%)$, vomiting $(12 \%)$, and dizziness $(12 \%)$

In the long-term retrospective trials (634 patients exposed to divalproex sodium), the six most commonly reported adverse events were somnolence $(31 \%)$, tremor $(29 \%)$, headache $(24 \%)$, asthenia (23\%), diarrhea $(22 \%)$, and nausea $(20 \%)$

Associated with Discontinuation of Treatment: In the placebo-controlled trials, adverse events which resulted in valproate discontinuation in at least one percent of patients were nausea $(4 \%)$ abdominal pain ( $3 \%)$, somnolence ( $2 \%)$, and rash $(2 \%)$

In the long-term retrospective trials, adverse events which resulted in valproate discontinuation in at least one percent of patients were alopecia $(2.4 \%)$, somnolence $(1.9 \%)$, nausea $(1.7 \%)$, and tremor $(1.4 \%)$. The time to onset of these events was generally within the first two months of initial exposure to valproate. A notable exception was alopecia, which was first experienced after 3-6 months of exposure by 8 of the 15 patients who discontinued valproate in response to the event.

Controlled Trials: Table 1 summarizes those treatment-emergent adverse events reported for patients in the placebo-controlled trials when the incidence rate in the divalproex sodium group was at least $5 \%$. (Maximum treatment duration was 21 days; maximum dose in $83 \%$ of patients was between $1000 \mathrm{mg}-2500 \mathrm{mg}$ per day) Table 1

Treatment-Emergent Adverse Event Incidence $(25 \%)$ in ShortTerm Placebo-Controlled Trials

\begin{tabular}{|c|c|c|}
\hline \multirow[t]{2}{*}{ Body System/Event } & \multicolumn{2}{|c|}{ Pencentage of Patients } \\
\hline & $\begin{array}{c}\text { divalproex sodium } \\
(\mathrm{N}=89)\end{array}$ & $\begin{array}{l}\text { placebo } \\
(\mathrm{N}=97)\end{array}$ \\
\hline $\begin{array}{l}\text { Body as a Whole } \\
\text { Headache } \\
\text { Pain } \\
\text { Accidental injury } \\
\text { Asthenia } \\
\text { Abdominal Pain } \\
\text { Back Pain } \\
\text { Digestive System } \\
\text { Nausea } \\
\text { Vomiting } \\
\text { Diarrhea } \\
\text { Dyspepsia } \\
\text { Constipation } \\
\text { Nervous System } \\
\text { Somnolence } \\
\text { Dizziness } \\
\text { Tremor } \\
\text { Respiratory System } \\
\text { Pharyngitis } \\
\text { Skin and Appendages } \\
\text { Rash }\end{array}$ & $\begin{array}{r}21.3 \\
14.6 \\
11.2 \\
10.1 \\
9.0 \\
5.6 \\
\\
22.5 \\
12.4^{*} \\
10.1 \\
9.0 \\
7.9 \\
\\
19.1 \\
12.4 \\
5.6 \\
\\
6.7 \\
\\
5.6\end{array}$ & $\begin{array}{r}30.9 \\
15.5 \\
5.2 \\
7.2 \\
8.2 \\
6.2 \\
\\
15.5 \\
3.1 \\
13.4 \\
8.2 \\
8.2 \\
12.4 \\
4.1 \\
6.2 \\
9.3 \\
3.1\end{array}$ \\
\hline
\end{tabular}

"Statistically significant at $\rho \leq 0.05$ level.

Adverse Events in Elderly Patients: In elderly patients (above 65 years of age), there were more frequent reports of accidental injury, infection, pain, and to a lesser degree, somnolence and tremor, when compared to patients 18-65 years of age. Somnolence and tremor tended to be associated with the discontinuation of valproate.

SYMPTOMS AND TREATMENT OF OVEROOSAGE: In a reported case of overdosage with valproic acid after ingesting $36 \mathrm{~g}$ in combination with phenobarbital and phenytoin, the patient presented in deep coma. An EEG recorded diffuse slowing, compatible with the state of consciousness. The patient made an uneventful recovery, Naloxone has been reported to reverse the CNS depressant effects of valproic acid overdosage.

Because naloxone could theoretically also reverse the antiepileptic effects of EPIVAL ${ }^{\circ}$, it should be used with caution in patients with epilepsy.

Since EPIVAL ${ }^{\circ}$ tablets are enteric-coated, the benefit of gastric lavage or emesis will vary with the time since ingestion. General supportive measures should be applied with particular attention to the prevention of hypovolemia and the maintenance of adequate urinary output.

\section{DOSAGE AND ADMINISTRATION:}

Epilepsy: EPIVAL (divalproex sodium) is administered orally. The recommended initial dosage is $15 \mathrm{mg} / \mathrm{kg} /$ day, increasing at one week intervals by 5 to $10 \mathrm{mg} / \mathrm{kg} /$ day until seizures are controlled or side effects preclude further increases.

The maximal recommended dosage is $60 \mathrm{mg} / \mathrm{kg} /$ day. When the total daily dose is $125 \mathrm{mg}$ or greater, it should be given in a divided regimen (see Table 2).

The frequency of adverse effects (particularly elevated liver enzymes) may increase with increasing dose. Therefore, the benefit gained by improved seizure control must be weighed against the increased incidence of adverse effects.

Table 2

Initial Doses by Weight (based on $15 \mathrm{mg} / \mathrm{kg} /$ day)

\begin{tabular}{c|c|c|ccc}
\hline \multicolumn{2}{c|}{ Weight } & \multirow{2}{*}{ Total Daily } & \multicolumn{3}{c}{ Dosage (mg) } \\
Bquivatent to valproic acid \\
kg & lb & Dose (mg) & Dose 1 & Dose 2 & Dose 3 \\
\hline $10-24.9$ & $22-54.9$ & 250 & 125 & 0 & 125 \\
$25-39.9$ & $55-87.9$ & 500 & 250 & 0 & 250 \\
$40-59.9$ & $88-131.9$ & 750 & 250 & 250 & 250 \\
$60-74.9$ & $132-164.9$ & 1000 & 250 & 250 & 500 \\
$75-89.9$ & $165-197.9$ & 1250 & 500 & 250 & 500 \\
\hline
\end{tabular}

As the dosage of divalproex sodium is raised, blood levels of phenobarbital and/or phenytoin may be affected (see PRECAUTIONS, under Drug Interactions)

Patients who experience G.I. irritation may benefit from administration of the drug with food or by a progressive increase of the dose from an initial low level. The tablets should be swallowed without chewing.

Acute Mania: The recommended initial dose is $250 \mathrm{mg}$ three times a day. The dose should be increased as rapidly as possible to achieve the lowest therapeutic dose which produces the desired clinical effect or the desired range of plasma concentrations.

In placebo-controlled trials, $84 \%$ of patients received and tolerated maximum daily doses of between $1000 \mathrm{mg} /$ day to $2500 \mathrm{mg} / \mathrm{day}$ The maximum recommended dosage is $60 \mathrm{mg} / \mathrm{kg} /$ day.

The relationship of plasma concentration to clinical response has not been established for EPIVAL:. In controlled clinical studies $79 \%$ of patients achieved and tolerated serum valproate concentrations between $50 \mu \mathrm{g} / \mathrm{mL}$ and $125 \mu \mathrm{g} / \mathrm{mL}$.

When changing therapy involving drugs known to induce hepatic microsomal enzymes (e.g., carbamazepine) or other drugs with valproate interactions (see PRECAUTIONS, Drug Interactions), it is advisable to monitor serum valproate concentrations.

Conversion from Depakene" to EPIVAL": EPIVAL" (divalproex sodium) dissociates into valproic acid in the gastrointestinal tract. Divalproex sodium tablets are uniformly and reliably absorbed. however, because of the enteric-coating, absorption is delayed by an hour when compared with Depakene (valproic acid) capsules. The bioavailability of divalproex sodium tablets is equivalent to that of Depakene (valproic acid) capsules.

In patients previously receiving Depakene? (valproic acic) therapy, EPIVAL ${ }^{\circ}$ should be initiated at the same daily dose and dosing schedule. After the patient is stabilized on EPIVAL ${ }^{\circ}$, a dosing schedule of two or three times a day may be elected in selected patients. PHARMACEUTICAL INFORMATION:

Drug Substance

Tradename:

Proper Name: Divatproex sodium

USAN Names: INN: Valproate semisodium

BAN: Semisodium vatproate

Chemical Name: Sodium hydrogen bis (2-propylpentanoate) or Sodium hydrogen bis (2-propylvalerate)

Molecular Weight: 310.14 Molecular Formula: $\mathrm{C}_{16} \mathrm{H}_{31} \mathrm{NaO}_{4}$

Structural Formula:

$\mathrm{CH}_{3} \mathrm{CH}_{2} \mathrm{CH}_{2}-\mathrm{CH}-\mathrm{CH}_{2} \mathrm{CH}_{2} \mathrm{CH}_{3}$

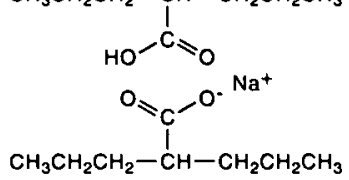

Description: Divalproex sodium is a stable coordination compound comprised of sodium valproate and valproic acid in a 1:1 mola relationship and formed during the partial neutralization of valproic acid with 0.5 equivalent of sodium hydroxide. It is a white powder with a characteristic odor, freely soluble in many organic solvents and in aqueous alkali solutions.

Non-Medicinal Ingredients: EPIVAL Enteric-Coated Tablets: Cellulosic polymers, silica gel, diacetylated monoglycerides, povidone, pregelatinized starch (contains corn starch), talc, titanium dioxide, and vanillin.

In addition, individual tablets contain:

$125 \mathrm{mg}$ tablets: FD\&C Blue No.1 and FD\&C Red No. 40

$250 \mathrm{mg}$ tablets: FD\&C Yellow No. 6 and iron oxide

$500 \mathrm{mg}$ tablets: D\&C Red No. 30. FD\&C Blue No. 2, and iron oxide.

Storage Recommendations: Store between $15^{\circ}-30^{\circ} \mathrm{C}\left(59^{\circ}-86^{\circ} \mathrm{F}\right)$.

AVAILABILITY OF DOSAGE FORMS: EPIVAL (divalproex sodium) particle coated tablets are available as salmon-pink coloured tablets of $125 \mathrm{mg}$ in bottles of 100 tablets; peach-coloured tablets of $250 \mathrm{mg}$ and lavender-coloured tablets of $500 \mathrm{mg}$ in bottles of 100 and 500 tablets.

INFORMATION FOR THE CONSUMER: Since EPIVAL" (divalproex sodium) may produce CNS depression, especially when combined with another CNS depressant (e.g., alcohol), patients should b advised not to engage in hazardous activities, such as driving a car or operating dangerous machinery, until it is known that they do not become drowsy from the drug.

REFERENCES: 1. Dean JC. Valproate. In: Wyllie E, ed. The Treatment of Epilepsy: Principles and Practices. Philadelphia, Pa: Lea \& Febiger;1993:chap 77. 2. Wilder BJ, Ramsay RE, Murphy JV, Karas BJ Marquardt K Hammond EJ Comparison of valproic acid and phenytoin in newly diagnosed tonic-clonic seizures. Neurology 1983;33:1474-6. 3. Turnbull DM, Howel D, Rawlins MD, Chadwick $D W$. Which drug for the adult epileptic patient: phenytoin or valproate? Br Med J 1985;290:815-9. 4. Covanis A, Gupta AK Jeavons PM. Sodium valproate: monotherapy and polytherapy. Epilepsia 1982;23:693-720. 5. Kakegawa N Miyakoshi M, Seino M. Monopharmacy by sodium valproate (SV) and the blood concentration. In: Program and abstracts of the XI Epilepsy International Symposium; September 30, 1979; Firenze, Italy. Abstract:153. 6. Dreifuss FE, Langer $\mathrm{DH}$. Side effects of valproate Am J Med 1988:84 (suppl 1A):34-41. 7. Epival Product Monograph. Abbott Laboratories, Limited. 8. Manufacturers' Prescribing Information. 9. Wilder BJ, Rangel RJ. Review of valproate monotherapy in the treatment of generalized tonic-clonic seizures. Am J Med 1988;84(suppl 1A):7-13.

\section{ABDOTT LADORATORIEB. LIMTED} PO. BOX BISOD STATION CINTRE.VILL

Product Monograph available on request. 
ETEGRETOL ${ }^{\circledR}$

Tablets

(Carbamazepine)

Suspension (100 mg/tsp)

\section{THERAPEUTIC CLASSIFICATION}

A. Anticonvulsant

B. For Symptomatic Relief of Trigeminal Neuralgia

C. Antimanic

\section{INDICATIONS AND CLINICAL USE}

A. Epilepsy: TEGRETOL (carbamazepine) is indicated for use as an anticonvulsant drug either alone or in combination with other anticonvulsant drugs.

Carbamazepine is not effective in controlling absence. myoclonic or atonic seizures, and does not prevent the generalization of epileptic discharge. Moreover, exacerbation of seizures may occasionally occur in patients with atypical absences.

B. Trigeminal Neuralgia: TEGRETOL is indicated for the symptomatic relief of pain of trigeminal neuralgia during periods of exacerbation of true or primary trigeminal neuralgia (tic douloureux). It should not be used preventively during periods of remission. In some patients. TEGRETOL has relieved glossopharyngeal neuralgia. For patients who fail to respond to TEGRETOL, or who are sensitive to the drug. recourse to other accepted measures must be considered Carbamazepine is not a simple analgesic and should not be used to relieve trivial facial pains or headaches.

C. Treatment of Acute Mania and Prophylaxis in Bipolar (Manic-Depressive) Disorders: TEGRETOL may be used as mono-therapy or as an adjunct to lithium in the treatment of acute mania or prophylaxis of bipolar (manic-depressive) disorders in patients who are resistant to or are intolerant of conventional antimanic drugs. Carbamazepine may be a useful alternative to neuro-leptics in such patients. Patients with severe mania, dysphoric mania or rapid cycling who are non-responsive to lithium may show a positive response when treated with carbamazepine.

These recommendations are based on extensive clinical experience and some clinical trials versus active comparison agents.

\section{CONTRAINDICATIONS}

TEGRETOL (carbamazepine) should not be administered to patients with hepatic disease, a history of acute intermittent porphyria, or serious blood disorder.

TEGRETOL should not be administered immediately before, in conjunction with, or immediately after a monoamine oxidase (MA0) inhibitor. When it seems desirable to administer TEGRETOL to a patient who has been receiving an MAO inhibitor, there should be as long a drug-free interval as the clinical condition allows, but in no case should this be less than 14 days. Then the dosage of TEGRETOL should be low initially, and increased very gradually.

TEGRETOL should not be administered to patients presenting atrioventricular heart block.

TEGRETOL should not be administered to patients with known hypersensitivity to carbamazepine, to any of the components of the tablets or suspension, or to any of the tricyclic compounds, such as amitriptyline, trimipramine, imipramine, or their analogues or metabolites, because of the similarity in chemical structure.

WARNINGS

ALTHOUGH REPORTED INFREQUENTLY, SERIOUS ADVERSE EFFECTS HAVE BEEN OBSERVED DURING THE USE OF TEGRETOL (CARBAMAZEPINE), AGRANULOCYTOSIS AND APLASTIC ANEMIA HAVE OCCURRED IN A FEW INSTANCES WITH A FATAL OUTCOME. LEUCOPENIA, THROMBOCYTOPENIA, HEPATOCELLULAR AND CHOLESTATIC JAUNDICE, AND HEPATITIS HAVE ALSO BEEN REPORTED. IN THE MAJORITY OF CASES, LEUCOPENIA AND THROMBOCYTOPENIA WERE TRANSIENT AND DID NOT SIGNAL THE ONSET OF EITHER APLASTIC ANEMIA OR AGRANULO CYTOSIS. TEGRETOL SHOULD BE USED CAREFULLY AND CLOSE CLINICAL AND FREQUENT LABORATORY SUPER VISION SHOULD BE MAINTAINED THROUGHOUTTREATMENT IN ORDER TO DETECT AS EARLY AS POSSIBLE SIGNS AND SYMPTOMS OF A POSSIBLE BLOOD DYSCRASIA. TEGRETOL SHOULD BE DISCONTINUED IF ANY EVIDENCE OF SIGNIFICANT BONE MARROW DEPRESSION APPEARS. (SEe Precautions).

SHOULD SIGNS AND SYMPTOMS SUGGEST A SEVERE SKIN REACTION SUCH AS STEVEN-JOHNSON SYNDROME OR LYELL SYNDROME, TEGRETOL SHOULD BE WITHDRAWN AT ONCE.

LONG-TERM TOXICITY STUDIES IN RATS INDICATED A POTENTIAL CARCINOGENIC RISK. THEREFORE, THE POSSIBLE RISK OF THE DRUG MUST BE WEIGHED AGAINST THE POTENTIAL BENEFITS BEFORE PRESCRIBING TEGRETOL TO INDIVIDUAL PATIENTS.
Pregnancy and Nursing

Women with epilepsy who are, or intend to become pregnant, should be treated with special care.

In women of childbearing potential, TEGRETOL should, whenever possible, be prescribed as monotherapy, because the incidence of congenital abnormalities in the offspring of women treated with more than one anti-epileptic drug is greater than in those of women receiving a single antiepileptic.

Minimum effective doses should be given and the plasma levels monitored.

If pregnancy occurs in a woman receiving TEGRETOL, or if the problem of initiating TEGRETOL arises during pregnancy, the drug's potential benefits must be weighed against its hazards, particularly during the first 3 months of pregnancy. TEGRETOL should not be discontinued or withheld from patients if required to prevent major seizures because of the risks posed, to both mother and fetus, by status epilepticus with attendant hypoxia.

The possibility that carbamazepine, like all major antiepileptic drugs, increases the risk of malformations has been reported. There are rare reports on developmental disorders and malformations, including spina bifida, in association with carbamazepine. Conclusive evidence from controlled studies with carbamazepine monotherapy is lacking. Patients should be counselled regarding the possibility of an increased risk of malformations and given the opportunity of antenatal screening.

Folic acid deficiency is known to occur in pregnancy. Antiepileptic drugs have been reported to aggravate folic acid deficiency, which may contribute to the increased incidence of birth defects in the offspring of treated epileptic women. Folic acid supplementation has therefore been recommended before and during pregnancy. To prevent neonatal bleeding disorders, Vitamin $\mathrm{K}_{1}$ administration to the mother during the last weeks of pregnancy, as well as to the newborn, has been recommended.

Carbamazepine passes into breast milk in concentrations of about $25-60 \%$ of the plasma level. No reports are available on the long-term effect of breast feeding. The benefits of breast feeding should be weighed against the possible risks to the infant. Should the mother taking carbamazepine nurse her infant, the infant must be observed for possible adverse reactions, e.g., somnolence.

A severe hypersensitivity skin reaction in a breast-fed baby has been reported.

The reliability of oral contraceptives may be adversely affected by carbamazepine (see Drug Interactions section under Precautions)

PRECAUTIONS

Clinical Monitoring of Adverse Reactions: TEGRETOL (carbamazepine) should be prescribed only after a critical risk-benefit appraisal in patients with a history of cardiac. hepatic or renal damage, adverse hematological reactions to other drugs, or interrupted courses of the rapy with TEGRETOL. Careful clinical and laboratory supervision should be maintained throughout treatment. Should any signs or symptoms or abnormal laboratory findings be suggestive of blood dyscrasia or liver disorder, TEGRETOL should be immediately discontinued until the case is carefully reassessed

(a) Bone marrow function: Complete blood counts, including platelets and possibly reticulocytes and serum iron, should be carried out before treatment is instituted. Suggested guidelines for monitoring are weekly for the first month, then monthly for the next five months, thereafter $2-4$ times a year If low or decreased white blood cell or platelet counts are observed during treatment, the patient and the complete blood count should be monitored closely. Non-progressive fluctuating asymptomatic leucopenia, which is encountered does not generally call for the withdrawal of TEGRETOL. However, treatment with TEGRETOL should be discontinued if the patient develops leucopenia which is progressive or accompanied by clinical manifestations, e.g., fever or sore throat, as this could indicate the onset of significant bone marrow depression.

Because the onset of potentially serious blood dyscrasias may be rapid, patients should be made aware of early toxic signs and symptoms of a potential hematological problem. as well as symptoms of dermatological or hepatic reactions. If reactions such as fever, sore throat, rash, ulcers in the mouth, easy bruising, petechial or purpuric hemorrhage appear, the patient should be advised to consult his/her physician immediately.

(b) Hepatic function: Baseline and periodic evaluations of hepatic function must be performed, particularly in elderly patients and patients with a history of liver disease. Withdraw TEGRETOL immediately in cases of aggravated liver dysfunction or active liver disease.

(c) Kidney function: Pretreatment and periodic complete urinalysis and BUN determinations should be performed. (d) Ophthalmic examinations: Carbamazepine has been associated with pathological eye changes. Periodic eye examinations, including slit-lamp funduscopy and tonometry are recommended

e) Plasma levels: Although correlations between dosage and plasma levels of carbamazepine, and between plasma levels and clinical efficacy or tolerability are rather tenuous, monitoring plasma levels may be useful in the following conditions: dramatic increase in seizure frequency/verification of patient compliance; during pregnancy; when treating children or adolescents; in suspected absorption disorders; in suspected toxicity, especially where more than one drug is being used (see Drug Interactions)

Increased seizure frequency: TEGRETOL should be used with caution in patients with a mixed seizure disorder that includes atypical absence seizures, since its use has been associated with increased frequency of generalized convulsions. In case of exacerbation of seizures, discontinue TEGRETOL.

Dermatologic: Mild skin reactions, e.g., isolated macular or maculopapular exanthema, usually disappear within a few days or weeks, either during a continued course of treatment or following a decrease in dosage. However, the patient should be kept under close surveillance because of the rare possibility of Steven-Johnson syndrome or Lyell's syndrome occurring (see WARNINGS)

Urinary Retention and Increased Intraocular Pressure: Because of its anticholinergic action, carbamazepine should be given cautiously, if at all, to patients with increased intraocular pressure or urinary retention. Such patients should be followed closely while taking the drug.

Occurrence of Behavioral Disorders: Because it is closely related to the other tricyclic drugs, there is some possibility that carbamazepine might activate a latent psychosis, or, in elderly patients, produce agitation or confusion, especially when combined with other drugs. Caution should also be exercised in alcoholics.

Use in Patients with Cardiovascular Disorders: Use TEGRETOL cautiously in patients with a history of coronary artery disease, organic heart disease, or congestive heart failure. If a defective conductive system is suspected, an ECG should be performed before administering TEGRETOL, to exclude patients with atrioventricular block.

Driving and Operating Hazardous Machinery: Because dizziness and drowsiness are possible side effects of TEGRETOL, warn patients about the possible hazards of operating machinery or driving automobiles.

Drug Interactions: Induction of hepatic enzymes in response to carbamazepine may diminish or abolish the activity of certain drugs that are also metabolized in the liver. Dosage of the following drugs may have to be adjusted when administered with TEGRETOL: clobazam, clonazepam, ethosuximide, primidone, valproic acid, alprazolam, corticosteroids (e.g. prednisolone, dexamethasone), cyclosporin, digoxin, doxycycline, felodipine, haloperidol, thioridazine, imipramine, methadone, oral contraceptives, theophylline, and oral anticoagulants (warfarin, phenprocoumon, dicumarol)

Phenytoin plasma levels have been reported both to be raised and lowered by carbamazepine, and mephenytoin plasma levels have been reported in rare instances to increase.

The following drugs have been shown to raise plasma carbamazepine levels: erythromycin, troleandomycin, possibly josamycin, isoniazid, verapamil, diltiazem, propoxyphene, viloxazine, fluoxetine, cimetidine, acetazolamide, danazol, and possibly desipramine. Nicotinamide raises carbamazepine plasma levels in children, but only at high dosage in adults Since an increase in carbamazepine plasma levels may result in unwanted effects (e.g., dizziness, drowsiness, ataxia, diplopia and nystagmus), the dosage of TEGRETOL should be adjusted accordingly and the blood levels monitored

Plasma levels of carbamazepine may be reduced by phenobarbitone, phenytoin, primidone, progabide, or theophylline, and possibly by clonazepam. Valproic acid, valpromide, and primidone have been reported to raise plasma levels of the pharmacologically active metabolite, carbamazepine-10,11 epoxide. The dose of TEGRETOL may consequently have to be adjusted.

Combined use of TEGRETOL with lithium, metoclopramide, or haloperidol, may increase the risk of neurotoxic side effects (even in the presence of "therapeutic plasma levels") Concomitant use of TEGRETOL and isoniazid has been reported to increase isoniazid-induced hepatotoxicity.

TEGRETOL, like other anticonvulsants, may adversely affect the reliability of oral contraceptives; breakthrough bleeding may occur. Accordingly, patients should be advised to use some alternative, non-hormonal method of contraception.

Concomitant medication with TEGRETOL and some diuretics (hydrochlorothiazide, furosemide) may lead to symptomatic hyponatremia.

Carbamazepine may antagonize the effects of non-depola rising muscle relaxants (e.g., pancuronium); their dosage may need to be raised and patients should be monitored closely for more rapid recovery from neuromuscular blockade than expected.

Isotretinoin has been reported to alter the bioavailability and/ or clearance of carbamazepine and its active 10,11-epoxide; 
carbamazepine plasma levels should be monitored.

Carbamazepine, like other psycho-active drugs, may reduce alcohol tolerance; it is therefore advisable to abstain from alcohol during treatment.

TEGRETOL should not be administered in conjunction with an MAO inhibitor. (See CONTRAINDICATIONS)

\section{ADVERSE REACTIONS}

The reactions which have been most frequently reported with TEGRETOL (carbamazepine) are CNS (e.g., drowsiness, headache, unsteadiness on the feet, diplopia, dizziness) gastrointestinal disturbances (nausea, vomiting), as well as allergic skin reactions. These usually occur only during the initial phase of therapy, if the initial dose is too high, or when treating elderly patients. They have rarely necessitated discontinuing TEGRETOL therapy, and can be minimized by initiating treatment at a low dosage.

The occurrence of CNS adverse reactions may be a manifestation of relative overdosage or significant fluctuation in plasma levels. In such cases it is advisable to monitor the plasma levels and possibly lower the daily dose and/or divide it into 3 - 4 fractional doses.

The more serious adverse reactions observed are the hematologic, hepatic, cardiovascular and dermatologic reactions, which require discontinuation of therapy.

If treatment with TEGRETOL has to be withdrawn abruptly, the change-over to another antiepileptic drug should be effected under cover of diazepam.

The following adverse reactions have been reported:

Hematologic: Occasional or frequent: leucopenia; occasional eosinophilia, thrombocytopenia; Rare: leucocytosis lymphadenopathy. Isolated cases: agranulocytosis, aplastic anemia, pure red cell aplasia, macrocytic anemia, megaloblastic anemia, acute intermittent porphyria, reticulocytosis, folic acid deficiency, thrombocytopenic purpura, and possibly hemolytic anemia. In a few instances, deaths have occurred. Hepatic: Frequent: elevated gamma-GT (due to hepatic enzyme induction), usually not clinically relevant.

Occasional: elevated alkaline phosphatase.

Rare: Elevated transaminases, jaundice, hepatitis of cholestatic parenchymal (hepatocellular), or mixed type. Isolated cases: granulomatous hepatitis.

Dermatologic: Occasional or frequent: skin sensitivity reac tions and rashes, erythematous rashes, urticaria. Rare: exfoliative dermatitis and erythroderma, Steven-Johnson syndrome, systemic lupus erythematosus-like syndrome. Isolated cases: toxic epidermal necrolysis (Lyell's syndrome), photosensitivity, erythema multiform and nodosum, skin pigmentation changes, pruritus, purpura, acne, diaphoresis, alopecia and neurodermatitis. Isolated cases of hirsuitism have been reported, however the causal relationship is not clear. Neurologic: Frequent: vertigo, somnolence, ataxia and fatigue. Occasional: an increase in motor seizures (see INDICATIONS), headache, diplopia, nystagmus, accommodation disorders (e.g., blurred vision); Rare: abnormal involuntary disorders (e.g., tremor, asterixis, orofacial dyskinesia, choreoathetosis disorders, dystonia, tics); Isolated cases: oculomotor disturbances, speech disorders (e.g., dysarthria or slurred speech), peripheral neuritis, paraesthesia, muscle weakness. There have been some reports of paralysis and other symptoms of cerebral arterial insufficiency but no conclusive relationship to the administration of TEGRETOL could be established.

Cardiovascular: Rare: disturbances of cardiac conduction. Isolated cases: bradycardia, arrhythmias, Stokes-Adams in patients with AV-block, collapse, congestive heart failure, hypertension or hypotension, aggravation of coronary artery disease, thrombophlebitis, thromboembolism. Some of these complications (including myocardial infarction and arrhythmia) have been associated with other tricyclic compounds. Psychiatric: Isolated cases: hallucinations (visuat or acoustic), depression, sometimes with talkativeness, agitation, loss of appetite, restlessness, aggressive behaviour, confusion activation of psychosis

Genitourinary: Isolated cases: interstitial nephritis and renal failure, as well as signs of renal dysfunction (e.g., albuminuria, glycosuria, hematuria, oliguria sometimes associated with elevated blood pressure, and elevated BUN/azotemia), urinary frequency, urinary retention and sexual disturbances/impotence. Gastrointestinal: Frequent: nausea, vomiting; Occasional: dryness of the mouth and throat; Rare: diarrhea or constipation; Isolated cases: abdominal pain, glossitis, stomatitis anorexia.

Sense organs: Isolated cases: lens opacities, conjunctivitis, retinal changes, tinnitus, hyperacusis, taste disturbances. Endocrine system and metabolism: Occasional: edema, fluid retention, weight increase, hyponatremia and reduced plasma osmolality due to antidiuretic hormone (ADH)-like effect occurs, leading in isolated cases to water intoxication accompanied by lethargy, vomiting, headache, mental confusion, neurological abnormalities. Isolated cases: gynecomastia, galactorrhea, abnormal thyroid function tests (decreased L-thyroxine i.e. $\mathrm{FT}_{4}, \mathrm{~T}_{4}, \mathrm{~T}_{3}$, and increased $\mathrm{TSH}$, usually without inical manifestations), disturbances of bone metabolism decrease in plasma calcium and $25-\mathrm{OH}$-calciferol), leading in isolated cases to osteomalacia, as well as reports of elevated levels of cholesterol, including HDL cholesterol and triglycerides

Musculoskeletal system: Isolated cases: arthralgia, muscle pain or cramp.

Respiratory: Isolated cases: pulmonary hypersensitivity characterized by fever, dyspnea, pneumonitis or pneumonia. Hypersensitivity reactions: Rare: delayed multi-organ hypersensitivity disorder with fever, skin rashes, vasculitis, lymphadenopathy, disorders mimicking lymphoma, arthralgia, leucopenia, eosinophilia, hepatosplenomegaly and abnorma iver function tests, occurring in various combinations. Other organs may also be affected (e.g. lungs, kidneys, pancreas, myocardium). Isolated cases: aseptic meningitis, with myoclonus and eosinophilia; anaphylactic reaction. Treatment should be discontinued should such hypersensitivity reactions occur.

\section{DOSAGE AND ADMINISTRATION}

Use in Epilepsy (See INDICATIONS): TEGRETOL may be used alone or with other anticonvulsants. A low initial daily dosage of TEGRETOL with a gradual increase in dosage adjusted to the needs of the individual patient, is advised.

TEGRETOL should be taken with meals whenever possible.

TEGRETOL Tablets, CHEWTABS and Suspension should be taken in 2 to 4 divided doses daily.

TEGRETOL Suspension should be well shaken before use since improper re-suspension may lead to administering an incorrect dose. Since a given dose of TEGRETOL Suspension produces higher peak carbamazepine levels than the same dose in tablet form, it is advisable to start with low doses and to increase slowly to avoid adverse reactions. When switching a patient from TEGRETOL Tablets to TEGRETOL Suspension, the same number of $\mathrm{mg}$ per day should be given in smaller, more frequent doses (i.e., BID Tablets to TID Suspension). TEGRETOL CHEWTABS and the Suspension are particularly suitable for patients who have difficulty swallowing tablets or who need initial careful adjustment of dosage.

The controlled release characteristics of TEGRETOL CR reduce the daily fluctuations of plasma carbamazepine. TEGRETOL CR tablets (either whole or, if so prescribed, only half a tablet) should be swallowed unchewed with a little liquid during or after a meal. These controlled release tablets should be prescribed as a twice-daily dosage. If necessary, three divided doses may be prescribed. Some patients have been reported to require a dosage increase when switching from tablets to CR tablets. Dosage adjustments should be individualized based on clinical response and, if necessary, plasma carbamazepine levels.

Adults and Children Over 12 Years of Age: Initially, 100 to $200 \mathrm{mg}$ once or twice a day depending on the severity of the case and previous therapeutic history. The initial dosage is

\section{AVAILABILITY OF DOSAGE FORM}

\begin{tabular}{|c|c|c|c|c|c|c|}
\hline & $\begin{array}{l}\text { Pr TEGRETOL }{ }^{\circ} \\
\text { Tablets } \\
200 \mathrm{mg}\end{array}$ & $\begin{array}{l}\text { Pr TEGRETOL } \\
\text { CHEWTABS } \\
100 \mathrm{mg}\end{array}$ & $\begin{array}{l}\text { Pr TEGRETOL } \\
\text { CHEWTABS } \\
200 \mathrm{mg}\end{array}$ & $\begin{array}{c}\text { Pr TEGRETOL } \\
\text { CR } \\
200 \mathrm{mg}\end{array}$ & $\begin{array}{c}\text { Pr TEGRETOL } \\
\text { CR } \\
\mathbf{4 0 0} \mathrm{mg}\end{array}$ & $\begin{array}{l}\text { Pr TEGRETOL* } \\
\text { Suspension } \\
100 \mathrm{mg} / \mathrm{sp}\end{array}$ \\
\hline Colour & White & $\begin{array}{l}\text { White with red } \\
\text { specks }\end{array}$ & $\begin{array}{l}\text { White with red } \\
\text { specks }\end{array}$ & Beige-orange & Brown-orange & Orange \\
\hline Shape & $\begin{array}{c}\text { Round, flat-faced, } \\
\text { bevel-edged }\end{array}$ & $\begin{array}{l}\text { Round, flat-faced, } \\
\text { bevel-edged }\end{array}$ & Oval, biconvex & $\begin{array}{l}\text { Oval, slightly } \\
\text { biconvex }\end{array}$ & $\begin{array}{l}\text { Oval, slightly } \\
\text { biconvex }\end{array}$ & \\
\hline Imprint & $\begin{array}{c}\text { Engraved GEIGY } \\
\text { on one side and } \\
\text { quadrisected on } \\
\text { the other }\end{array}$ & $\begin{array}{c}\text { Engraved GEIGY } \\
\text { on one side and } \\
\mathrm{M} / \mathrm{R} \text { with bisect } \\
\text { on the other }\end{array}$ & $\begin{array}{c}\text { Engraved GEIGY } \\
\text { on one side and } \\
\text { P/U with bisect on } \\
\text { the other }\end{array}$ & $\begin{array}{l}\mathrm{C} / \mathrm{G} \text { engraved on } \\
\text { one side and } \mathrm{HC} \\
\text { on the other. } \\
\text { Bisected on both } \\
\text { sides }\end{array}$ & $\begin{array}{l}\mathrm{CG} / \mathrm{CG} \text { engraved } \\
\text { on one side and } \\
\text { ENE/ENE on the } \\
\text { other. Bisected on } \\
\text { both sides }\end{array}$ & Not applicable \\
\hline Availability & $\begin{array}{c}\text { Bottles of } 100 \& \\
500\end{array}$ & Bottles of 100 & Bottles of 100 & Bottles of 100 & Bottles of 100 & Bottles of $450 \mathrm{~mL}$ \\
\hline $\begin{array}{l}\text { Storage } \\
\text { Conditions }\end{array}$ & $\begin{array}{l}\text { Store below } \\
30^{\circ} \mathrm{C} \text {, protect } \\
\text { from humidity }\end{array}$ & $\begin{array}{l}\text { Store below } \\
30^{\circ} \mathrm{C} \text {, protect } \\
\text { from humidity } \\
\text { and light }\end{array}$ & $\begin{array}{l}\text { Store below } \\
30^{\circ} \mathrm{C} \text {, protect } \\
\text { from humidity } \\
\text { and light }\end{array}$ & $\begin{array}{l}\text { Store below } \\
25^{\circ} \mathrm{C} \text {, protect } \\
\text { from humidity }\end{array}$ & $\begin{array}{l}\text { Store below } \\
25^{\circ} \mathrm{C} \text {, protect } \\
\text { from humidity }\end{array}$ & $\begin{array}{c}\text { Store below } \\
30^{\circ} \mathrm{C} \text {, protect } \\
\text { from humidity } \\
\text { and light }\end{array}$ \\
\hline
\end{tabular}

Tegretol is a schedule F drug and can only be obtained by prescription from a licensed practitioner. Product Monograph available on request. December 7, 1995

\section{REFERENCES}

1. Smith DB et al: Results of a nationwide veterans administration cooperative study comparing the efficacy and toxicity of carbamazepine, phenobarbital, phenytoin, and primidone. Epilepsia 1987; 28(Suppl 3): 550-558.

2. Reynolds EH. Polytherapy, monotherapy, and carbamazepine. Epilepsia 1987; 28 (Suppl 3): 577-580

3. Aldenkamp et al: Controlled release carbamazepine: cognitive side effects in patients with epilepsy. Epilepsia 1987; 28(Suppl 3): 507-514. progressively increased, in divided doses, until the best response is obtained. The usual optimal dosage is 800 to $1200 \mathrm{mg}$ daily. In rare instances some adult patients have received $1600 \mathrm{mg}$. As soon as disappearance of seizures has been obtained and maintained, dosage should be reduced very

Children 6-12 Years of Age: Initially, $100 \mathrm{mg}$ in divided doses on the first day. Increase gradually by $100 \mathrm{mg}$ per day until the best response is obtained. Dosage should generally not exceed $1000 \mathrm{mg}$ daily. As soon as disappearance of seizures has been obtained and maintained, dosage should be reduced very gradually until a minimum effective dose is reached. Combination Therapy: When added to existing anti-convulsant therapy, the drug should be added gradually while the other anticonvulsants are maintained or gradually decreased except for phenytoin, which may be increased (see Drug Interactions section under Precautions and Pregnancy And Nursing section under Warnings).

Use in Trigeminal Neuralgia: Initial daily dosage should be small; $200 \mathrm{mg}$ taken in 2 doses of $100 \mathrm{mg}$ each is recommended. The total daily dosage can be increased by $200 \mathrm{mg} /$ day until relief of pain is obtained. This is usually achieved at dosage between $200-800 \mathrm{mg}$ daily; but occasionally up to $1200 \mathrm{mg} /$ day may be necessary. As soon as relief of pain has een obtained and maintained, progressive reduction in dosage should be attempted until a minimal effective dosage is reached. Because trigeminal neuralgia is characterized by periods of remission, attempts should be made to reduce or discontinue the use of TEGRETOL at intervals of not more than 3 months, depending upon the individual clinical course. Prophylactic use of the drug in trigeminal neuralgia is not recommended.

Use in Mania and Bipolar (Manic-Depressive) Disorders: The initial daily dosage should be low, 200 to $400 \mathrm{mg} / \mathrm{day}$ administered in divided doses, although higher starting doses of 400 to $600 \mathrm{mg} /$ day may be used in acute mania. This dose may be gradually increased until patient symptomatology is controlled or a total daily dose of $1600 \mathrm{mg}$ is achieved. Increments in dosage should be adjusted to provide optimal patient tolerability. The usual dose range is 400 to $1200 \mathrm{mg} /$ day administered in divided doses. Doses used to achieve optimal acute responses and tolerability should be continued during maintenance treatment. When given in combination with lithium and neuroleptics, the initial dosage should be low, $100 \mathrm{mg}$ to $200 \mathrm{mg}$ daily, and then increased gradually. Adose higher than $800 \mathrm{mg} /$ day is rarely required when given in combination with neuroleptics and lithium, or with other psychotropic drugs such as benzodiazepines. Plasma levels are probably not helpful for guiding therapy in bipolar disorders. gradually until a minimum effective dose is reached.

\section{Geigy}

Pharmaceuticals

Mississauga, Ontario L5N 2W5 or

Dorval, Quebec H9S 1B1

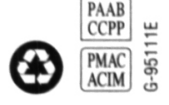




\section{EBETASERON ${ }^{\circledR}$

$$
\text { Interferon beta-1b }
$$

\section{THERAPEUTIC CLASSIFICATION}

Immunomodulator

\section{ACTION AND CLINICAL PHARMACOLOGY}

Description: BETASERON (nterferon beta-1b) is a purified, sterile, tyophilized protein product produced by recombinant DNA techniques and formulated for use by injection. Interferon beta- $t \mathrm{~b}$ is manufactured by bacterial fermentation of a strain of Escherichia colit that bears a genetically engineered plasmid containing the gene for human interleron beta $a_{\text {eer 17. }}$. The native gene was obtained from human fibroblasts and altered in a way that substitutes serine for the cysteine residue found at position 17. Interteron beta-10 is a highly purified protein that has 165 amino acids and an approximate molecular weight of 18,500 daltions. It does not include the carbohydrate side chains found in the natural materia.

The specific activity of BETASERON is approximately 32 million international unlts (lU)/mg Interferon beta-10. Each vial contains $0.3 \mathrm{mg}(9.6$ million 10$)$ of Interferon beta $-1 \mathrm{~b}$. The unit measurement is dertved by comparing the antivira: activity of the product to the Wortd Health Organization (WHO reference standard of recombinant human interferon beta. Dextrose and Abumin Human, USP ( $15 \mathrm{mg}$ each/vial) are added as stabilizers. Prior to 1993, a difterent analytical standard was used to determine potency. It assigned 54 million IU to $0.3 \mathrm{mg}$ Interferon beta- $1 \mathrm{~b}$.

Lyophilized BETASERON is a sterile, white to off-white powder intended for subcutaneous injection after reconstitution with the diluent supplied (Sodium ChJoride, $0.54 \%$ Solution)

General: Interferons are a family of naturally occurring proteins, which have molecular weights ranging from 15,000 to 21,000 daltons. Three major classes of interterons have been identified: alpha, beta, gamma, Interteron beta-1b, interferon alpha, and interferon gamma have overlapping yet distinct biologic activities. The activities of Interteron betaare specles-restricted and, therefore, the most pertinent pharmacological information on BETASERON (nterferon beta- 1 b) is derived from studies of human cells in culture and in humans.

Biologic Actlvities: Interteron beta-1b has been shown to possess both antlviral and immunomodulatory activities. The mechanlsms by which BETASERON exerts its actions in multiple sclerosis (MS) are not clearty understood. However, It is known that the biologic response-moditying properties of Interferon beta- $1 \mathrm{~b}$ are mediated through its interactions with speclific cell surface receptors found on the surface of human cells. The binding of Interferon beta- $1 \mathrm{~b}$ to these receptors induces the expression of a number of interferoninduced gene products (e.g., 2',5'-oligcadenylate synthetase protein kinase, and indolamine 2,3-dioxygenase) that are believed to be the mediators of the biological actions of Interferon beta- $1 \mathrm{~b}$. A number of these interferon-induced products have been readily measured in the serum and cellular fractions of blood collected from patients treated with Interferon beta-1b.

Table 1: 2-Year Study Results

\begin{tabular}{|c|c|c|c|c|c|c|}
\hline \multicolumn{7}{|l|}{ Primary and Secondary Clinical Endpoints } \\
\hline Efticacy Parameters & \multicolumn{3}{|c|}{ Treatment Groups } & \multicolumn{3}{|c|}{$\begin{array}{c}\text { Statistical Comparison } \\
\text { p-value }\end{array}$} \\
\hline Primary Endpoints & $\begin{array}{l}\text { Placebo } \\
(\mathrm{N}=123)\end{array}$ & $\begin{array}{c}0.05 \mathrm{mg} \\
(1.6 \mathrm{mlU}) \\
(\mathrm{N}=125)\end{array}$ & $\begin{array}{l}0.25 \mathrm{mg} \\
(8 \mathrm{mlV}) \\
(\mathrm{N}=124)\end{array}$ & $\begin{array}{c}\text { Placebo } \\
\text { vs } \\
0.05 \mathrm{mg} \\
(1.6 \mathrm{mlU})\end{array}$ & $\begin{array}{c}0.05 \mathrm{mg} \\
(1.6 \mathrm{mlU}) \\
\mathrm{vs} \\
0.25 \mathrm{mg} \\
(8 \mathrm{mlU})\end{array}$ & $\begin{array}{c}\text { Placebo } \\
\text { vs } \\
0.25 \mathrm{mg} \\
\text { (8 mll) }\end{array}$ \\
\hline Annual exacerbation rate & 1.31 & 1.14 & 0.90 & 0.005 & 0.113 & 0.0001 \\
\hline Proportion of exacerbation-free patients ${ }^{\dagger}$ & $16 \%$ & $18 \%$ & $25 \%$ & 0.609 & 0.288 & 0.094 \\
\hline $\begin{array}{l}\text { Exacerbation frequency } \\
\text { per patient }\end{array}$ & $\begin{array}{l}20 \\
32 \\
20 \\
15 \\
15 \\
21\end{array}$ & $\begin{array}{r}22 \\
31 \\
28 \\
15 \\
7 \\
16 \\
\end{array}$ & $\begin{array}{r}29 \\
39 \\
17 \\
14 \\
9 \\
8\end{array}$ & 0.151 & 0.077 & 0.001 \\
\hline \multicolumn{7}{|l|}{ Secondary Clinical Endpoints"t } \\
\hline $\begin{array}{l}\text { Median number of months } 10 \text { first } \\
\text { on-study exacerbation }\end{array}$ & 5 & 6 & 9 & 0.299 & 0.097 & 0.010 \\
\hline $\begin{array}{l}\text { Rate of moderate or severe } \\
\text { exacerbations per year }\end{array}$ & 0.47 & 0.29 & 0.23 & 0.020 & 0.257 & 0.001 \\
\hline $\begin{array}{l}\text { Mean number of moderate or severe } \\
\text { exacerbation days per patient }\end{array}$ & 44.1 & 33.2 & 19.5 & 0.229 & 0.064 & 0.001 \\
\hline $\begin{array}{l}\text { Mean change in EDSS scoret } \\
\text { at endpoint }\end{array}$ & 0.21 & 0.21 & -0.07 & 0.995 & 0.108 & 0.144 \\
\hline $\begin{array}{l}\text { Mean change in Scripps score }{ }^{\text {ti }} \\
\text { at endpoint }\end{array}$ & -0.53 & -0.50 & 0.66 & 0.641 & 0.051 & 0.126 \\
\hline $\begin{array}{l}\text { Median duration in days per } \\
\text { exacerbation }\end{array}$ & 36 & 33 & 35.5 & ND & ND & ND \\
\hline $\begin{array}{l}\text { \% change in mean MRI lesion area } \\
\text { at endpoint }\end{array}$ & $21.4 \%$ & $9.8 \%$ & $-0.9 \%$ & 0.015 & 0.019 & 0.0001 \\
\hline
\end{tabular}

ND Not done.

14 exacerbation-free patients ( 0 trom placebo, 6 trom $0.05 \mathrm{mg}$, and 8 trom $0.25 \mathrm{mg}$ ) dropped out of the study before completing 6 months of therapy. These patients are exciuded irom this analysis.

it Sequelae and Functional Neurologic Status, both required by protocol, were not analyzed individually but are included as a function of the EDSS.

\# EDSS scores range from 0-10, with higher scores reftecting greater disability

\# Scripps neurologic rating scores range from 0-100, with smaller scores reflect greater disability. acetaminophen), anti-depressants, and oral bacloten were allowed ad libitum but chronic nonsteroidal anti-inflammatory

The primary protocol-defined outcome assessment (1) employed as described in Table 1.

. substudy of patients $(\mathrm{N}=52)$ at one site, MRIs were performed every 6 weeks and quantitated for disease activity as Table 1):

In the 2 year analysis, there was a $31 \%$ reduction in annua exacerbation rate, from 1.31 in the placebo group to 0.9 in the was $16 \%$ in the plaportion of patients free of exacerbations the BETASERON $0.25 \mathrm{mg}$ ( 8 million III) group.

of the first 372 patients randomized, $72(19 \%)$ failed to given for withdrawal varied with treatment assignment. Excessive use of steroids accounted for 11 of the 26 place the 21 withdrawals itom 25 withdrawals trom the $0.25 \mathrm{mg}$ (8 million IU) assigned group, excessive steroid use accounted for only three (two in [8 million (U] group). Withdrawals for adverse events attributed to study article, however, were more common among

BETASERON treated patients: 1,5 and 10 withdrew from the placebo, $0.05 \mathrm{mg}$ ( $1.6 \mathrm{million}$ lU), and $0.25 \mathrm{mg}$ (8 million lus groups, respectively.

Over the 2-year period, there were $25 \mathrm{MS}$-related hospitalizations in the $0.25 \mathrm{mg}$ ( 8 million IU) BETASERON. treated group compared to 48 hospitalizations in the placebo group. In comparison, non-MS hospitalizations were eventy distributed between the groups, with 16 in the $0.25 \mathrm{mg}$ ( 8 million U) BETASERON group and 15 in the placebo group. The average number of days of MS-related steroid use was 41 days in the $0.25 \mathrm{mg}$ ( 8 million IU) BETASERON group and 55 days in the placebo group $(0=0.004)$

MRI data were also analyzed for patients in this study. A frequency distribution of the observed percent changes in $M$ area at the end of 2 years was obtained by grouping the percentages in successive intervals of equal width. Figure 1 displays a histogram of the proportions of patients who fell int each of these intervals. The median percent change in MR area for the $0.25 \mathrm{mg}$ (8 million lu) group was $-1.1 \%$ which was significantly smaller than the $16.5 \%$ observed for the placebo group ( $p=0.0001)$.

In an evaluation of frequent MRI scans (every 6 weeks) on 52 patients at one site, the percent of scans with new of expanding lesions was $29 \%$ in the placebo group and $6 \%$ in the $0.25 \mathrm{mg}(8$ million UU) treatment group $(p=0.006)$

\section{Figure 1: Distribution of Change in MRI Area}
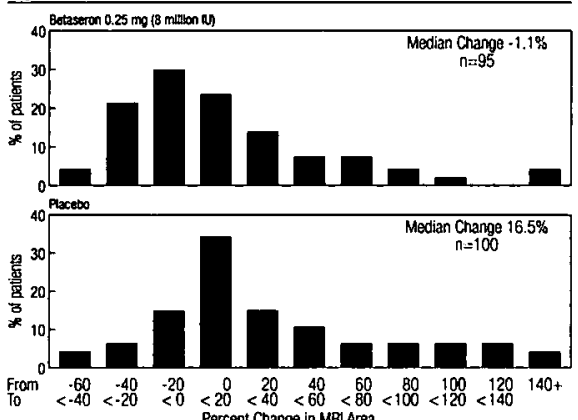
instruction on self-injection technique and procedures: It is recommended that the first proction be administered by or under the direct supervision of a physician. Appropriate instructions for reconstitution of BETASERON and self-injection, using aseptic techniques. should be given to the patient. A careful review of the BETASERON (Interferon beta-1b) Patient Information sheet is also recommended.

Patients should be cautioned against the reuse of needles or syringes and instructed in safe disposal procedures. Intormation on how to acquire a puncture resistant container for disposal of used needles and syringes should be given to the patient along with instructions for safe disposal of full containers.

Eighty-five percent of patients in the controlled MS trial reported injection site

MRI scanning is viewed as a useful means to visualize changes in white matter that are believed to be a reflection of the pathologic changes that, appropriately located within the central nervous system (CNS) account for some of the signs and symptoms that typify relapsing-remitting MS. The exact relationship between MRI findings and the clinical status of patients is unknown. Changes in lesion area often do not correlate with clinical exacertations probably because many of the lesions affect so-called "silent" regions of the CNS. Moreover, it is not clear what fraction of the lesions seen on MRI become foci of irreversible demyelinization (i.e. classic white matter plaques). The prognostic significance of the MRI findings in this study has not been evaluated.

At the end of 2 years on assigned treatment, patients in the study had the option of continuing on treatment under blinded conditions. Approximately $80 \%$ of patients under each treatment accepted. Although there was a trend toward patien benefit in the BETASERON groups during the third year, particularty in the $0.25 \mathrm{mg}$ (8 million II) group, there was no statistically significant difference between the BETASERONtreated vs. placebo-treated patients in exacerbation rate, or in any of the secondary endpoints described in Table 1. As noted above, in the 2-year analysis, there was a $31 \%$ reduction in exacerbation rate in the $0.25 \mathrm{mg}(8$ million 11$)$ group, compared with placebo. The p-value for this difference was 0.0001 . In the analysis of the third year alone, the difference between treatment groups was $28 \%$. The $p$-value was 0.065 The lower number of patients may account for the loss of statistical significance, and lack of direct comparability among the patient groups in this extension study make the interpretation of these results difficult. The third-year MRI dat did not show a trend toward additional benefit in the BETASERON arm compared with the placebo arm. Throughout the clinical trial, serum samples from patients were monitored for the development of antibodies to Interferon beta-10. In patients receiving $0.25 \mathrm{mg}$ ( 8 million IV) of BETASERON ( $N=124)$ every other day, $45 \%$ were found to have senum neutralizing activity on at least one occasion. On third had neutralizing activity confirmed by at least two consecutive positive titres. This development of neutralizing activity may be associated with a reduction in clinical efficac although the exact relationship between antibody formation and therapeutic efficacy is not yet known.

\section{INDICATIONS}

BETASERON (interferon beta-1b) is indicated for use in ambulatory patients with relapsing-remitting multiple scleros to reduce the frequency of clinical exacerbations. (See ACTION AND CLINICAL PHARMACOLOGY, Cllnical Trtals Relapsing-remltting MS is characterized by recurrent attacks of neurologic dysfunction followed by complete or incomple recovery. The satety and efficacy of BETASERON in chronic progressive MS has not been evaluated.

\section{CONTRANDICATIONS}

BETASERON (interferon beta-1b) is contraindicated in patients with a history of hypersensitivity to natural or recombinant interferon beta, Albumin Human, USP, or any other component of the formulation. reactions at one or more times during therapy. In general, these were transient and did not require discontinuation of therapy, but the nature and severity of all reported reactions should be caretully assessed. Patient understanding and use of aseptic self-injection technique and procedures should be periodically reevaluated.

Flu-like symptoms are not uncommon following initiation of therapy with BETASERON. In the controlled MS clinical trial acetaminophen was permitted for relief of fever or myalgias.

Patients should be cautioned not to change dosage or chedule of administration without medical consullation

Awareness of adverse reaction: Patients should be advised about the common adverse events associated with the use of BETASERON, particularly, injection site reactions and the flu-like symptom complex (see ADVERSE REACTIONS section).

Patients should be cautioned to report depression or suicidal ideation (see WARNINGS section).

Patients should be advised about the abortifacient potential of BETASERON (see PRECAUTIONS, Use in Pregnancy).

Laboratory Tests: The following laboratory tests are recommended on patients prior to initiating BETASERON therapy and at periodic intervals thereafter: thyroid function test nemoglobin complete and differential white blood cell counts, platelet counts and blood chemistries including liver function tests. A pregnancy test, chest roentgenogram and ECG should also be performed prior to initiating BETASERO therapy. In the controlled MS trial, patients were monitored every 3 months. The study protocol stipulated that

BETASERON therapy be discontinued in the event the absolute neutrophil count fell below $750 / \mathrm{mm}^{3}$. When the absolute neutrophil count had returned to a value greater than $750 / \mathrm{mm}^{3}$, therapy could be restarted at a $50 \%$ reduced dose. No patients were withdrawn or dose reduced for neutropenia or lymphopenia.

Similarly, if hepatic transaminase (SGOT/SGPT) levels exceeded 10 times the upper limit of normal or if the serum billinbin exceeded 5 times the upper limit of normal, therapy was discontinued. In each instance during the controlled MS trial, hepatic enzyme abnormalities returned to normal tollowing discontinuation of therapy. When measurements had decreased to below these levels, therapy could be restarted a a $50 \%$ dose reduction, if clinically appropriate. Two patients were dose reduced for increased liver enzymes; one continued on treatment and one was utimately withdrawn.

Drug Interactions: Interactions between BETASERON and other drugs have not been fully evaluated. Although studies designed to examine drug interactions have not been done, was noted that corticosteroid or ACTH treatment of relapses for periods of up to 28 days has been administered to patients $(\mathrm{N}=180)$ receiving BETASERON

BETASERON administered in three cancer patients over a dose range of $0.025 \mathrm{mg}(0.8 \mathrm{million}$ IV) $102.2 \mathrm{mg}$ (71 million IU) led to a dose-dependent inhibition of antipyrine elimination. The effect of alternate-day administration of 0.25 $\mathrm{mg}$ (8 million U) of BETASERON on drug metabolism in MS patients is unknown.

impaiment of Fertility: Studies in inesus monkeys at doses up to $0.33 \mathrm{mg}$ (10.7 million lu) $\mathrm{kg} /$ day (32 times the 
recommended human dose based on body surface area comparison)" In normally cycling rhesus female monkeys had no apparent adverse effects on the menstrual cycle or on associated hormonal profiles (progesterone and estradiol) when administered over 3 consecutive menstrual cycles. The extrapolablity of animal doses to human doses is not known. Effects of BETASERON on normal cycling human females are not known. "body surface dose based on 70-kg female Use In Pregnancy: Pregnancy Category $\mathrm{C}$ :

BETASERON was not terato-genic at doses up to $0.42 \mathrm{mg}$ (13.3 million lUJ/kg/day in rhesus monkeys, but demonstrated a dose-related aboriliacient activity when administered at doses ranging from $0.028 \mathrm{mg}(0.89$ million llo/kg/day 12.8 times the recommended human dose based on body surface area comparison) to $0.42 \mathrm{mg}$ (13.3 mill) on IU)/ $\mathrm{kg} / \mathrm{day}$ (40 times the recommended human cose based on body surface area comparison). The extrapolablity of animal doses to human doses is not known. Lower doses were not studied in monkeys. Spontaneous abortions while on treatment were reported in patients $(\mathrm{N}=4)$ who participated in the BETASERON MS cllnical trial. BETASERON given to rhesus monkeys on gestation days 20 to 70 did not cause teratogenic effects, however, it is not known if teratogenic effects exist in humans. There are no adequate and well controlled studies in pregna women. Women of child dbearling potential should take appropriate contraceptive measures. If the patient becomes pregnant or plans to become pregnant while taking BETASERON, the patient should discontinue therapy.

Nursing Mothers: It is not known whether BETASERON is excreted in human milk. Because many drugs are excreted in human milk and because of the potential for serious adverse reactions in nursing intants from BETASERON, a decision should be made as to whether either to discontinue nursing or discontinue the drug, taking into account the Importance of drug to the mother.

Pedlatric Use: Satety and efficacy in children under

18 years of age have not been established.

Dependence Ulability: № evidence or experience suggests that abuse or dependence occurs with BETASERON therapy; however, the risk of dependence has not been systematically evaluated.

\section{ADVERSE REACTIONS}

Experience with BETASERON (interteron beta-1b) in patients with MS is limited to a total of 147 patients at the recommended dose of $0.25 \mathrm{mg}$ ( 8 million $(\mathrm{V})$ every other day or more. Consequently, adverse events that are associated with the use of BETASERON in MS patients at a low incidence of $1 \%$ or less may not have been observed in premarketing studies. Cinical experlence with 8ETASERON in other populations (patients with cancer, HIV positive patients, etc.) provides some degree of added reassurance; however,

experience in non-MS populations may not be fully applicable 10 the MS pooulation.

injection site reactions (85\%) and injection site necrosis (5\%) occurred after administratlon of BETASERON. Intlammatlon, pain, hypersensittvily, necrosis, and non-specilic reaction were significantly associated $(p<0.05$ ) with the $0.25 \mathrm{mg}$ $(8$ million (U) BETASERON-treated group. Only Inflammation, pain, and necrosls were reported as severe events. The Incidence rate for injection site reactions was calculated over the course of 3 years. This incidence rate decreased over time, with $79 \%$ of patients experiencing the event during the first 3 months of treatment compared to $47 \%$ during the las 6 months. The medlan time to the first occurrence of an Injection site reaction was 7 days. Patlents with injection site reactions reported these events 183.7 days per year. Three patients withdrew from the $0.25 \mathrm{mg}$ ( 8 million li) BETASERON-treated group for injection site pain.

Flu-like syrnptom complex was reported $1 \pi 76 \%$ of the patlents treated with $0.25 \mathrm{mg}$ ( 8 million (U) BETASERON. A patient was defined as having a flu-like symptom complex if flu-like symptoms or at least two of the following symptoms were concurrently reported: tever, chills, myalgia, malalse or sweating. Only myalgia, lever, and chllls were reported as severe in more than $5 \%$ of the patients. The incidence rate lor flu-like symptom complex was also calculated over the course of 3 years. The incidence rate of these events decreased over time, with $51 \%$ of patients expetiencing the event during the first 3 months of treatment compared to $4 \%$ during the last 6 months. The median time to the firs occurrence of flu-like symptom complex was 3 days and the medkan duration per patlent was 10.4 days per year. Laboratory abnormalitles included:

- absolute neutrophili count less than $1500 / \mathrm{mm}^{3}(18 \%)$ (no patients had absolute neutrophil counts less than $500 / \mathrm{mm}^{3}$ ) - WBC less than $3000 / \mathrm{mm}^{3}(16 \%$

Mmphocye count less than $1500 / \mathrm{mm}^{3}{ }^{3}(82 \%)$

- SGPT greater than 5 times baseline value (19\%)

total bilirubin greater than 2.5 times baseline value $(6 \%)$

Three patients were wlthdrawn from treatment with $0,25 \mathrm{mg}$ ( 8 million IU) BETASERON for abnormal liver enzyme including one following dose reduction (see PRECAUTIONS, Laboratory Tests).

iwenty-one (28\%) of the 76 fernales, of chlldbearing age, treated at $0.25 \mathrm{mg}$ ( 8 million II) BETASERON and $10(13 \%)$ the 76 fernales, of child-bearing ane, treated with placebo reported menstrual disorders. All of these reports were of mild to moderate severlty and included: intermenstrual bleeding and spotting, early or delayed menses, decreased days of menstrual flow, and clotting and spotting during menstruation. Mental disorders have been observed in patients in this study. Symptoms included depression, anxiety, emotional ability, depersonalization, suicide attempts, confusion, etc. In the treatment group, two patients withdrew for confusion. One suicide and four attempted suicides were also reported. It is not known whether these symptoms may be related to the undertying neuro-logical basis of MS, to BETASERON treatment, or to a combination of both. Some similar symptom have been noted in patients receiving interferon alpha and both interferons are thought to act through the same receptor. Patients who experience these symptoms should be closely monitored and cessation of therapy considered.

Additional common adverse clinical and laboratory events associated with the use of BETASERON are isted in the following paragraphs. These events occurred at an incidence $5 \%$ or more in the $124 \mathrm{MS}$ patients treated with $0.25 \mathrm{mg}$ (8 million IU) of BETASERON every other day for periods of up to 3 years in the controlled trial, and at an incidence that was at least twice that observed in the 123 placebo patients.

Common adverse clinical and laboratory events

associated with the use of BETASERON were:

- injection site reaction (85\%).

- injection site necrosis $(5 \%)$

- flu-like symptoms (53\%),

- palpitation $(8 \%)$.

- hypertension $(7 \%)$

- tachycardia (6\%)

- peripheral vascular disorders $(5 \%$

- gastrointestinal disorders (6\%)

absolute neutrophil count $<1500 / \mathrm{mm}^{3}$ (18\%),

WBC $<3000 / \mathrm{mm}^{3}(16 \%)$

lymphocyte count <1500/rnm ${ }^{3}(82 \%$

- SGPT >5 times baseline value (19\%)

- total bilirubin $>2.5$ times baseline value $(6 \%)$

- somnolence $(6 \%)$

- dyspnea (8\%),

- menstrual disorder $(17 \%)$

- cystitis $(8 \%)$

- breast pain (7\%),

- pelvic pain (6\%), and

menorrhagia (6\%)

A total of $277 \mathrm{MS}$ patients have been treated with

BETASERON in doses ranging from $0.025 \mathrm{mg}(0.8$ million IU)

$100.5 \mathrm{mg}$ (16 million IU). Durlng the first 3 years of treatment. withdrawals due to clinical adverse events or laboratory

bnormalities not mentioned above included:

- fatigue $(2 \%, 6$ patients)

- cardiac arrhythmia (<1\%, 1 patient)

- allergic urticarial skin reaction to injections $<1 \%, 1$ patient

- headache (<1\%, 1 patient)

specified adverse events $k 1 \%, 1$ patien

"felt sick" (<1\%, 1 patient)

The table that follows enumerates adverse events and

laboratory abnormalities that occurred at an incidence of $2 \%$

or more among the $124 \mathrm{MS}$ patients treated with $0.25 \mathrm{mg}$

(8 million IU) BETASERON every other day for periods of up to 3 years in the controlled trial and at an incidence that was at least $2 \%$ more than that observed in the 123 placebo patients. Reported adverse events have been reclassified using the standard COSTART glossary to reduce the total number of terms employed in the table. In the following table, terms so general as to be uninformative, and those events where a drug cause was remote have been exctuded.

Table 2: Adverse Events and Laboratory Abnormalities

\section{Body as a Whole}

Injection site reaction

Headache

Fiu-like symptom complex

Filu-

Pain

Chills

Abdominal pain

Malaise"

Generalized edema

Pelvic pain

Injection site necrosis

Cyst

Necrosis

Suicide attempt

Cardlovascutar System

Migraine

Palpitation"

Hypertension

Tachycardia

Peripheral vascular disorder

Hemorrhage

Digestlve System

Diarrhea

Constipation

vomiting

Gastrointestinal disorder

- Goiter

Hemic and Lymphatic Syste

Lymphocyes < 1500/mm

ANC $<1500 / \mathrm{mm}^{3 *}$

\section{$\begin{array}{ll}\text { Placebo } & 0.25 \mathrm{mg} \\ \mathrm{N}=123 & (8 \mathrm{mIU})\end{array}$ \\ $\stackrel{N=124}{8}$}

$\begin{array}{ll}37 \% & 85 \% \\ 77 \% & 84 \%\end{array}$

$59 \%$

$\begin{array}{ll}56 \% & 76 \% \\ 48 \% & 52 \%\end{array}$

$\quad 49 \%$

$19 \% \quad 46 \%$

$32 \%$

Table 2: Adverse Events and Laboratory

Abnormalities (cont'd)

$\begin{array}{lcc}\text { Placebo } & 0.25 \mathrm{mg} \\ \mathrm{N}=123 & (8 \mathrm{~m} / \mathrm{V}) \\ \mathrm{N}=124\end{array}$

Hemic and Lymphatic System (cont'd) WBC $<3000$ hm $5 \%$

Lymphadenopathy SGPT > 5 times baseline" Glucose $<55 \mathrm{mg} / \mathrm{dL}$

Total bilinubin $>2.5$ times baseline Urine protein $>1+$

SGOT $>5$ times baseline. Weight gain

Weight loss

Myalgia*

Nervous System

Dizziness

Hypertoria

Depression

Andely

Somnolence

Confusion

Speech disorder

Convulsion

Amnesia

Respiratory System

Sinusitis

Dyspnea*

Laryngitis

Skin and Appendages

Sweating

Speclal Senses

Conjunctivitis

Abnormal vision

Urogenital System

Dysmenormea

Menstrual disorder

Metrornhagia

Cystitis

Breast pain

Menorthagia

Urinary urgency

Breast neoplasm

Significantly associated with BETASERON treatment

It should be noted that the figures cited in the table cannot be used to predict the incidence of side effects in the course of usual medicat practice where patient characteristics and other
factors differ from those that prevailed in the clinical trials. The cited figures do provide the prescribing physician with some basis for estimating the relative contribution of drug and nondrug tactors to the side effect incidence rate in the population studies.

Other events observed during premarketing evaluation of various doses of BETASERON in 1440 patients are listed in the paragraphs that follow. Because most of the events were observed in open and uncontrolled studies, the role of

TESERON in their causation cannot be reliably detemined. eaction, ascites, cellulitis, hernia, hydrocephalus, hypottermia, infection, peritonitis, photosensithity, sarcoma sepsis, and shock

Cardiovascular System: angina pectoris, arrhythmia atrial fibrillation, cardiomegaly, cardiac arrest, cerebral hemorrhage, cerebral ischemia, endocarditis, heart failure. hypotension, myocardial infarct, pericardial eftusion, postura hypotension, pulmonary embolus, spider angioma, subarachnoid hemorthage, syncope, thromboph'ebitis, thrombosis, varicose vein, vasospasm, venous pressure increased, ventricular extrasysto!es, and ventrtcular fibrillation; 


\section{Lamictal' \\ Lamotrigine Tablets}

Antieplipt 1

\section{ACTION AND CLINICAL PHARMACOLOGY}

LAMICTAL (lamotingine) is a drug of the phenytriazine class chemically unrelateo to existing antiepileptic dnugs (AEDs), Lamotrigine is thought to ect at voltage-sensitive sodium channels to stabilize neuronal membranes and inhibit the release of excitatory amino acid neurotran

Clinical Thals in placi epteptic sezures. frequency and the number of days with seizures when added to existing antiepileptic dng therapy in adult patients with partial seizures, with or without generailzed tonic-clonic seizures, that are not satistactorily controlled.

Phamacokinetics Adults: CAMICTAL is rapidly and completely absorbed following oral administration, reaching peak plasma concentations 1.4 to 4.8 hours $(1, y)$ post-dosing. When administered with food, the rate of absorption is slighty reduced, but the extent remains unchanged. Following single LAMICTAL doses of $50-400 \mathrm{mg}$, peak plasma concentration ( $C_{\text {max }}=0.6-4.6 \mu \mathrm{g} / \mathrm{mL}$ ) and the area under the plasma concentration-versus-time cuvve (AUC=29.9 . $211 \mathrm{~h} \cdot \mathrm{ug} / \mathrm{mL}$ ) increase linearty with dose. The time-io-peak concentration, elimination hallifite $\left(\mathrm{t}_{1}\right)$ and volume of distribution ( $V d / F$ are independent of dose. The $t_{p}$ averages 33 hours after single doses and $V d F$ ranges from 0.9 to $1.4 \mathrm{Lkg}$. Following repeated dosing in healthy volunteers for 14 days, the $\mathrm{l}_{\mathrm{g}}$ decreased by an average of $26 \%$ (mean steady state $t_{12}$ of 26.4 hours) and plasma clearance increased by an average of $33 \%$. in a single-dose study where healthy volunteers were administered both oral and intravenous doses of lamotrigine, the absolute bioavailabilly of oral lamotigine was $98 \%$.

Lamotngine is approximately $55 \%$ bound to human plasma proteins. This binding is unaffected by therapeutic concentrations of phenytoin, phenobarbital or valproic acid. Lamotrigine does not displace other antiepileptic drugs (cartarmazepine, phenyioin, phenobarbital) from protein binding sites,

Lamotrigine is metabolized predominantly in the liver by glucuronic acid conjugation. The major metabolite is an inactive 2-N-glucuronide conjugate that can be hydrolyzed by B-glucuronidase. Approximately $70 \%$ of an oral LAMICTAL dose is recovered in unine as this metabolite.

Elderty: The phamacokinetics of lamotingine in 12 healthy elderny volunteers $\geq 65$ years) who each received a single oral dose of LAMICTAL (150 mg) were not different trom those in healthy young volunteers. (However, see PRECAUTIONS, Use in the Eldenty, and DOSAGE AND ADMINISTRATION.

Renal Impaiment: The phamacokinetics of a single oral dose of LAMICTAL $(100 \mathrm{mg})$ were evaluated in 12 individu als with chronic renal falure (with mean creatinine clearance of $13 \mathrm{mU}$ min) who were not receiving other antiepleptic drugs. In this sturdy, the elimination halt-jite of unchanged lamotigine was prolonged (by an average of 63\%) relative to individuals with nomal renal function (see PRECAUTIONS, Renal Failure and DOSAGE AND ADMINISTRATION). Hemodlalysis: In six hemodialysis patients, the ellimination half-life of unchanged lamotrigine was doubled off dialysis.

and reduced by $50 \%$ on dialysis, relative to individuals with nom al renal tunction.
Hepatic impaiment: The phamacokinetics of lamotrigine in patients with impaired liver tunction have not been evaluated.

Gilbert's Syndrome: Gilbert's syndrome (idiopathic unconjugated hypertilinubinemia) does not appear to affect the phamacokinetic profile of lamatrigine.

Concomitant Antieplleptic Drugs: In patients with epilepsy, concomitant administration of LAMICTAL with enzymeinducing AEDs (phenytoin, carbamazepine, primidone or phenobarbital) decreases the mean lamotrigine $t_{1 / 2}$ to 13 hours. Concomitant administration of LAMICTAL with valproic acd significanty increases $t_{1}$ and decreases the clearance of lamotricine, whereas concomitant administration of LAMICTAL with valproic acid plus enzyme-induaing AEDs can prolong $t_{12}$ up to approximately 27 hours. Acetaminophen was shown to slighty decrease the $t_{1 / 2}$ and increase the dearance of lanotrigine. The key lamotrigine parameters for adutt patients and healthy volunteers are summarized in Table 1.

Table1: Mean Pharmacokinetic Parameters in Adutt Patients wth Epllepsy or Healthy Volunteers

\begin{tabular}{|c|c|c|c|c|c|c|}
\hline & \multirow[b]{2}{*}{$\begin{array}{l}\text { LAMICTAL } \\
\text { Adminlstered }\end{array}$} & \multicolumn{2}{|c|}{ Healthy Young Volunteers } & \multicolumn{3}{|c|}{ Patients with Epilepsy } \\
\hline & & LAMICTAL & $\begin{array}{l}\text { LAMICTAL+ } \\
\text { Valproic } \\
\text { Acld }^{2}\end{array}$ & $\begin{array}{l}\text { LAMICTAL } \\
\text { +Enzyme } \\
\text { Inducing } \\
\text { AEDs }\end{array}$ & $\begin{array}{l}\text { LAMICTAL+ } \\
\text { Valprolc } \\
\text { Acid }\end{array}$ & $\begin{array}{l}\text { LAMICTALL } \\
\text { Valproic Acid } \\
\text { +Enzyme- } \\
\text { Inducing AEDS }\end{array}$ \\
\hline $\begin{array}{l}T_{\max } \\
(h r s)\end{array}$ & $\begin{array}{l}\text { Single Dose } \\
\text { Multiple } \\
\text { Dose }\end{array}$ & $\begin{array}{c}2.2 \\
(0.25-12.0)^{\prime} \\
1.7 \\
(0.5-4.0)\end{array}$ & $\begin{array}{c}1.8 \\
(1.0-4.0) \\
1.9 \\
(0.5-3.5)\end{array}$ & $\begin{array}{c}2.3 \\
(0.5-5.0) \\
2.0 \\
(0.75-5.93)\end{array}$ & $\begin{array}{c}4.8 \\
(1.8-8.4) \\
\text { ND }\end{array}$ & $\begin{array}{c}3.8 \\
(1.0-10.0) \\
\text { ND }\end{array}$ \\
\hline$t_{1 / 2}$ & $\begin{array}{l}\text { Single Dose } \\
\text { Multiple } \\
\text { Dose }\end{array}$ & $\begin{array}{c}32.8 \\
(14.0-103.0) \\
25.4 \\
(11.6-61.6)\end{array}$ & $\begin{array}{c}48.3 \\
(31.5-88.6) \\
\\
70.3 \\
(41.9-113.5)\end{array}$ & $\begin{array}{c}14.4 \\
(6.4-30.4) \\
12.6 \\
(7.5-23.1)\end{array}$ & $\begin{array}{c}58.8 \\
(30.5-88.8) \\
\text { ND }\end{array}$ & $\begin{array}{c}27.2 \\
(11.2-51.6) \\
\text { ND }\end{array}$ \\
\hline $\begin{array}{c}\text { Plasma Clearance } \\
\text { (mL/minkg) }\end{array}$ & $\begin{array}{l}\text { Single Dose } \\
\text { Multiple } \\
\text { Dose }\end{array}$ & $\begin{array}{c}0.44 \\
(0.12-1.10) \\
\\
0.58 \\
(0.24-1.15)\end{array}$ & $\begin{array}{c}0.30 \\
(0.14-0.42) \\
\\
0.18 \\
(0.12-0.33)\end{array}$ & $\begin{array}{c}1.10 \\
(0.51-2.22) \\
1.21 \\
(0.66-1.82)\end{array}$ & $\begin{array}{c}0.28 \\
(0.16-0.40) \\
\text { ND }\end{array}$ & $\begin{array}{c}0.53 \\
(0.27-1.04) \\
\text { ND }\end{array}$ \\
\hline
\end{tabular}

$\mathrm{ND}=$ Not done

ual values across studies

2. Valproic Acid administered chronically (Multiple Dose Study) or for 2 days (Single Dose Study)

INDICATIONS AND CLINICAL USE

LAMICTAL (lamotigine) is indicated as adjunctive therapy for the management of patients with epilepsy who are not satistactorly controlled by comventional therapy. There is limited intomation on the use of LAMICTAL in monotherapy at this time.

CONIRAINDICATIONS

LAMICTAL (lamotigine) is contraindicated in patients with known hypersensitivity to lamotigine or to any cormponents of the fomulation.

Serious dermatologic events have been reported infrequenty in patients recelving LAMICTAL (lamotigine). Such events were more ilkely to occur during the first six weeks of therapy. More rapid initial titration dosing and use of cont comitant valproic acid were associated with a higher incidence of serious dermatologic events (see PRECAUTIONS, Skin-Related Events, Tables 2 and 3; seo also DOSAGE AND ADMINISTRATION). These events have included Stevens-Johnson syndrome, toxic epidermal necrolysis, angioedema, and hypersensitvity syndrome (which usually consisted of fever, rash, facial swelling and other systemic involvement, e.g. hematologic, hepatic, and or lymphatic).
Hepatic injury, as part of a hypersensitivity syndrome, may have been the initating event in one repotted death. It is recommended that the physician dosely monitor (including hepatic, renal and cloting parameters) patients who acutely develop any combination of unexplained rash fever, flu-like symptoms or worsening of seizure control especilly within the firs month of starting treatment LAMICTAL should be discontinued in all patients with a medically serious rash. Although many patients who developed a skin rash in clinical tials continued to receive LAMICTAL without consequences, the initial presentation of a rash is not always indicative of its eventual seriousness.

The potential medical benefits of continued therapy with LAMICTAL must be weighed against the increased risk of serious rash in patients who have already developed a rash.

PRECAUTIONS

Drug Discontinuation Abrupt discontinuation of any antiepileptic dnug (AED) in a responsive patient with epilepsy may provoke rebound seizures. In general, withdrawal of an AED should be gradual to minimize this risk. Unless safety concems require a more rapid withdrawal, the dose of LAMIC
of at least two weeks (see DOSAGE AND ADMINISTRATION).
Occupational Hazards Patients with uncontrolled epilepsy should not drive or handle potentially dangerous machinery. During clinical trials common acverse effects induded dizziness, ataxia, drowsiness, diplopia, and blurred vision. Patients should be advised to refrain from activities requiring mental alertness or physical coordination until they are sure that LAMICTAL does not affect them adversely.

Skin-Related Events In controlled studies of adjunctive lamotrigine therapy, the incidence of rash (usually maculopapuar andor enythematous) in patients receining LAMCTAL was $10 \%$ compared with $5 \%$ in placobo patients The rash usually occurred within the first six weeks of therapy and resolved during continued administration LAMICTAL LAMICTAL was discontinued because of rash in 1.1\% of patients in controlled studies and $3.8 \%$ of patients in all studies. The rate of rash-related withdrawal in dinical studies was higher with more rapid initial titration

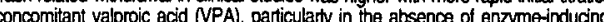
dosing, and in patients receiving concomitant valproic acid (NPA), particularty in the absen
AEDs. See Tables 2 and 3; see also WARNINGS, and DOSAGE AND ADMINISTRATION.

Table 2: Effect of Concomitant AEDs on Riash Assoclated with LAMICTAL in All Controlled and Uncontrolled Clinical Trlals Regardless of Dosing Escalation Scheme

\begin{tabular}{|c|c|c|c|c|}
\hline AED Group & $\begin{array}{l}\text { Total } \\
\text { Patient } \\
\text { Number }\end{array}$ & All Rashes & $\begin{array}{l}\text { Withdrawal } \\
\text { Due to Rash }\end{array}$ & $\begin{array}{l}\text { Hospitalization } \\
\text { in Association } \\
\text { with Rash }\end{array}$ \\
\hline $\begin{array}{l}\text { Enzyme-Inducing AEDs }{ }^{1} \\
\text { Enzyme-Inducing AEDs }{ }^{1}+V^{2} \\
\text { VPA ENon-Enzyme-Inducing AEDs }{ }^{2} \\
\text { Non-Enzyme-Inducing AEDs }{ }^{2}\end{array}$ & $\begin{array}{l}1788 \\
318 \\
159 \\
27\end{array}$ & $\begin{array}{l}9.2 \% \\
8.8 \% \\
20.8 \% \\
18.5 \%\end{array}$ & $\begin{array}{l}1.8 \% \\
3.5 \% \\
11.9 \% \\
0.0 \%\end{array}$ & $\begin{array}{l}0.1 \% \\
0.9 \% \\
2.5 \% \\
0.0 \%\end{array}$ \\
\hline
\end{tabular}

1. Enzymeinduding AEDs indude cartamazepine, phenobartital, phenytoin, and primidone

2. Nonenzyme-incucing AEDs include chonazepam, dobazam, ethosuximide, methsuximide, vigabatin, and gabapentin

Table 3: Effect of the Initial Daily Dose' of LAMICTAL in the Presence of Concomitant AEDs, on the Incidence of Rash Leading to Withdrawal of Treatment in Add-On Clinical Trials

\begin{tabular}{|c|c|c|c|c|c|c|}
\hline AED Group & \multicolumn{2}{|c|}{ Enzymo-lnduclng AEDs² } & \multicolumn{2}{|c|}{$\begin{array}{l}\text { Enzyme-1nducing } \\
\text { AEDs }^{2}+\text { VPA }\end{array}$} & \multicolumn{2}{|c|}{$\begin{array}{l}\text { VPA } \pm \text { Non-Enzyme- } \\
\text { Inducing AEDs }\end{array}$} \\
\hline $\begin{array}{c}\text { LAMICTAL } \\
\text { Average } \\
\text { Daily Dose (mg) }\end{array}$ & $\begin{array}{c}\text { Total } \\
\text { Pattent } \\
\text { Number }\end{array}$ & $\begin{array}{l}\text { Percentage of } \\
\text { Patlents } \\
\text { Withdrawn }\end{array}$ & $\begin{array}{c}\text { Total } \\
\text { Patient } \\
\text { Number }\end{array}$ & \begin{tabular}{|c|} 
Percentage of \\
Patients \\
Withdrawn \\
\end{tabular} & $\begin{array}{c}\text { Total } \\
\text { Patient } \\
\text { Number }\end{array}$ & $\begin{array}{l}\text { Percentage of } \\
\text { Patients } \\
\text { Withdrawn }\end{array}$ \\
\hline $\begin{array}{c}12.5 \\
25 \\
50 \\
100 \\
2125\end{array}$ & $\begin{array}{c}9 \\
3 \\
182 \\
993 \\
601\end{array}$ & $\begin{array}{l}0.0 \\
0.0 \\
1.1 \\
1.4 \\
2.8\end{array}$ & $\begin{array}{c}10 \\
7 \\
111 \\
179 \\
11\end{array}$ & $\begin{array}{l}0.0 \\
0.0 \\
0.9 \\
4.5 \\
18.2\end{array}$ & $\begin{array}{l}51 \\
58 \\
35 \\
15 \\
0\end{array}$ & $\begin{array}{c}7.8 \\
12.1 \\
5.7 \\
40.0 \\
0.0\end{array}$ \\
\hline
\end{tabular}

1. Average daily dose in week 1

2. Enzyme-inducing AEDs include cartamazepine, phenobartital, phenytoin, and primidone

3. Nonenzyme-inducing AEDs indude donazepam, cobazam, ethosuximide, methsuximide, vigabatrin, and gabapentin Increased incidence of rash-related withdrawal was seen when initial doses were higher and titration more rapid than Dcommended under DOSAGE AND ADMINISTRATION.

Antiepileptic Drugs (AEDs): Lamotrigine does not affect the plasma concentrations of concomitanty administered enzyme-inducing AEDs. Antiepileptic drugs that induce hepatic drug-metabolizing enzymes (phenytoin, carbamazepine, phenobatitit, primidone) increase the plasm
(see ACTON AND CLINICAL PHARMACOLOGY).

Valoric acd redues the CLINICAL PHARMACOLOGY. When LAMICTAL was administered to 18 healthy volunteers already receiving valproic acid, a modest decrease (25\% on average) in the trough steady-state valproic acid plasma concentrations was observed over a 3-week period, followed by stabilization. However, the addition of LAMICTAL did not affect the plasma concentration of valproic acid in patients receiving enzyme-induding AEDs in combination with valproic acid. See also PRECAUTTONS, Skin-Related Events.

Oral Contraceptives: In a study of 12 temale volunteers. LAMICTAL did not affect plasma concentrations of ethinyoestradiol and levonorgestrel following administration of the oral contraceptive pill. However, as with the introduction of other chronic therapy in patients taking oral contraceptives, the patient should be asked to report any change in the menstrual bleeding pattem.

Onugs Depressing Carcliac Conduction: (see Patients with Special Diseases and Conditions)

Drughaboratory Test Interactions: LAMICTAL has not been associated with any assay interferences in dinical laboratory tests

Use in the Elderly The safety and efficacy of LAMICTAL in elderly patients with epilepsy have not been systematically evaluated in clinical trials. Caution should thus be exercised in dose selection for an elderly patient, recognizing th more frequent hepatic, renal and cardiac dystunctions and limited experience with LAMICTAL in this population. Use in Children The satety and efficacy of LAMICTAL in chidren under 18 years of age have not yet been established. Use in Obstetric

Pregnancy: Studies in mice, rats and rabbits given lamotrigine orally or intravenously revealed no evidence of Peratogenicity, however, matemal and secondary etal toxicity were coserved. Sudies in rats and rabbits indicate that lamotrigine crosses the placenta; placental and fetal levels of lamotrigine were low and comparable to levels in matemal phasma. Because animal reproduction studies are not always predictive of human response, LAMICTAL should ony be used during pregnancy it the benefits of therapy outweigh the risks associated with it.

Clinical trals data indicate that lamotigine has no effect on blood tolate concentrations in adutts; however, its effects during human tetal development are unknown.

Labor and Delivery: The ettect of LAMICTAL on labor and delivery in humans is unknown.

Nursing Mothers: LAMICTAL is excreted in human milk. Because of the potential for adverse reactions from LAMICTAL in nursing infants, breast-feeding while taking this medication is not recommended.

Patients with Speclal Diseases and Condlitions Cinical experience with LAMICTAL in patients with concomitant illness is limited. Caution is advised when using LAMICTAL in patients with diseases or condrions that could affect the metabolism or elimination of the drug.

Renal Fallure: A study in individuals with chronic renal failure (not receiving other AEDs) indicated that the elimination halt-life of unchanged lamotrigine is prolonged relative to individuals with rommal renal function (see ACTION AND
CLINICAL PHAFMACOLOGY). Use of LAMICTAL in patients with severe renal impaiment should proceed with CLINICAL

Impaired Liver Function: There is no experience with the use of LAMICTAL in patients with impaired liver function. Caution should be exercised in dose selection for patients with this condition.

Cardlac Conduction Abnormalities: One placebo-controlled thal that compared electrocardiograms at baseline and

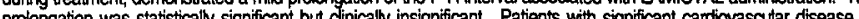
prodongation was statisticaly significant but cinically insignificant. Patents with significant cardiovascurar disease or

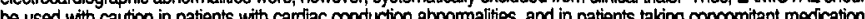
which depress AV conduction

Dependence Liability No evidence of abuse potento

psychological or physical dependence in humans. plasma levels of concomitant AEDs.

Acherse expariences in patients recelving LAMICTAL (amotigine) were generally mild ocourred within the first tho weeks of therapy, and resolved without discontinuation of the drug.

Commonly Observed The most commonly observed adverse experiences associated with the use of adjunctive therapy with LAMICTAL (incidence of at least 10\%) were dizziness, headache, diplopia, somnolence, ataxia, nausea, and asthenia.

Dizziness, diplopia, atacia, and btumed vision were doserelated and occurred more commonly in patients receiving carbamazepine in combination with LAMICTAL than in patients receiving ofher enzyme-inducing AEDs with LAMICTAL. Reduction of the daily dose and/or alteration of the timing of doses of concomitant antiepileptic drugs and/or LAMICTAL may reduce or eliminate these symptoms. Clinica data suggest a higher incidence of rash in patients who are receiving concomitant val

RECAUTONS, Skin-Related Events, Table 2). LAMICTAL discontinued therapy due to an adverse experience, versus $2.9 \%$ of the 419 patients recelving placebo. O 3501 patients and volunteers who received LAMICTAL in premarketing cinical studies, $358(10.2 \%)$ discontinued therapy due to an adverse experience. Across all studies, the most common adverse experiences associated with 
on, asthenia, and blurred vision

Discontinuation due to an adverse experience classified as serious $\infty$ ccurred in $2.3 \%$ of patients and volunteers who (i) (1) More rapid initial titration dosing of LAMICTAL, and concomitant use of valproic acid were associated with higher incidences of rash-related withdrawal in clinical studies (see WARNINGS; see also CoCAUTIONS Skn-Related Events, Table 3).

Controlled Clinical Studies Table 4 enumerates adverse experiences that occurred with an incidence of $2 \%$ or Grater among refractory patients with epilepsy treated with LAMICTAL

Other Events Observed During Clinlcal Studies: During dinical testing, multiple doses of LAMICTAL, were administered to 3501 patents and volunteers. The conditions and duration of exposure to LAMICTAL during these clinical studies varied greatly. Studies inctuded monotherapy and pediatric trials. A substantial proportion of the exposure was gained in open, uncontrolled clinical studies. Adverse experiences associated with exposure to AMICTAL were recorded by clinical investigators using terminology of their own choosing. Consequenty it is not possibte to provide a meaningtul estimate of the proportion of individuals experiencing adverse events without first grouping similar types of adverse experiences into a smaller number of standardized event catecories.

Since the adverse experiences reported occurred during treatment with LAMICTAL in combination with other antepteptic dings, they were not necessarily caused by LAMICTAL.

The lollowing adverse events have been reported on one or more occasions by at least $1 \%$ of patients and volunteers exposed to LAMICTAL: anorexia, weight gain, amnesia, concentration disturbance, confusion, emotional lability, nevousness, nystagmus, paresthesia, thinking abnormality and vertigo. (All types of events are included except those arrady listed in Table 4.)

Tablo 4 Treatment-Emergent Adverse Expertence Incidence In Placebo-Controlled Clinical Studles'

\begin{tabular}{|c|c|c|c|}
\hline $\begin{array}{l}\text { Body Systern/ } \\
\text { Adverse Experlence }\end{array}$ & $\begin{array}{l}\text { Percent of Patlents } \\
\text { Recelving LAMICTAL } \\
\text { (and other AEDs) } \\
\text { (n=711) }\end{array}$ & $\begin{array}{l}\text { Percent of Patlents } \\
\text { Receiving Placebo } \\
\text { (and other AEDs) } \\
\qquad(n=419)\end{array}$ & $\begin{array}{l}\text { Percent of Patlents } \\
\text { Recelving LAMICTAL } \\
\text { (and other AEDs) Who } \\
\text { Were Discontinued } \\
\text { (n=711) }\end{array}$ \\
\hline \multicolumn{4}{|l|}{ BODY AS A WHOLE } \\
\hline Headache & 29.1 & 19.1 & 1.3 \\
\hline Accidental Injury & 9.1 & 8.6 & 0.1 \\
\hline Asthenia & 8.6 & 8.8 & 0.3 \\
\hline Flu Syndrome & 7.0 & 5.5 & 0.0 \\
\hline Pain & 6.2 & 2.9 & 0.1 \\
\hline Back Pain & 5.8 & 6.2 & 0.0 \\
\hline Fever & 5.5 & 3.6 & 0.1 \\
\hline Abdominal Pain & 5.2 & 3.6 & 0.1 \\
\hline Infection & 4.4 & 4.1 & 0.0 \\
\hline Neck Pain & 2.4 & 1.2 & 0.0 \\
\hline Malaise & 2.3 & 1.9 & 0.3 \\
\hline Seizure Exacerbation & 2.3 & 0.5 & 0.3 \\
\hline \multicolumn{4}{|l|}{ DIGESTIVE } \\
\hline Nausea & 18.6 & 9.5 & 1.3 \\
\hline Vomiting & 9.4 & 4.3 & 0.3 \\
\hline Diarmea & 6.3 & 4.1 & 0.3 \\
\hline Dyspepsia & 5.3 & 2.1 & 0.1 \\
\hline Constipation & 4.1 & 3.1 & 0.0 \\
\hline Tooth Disorder & 3.2 & 1.7 & 0.0 \\
\hline \multicolumn{4}{|l|}{ MUSCULOSKELETAL } \\
\hline Myalgia & 2.8 & 3.1 & 0.0 \\
\hline Arthralgia & 2.0 & 0.2 & 0.0 \\
\hline \multicolumn{4}{|l|}{ NERVOUS } \\
\hline Dizziness & 38.4 & 13.4 & 2.4 \\
\hline Ataxia & 21.7 & 5.5 & 0.6 \\
\hline Somnolence & 14.2 & 6.9 & 0.0 \\
\hline Incoordination & 6.0 & 2.1 & 0.3 \\
\hline Insomnia & 5.6 & 1.9 & 0.4 \\
\hline Tremor & 4.4 & 1.4 & 0.0 \\
\hline Depression & 4.2 & 2.6 & 0.0 \\
\hline Anxiety & 3.8 & 2.6 & 0.0 \\
\hline Convulsion & 3.2 & 1.2 & 0.3 \\
\hline Irritablity & 3.0 & 1.9 & 0.1 \\
\hline Speech Disorder & 2.5 & 0.2 & 0.1 \\
\hline Memory Decreased & 2.4 & 1.9 & 0.0 \\
\hline \multicolumn{4}{|l|}{ RESPIRATORY } \\
\hline Rhinitis & 13.6 & 9.3 & 0.0 \\
\hline Pharyngitis & 9.8 & 8.8 & 0.0 \\
\hline Cough Increased & 7.5 & 5.7 & 0.0 \\
\hline Respiratory Disorder & 5.3 & 5.5 & 0.1 \\
\hline \multicolumn{4}{|l|}{ SKIN AND APPENDAGES } \\
\hline Rash & 10.0 & 5.0 & 1.1 \\
\hline Pruritus & 3.1 & 1.7 & 0.3 \\
\hline \multicolumn{4}{|l|}{ SPECIAL SENSES } \\
\hline Diplopia & 27.6 & 6.7 & 0.7 \\
\hline Blurred Vision & 15.5 & 4.5 & 1.1 \\
\hline \multirow{2}{*}{\multicolumn{4}{|c|}{ UROGENITAL }} \\
\hline & & & \\
\hline Female Patients & $(n=365)$ & $(n=207)$ & \\
\hline Dysmenorthea & 6.6 & 6.3 & 0.0 \\
\hline Menstrual Disorder & 5.2 & 5.8 & 0.0 \\
\hline Vaginitis & 4.1 & 0.5 & 0.0 \\
\hline
\end{tabular}

1. Patients in these studies were receiving 1 to 3 concomitant enzyme-inducing antiepileptic drugs in addition to LAMICTAL or placebo. Patients may have reported multiple adverse experiences during the study or at

2. Adverse experiences reported by at least $2 \%$ of patients treated with LAMICTAL are induded.

Other Events Observed during Cilnical Practice and from "Compassionate Plea" Patients: In addition to the adverse experiences reported during clinical testing of LAMICTAL, the following adverse experiences have been reported in patients receiving LAMICTAL marketed in other countries and from worldwide "compassionate plea: patients. These adverse experiences have not been listed above and data are insufficient to support an estimate of their incidence or to establish causation. The listing is alphabetized: Apnea, erythema multitorme, esophagitis, hematernesis, hemoytic anemia, pancreatits, pancytopenia and progressive immunosuppression.

During the dinical dovelopment program, the highest known overdose of LAMICTAL (lamotrigine) coculted in a 33-year old fermal 9 who ingested between 4000 and $5000 \mathrm{mg}$ LAMICTAL that corresponded to a plasma level of $52 \mathrm{ug} / \mathrm{mL}$ four hours after the ingestion. The patient presented to the emergency room comatose and remained comatose tor 8 to 12 hours, retumed to almost nomal over the next 24 hours, and completely recovered by the third day.

There are no specific antidotes tor LAMICTAL. Following a suspected overdose, hospitalization of the patient is advised. General supportive care is indicated, including trequent monitoring of vitar signs and close observation of the patient. If indicaled, emesis should be induced or gastric lavage should be performed. It is uncertain whether hemodialysis is an effective means of removing lanotrigine from the blood. In six renal failure patients, about $20 \%$ of the amount of lamotrigine in the body was removed during 4 hours of hemodialysis.

DOSAGE AND ADMINISTRATION

Adults LAMICTAL (lamotrigine) is intended for oral administration and may be taken with or without food. LAMICTAL

Hepatic enzyme-inducing drugs such as carbamazepine, phenytoin, phenobarbital, and primidone reduce the

elimination half-life of lamotrigine by $50 \%$ and double the plasma clearance; conversely, valproic acid more than doubles the elimination half-life of lamotrigine and reduces the plasma dearance by $50 \%$ (see ACTION AND CLNICAL

Table 5 .
LAMICTAL does not alter plasma concentrations of concomitanty administered enzyme-inducing AEDs and therefore they do not usually require dose adjustment to maintain therapeutic plasma concentrations. For patients receiving LAMICTAL in combination with other AEDs, an evaluation of all AEDs in the regimen should be considered if a chang in seizure control or an appearance or worsening of adverse experiences is observed. If there is a need to discontinue therapy with LAMICTAL, a step-wise reduction of dose over at least lwo weeks (approximately 50 :

The relationship of plasma concentration to dinical response has nol been established for lamotriging. Dosing of LAMICTAL should be based on therapeutic response. In controlled dinical studies, doses of LAMICTAL that were efficacious generally produced steady-state trough plasma lamotrigine concentrations of 1 to $4 \mu \mathrm{mg} / \mathrm{mL}$ in pattents recelving one or more concomitant AEDs. Doses of LAMICTAL producing this plasma concentration range were we paterated. As with any antiepileptic diug, the orat dose of LAMICTAL should be adjusted to the needs of the individua
patient, taking into consideration the concomitant AED therapy the patient is receiving. Table 5 LAMICTAL Recommended Dosage Schedule for Adults

\begin{tabular}{|l|l|l|}
\hline \multirow{2}{*}{ Treatment Week } & \multicolumn{2}{|c|}{ Patients Taking } \\
\cline { 2 - 3 } & $\begin{array}{c}\text { Enzymo-Inducing AEDs } \\
\text { Without Valproic Acld }\end{array}$ & $\begin{array}{c}\text { Enzymo-Inducing AEDs }{ }^{1} \\
\text { With Valprolc Acld }\end{array}$ \\
\hline Weeks $1+2$ & 50 mg once a day & 25 mg once a day \\
\hline Weeks $3+4$ & $50 \mathrm{mg}$ iwice a day & $25 \mathrm{mg}$ wice a day \\
\hline Usual Maintenance & $150-250$ mg wice a day & $50-100 \mathrm{mg}$ wico a day \\
\hline
\end{tabular}

For Intormation"

1. Enzyme-inducing AEDs indude carbamazepine,

phenobartital, phenytoin, and primidone

Patients Talding
Valprolc Acld Only
25 mg every other day
25 mg once a day
$50-100$ mg twice a day
Column reflects dosage
recommendations in the
United Kingdom and is
provided tor intormation.

Optimal escalation doses from Week 5 to malntenance have not been tully established; titration is subject to clinical evaluation of the pattent.

There have been no controlled studies to establish the effectiveness of optimal dosing regimen of add-on LAMICTAL therapy in patients receiving only non-enzymeindusing AEOs of valproic acid. However, available data from open dinical trials indicate that the addition of LAMICTAL under these conditions is associated with a higher incidence of serious rash or rash-retated withdrawal, even at an iritial titration dose of $12.5 \mathrm{mg}$ daily (see PRECAUnONS, Skin Related Events, Table 3; see also WARNINGS). The potential medical benefits of addition of LAMICTAL undes these conditions must be weighed against the increased risk of serious rash. If use of LAMICTAL under these conditions is considered clinically indicated, thration dosing should proceed with extreme caution, espocially during the first six weeks of dose titration

Withdrawal of Concomitant AEDs: In patients receiving LAMICTAL who have all concomilant enzymoinduding AEDs withdrawn, the $t_{12}$ of lamotrigine will be approximately doubled (see ACTION AND CUNICAL PHARMACOLO GY. Under these concitions, it may be necessary to reduce the dose of LAMICTAL. In contrast, in patients recelving
LAMICTAL who have valproic acid withdrawn, the t $t_{12}$ of lamotrigine will be decreased; under these conditions, it may LAMICTAL who have valproic acid withdrawn, the

be necessary 10 increase the dose of LAMICTAL.

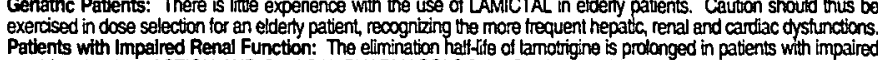
renal tunction (see ACTION AND CLNICAL PHARMACOLOGY). Caution should be exercised in dose selection to renal function (see ACTION AND CLN

patients with impaired renal tunction. impaired iver function. Because lamotigine is metabolized by the liver, caution shoutd be exercised in dose setection for patients with this condition.

Children Dosage recommendations for children under 18 years of age are not yet established.

Drug Substance

Brand Name: LAMICTAL

Common Name:Lamotigine

Chemical Name: 1,24-Trazine-3,5-diamine, 6-(2,3-dichlorophemy)-USAM

Chemical Name:6-2,3-dichtorophenth-1,2,4-tiazine-3,5-ciantine [Chem. Abstr.]

Structural Formula:[USAN]<smiles>Nc1nnc(-c2cccc(Cl)c2Cl)c(N)n1</smiles>

Molecular Formula: $\mathrm{C}_{9} \mathrm{H}_{7} \mathrm{C}_{2} \mathrm{~N}_{5} \quad$ Molecular Weight: 256.09
Description: Lamotrigine is a white to pate cream powder. The $\mathrm{pK}_{6}$ at $25^{\circ} \mathrm{C}$ is

Molecular Weight: 256.09 5.7. It is practicaly insotuble in water $(0.017 \%$ 's whi); slighty solutie in ethanol

Composition

LAMICTAL Tablets contain lamotrigine and the following non-medicinal ingredients:

- cellulose, lactose, magnesium stearate, povidone, sodum starch gycolate and coloring agents:

- $25 \mathrm{mg}$ (white tablets

- Sunset Yellow FCF Lak

$150 \mathrm{mg}$ (cream tablets) - Feric Oxide, Yellow

Stablic and Storago Recommendations

LAMICTAL Tabiets should be stored at controled rocm temperatire ( $15^{\circ} \mathrm{C}$ to $30^{\circ} \mathrm{C}$ ) in a dy place and protected from light. LAMICTAL Tablets are avaliable in three different strengths: LAMICTAL Tablets $25 \mathrm{mg}$ : White, scored, shielt-shaped
tablets engraved with "LAMICTAL" and "25". Bottes of 100 .

LAMICTAL Tablets $100 \mathrm{mg}$ : Peach, scored, shielto-shaped tabiets engraved with "LAMICTAL" and "100". Botties of 100 LAMICTAL Tablets $150 \mathrm{mg}$ : Cream, scored, shield-shaped tablets engraved with "LAMICTAL" and "150". Bottles of 60 .

Product Monograph available to health professionals upon request.

Reterences: 1. Goa KL et al Lamotrigine: A review of its phamacological properties and dinicat etficacy in epilepsy. Onugs 1993;46(1):152-176. 2. Leach M ef al. Neurochemical and behavioral aspects of lamotrigine. Epilepsi3 1991;32(Suppl.2);S4-SB 3. Data on flo Glaxo Wellome (GWMN(1)695). 4. Brodie MJ. Lamatigine versus other antiepleptic duags: A star rating system is bom.

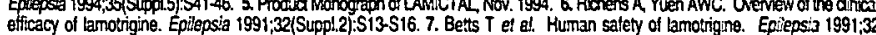

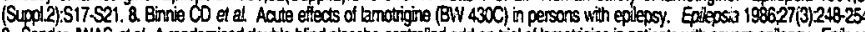

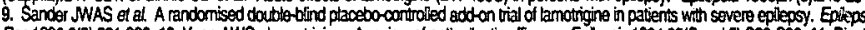

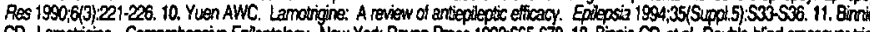

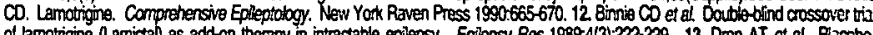
of lanotigigne (Lamictal) as add-on therapy in intractable eplepsy. Eplapsy Res 1989,4(3):222-229. 13. Dien AT ef a! Piscebo-

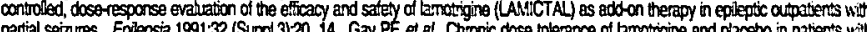

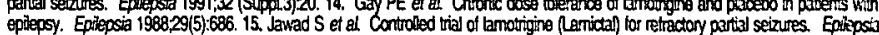

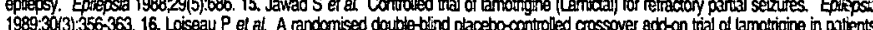
with treatment-resistant partial seizures. Endepsy fies 1990.7(2):136-145. 17. Matswo F ef al Placebo-controled study of the efficary

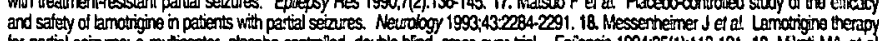

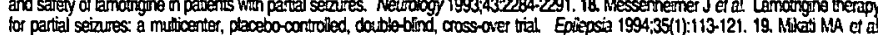
Long-term tolerability, phamacokknetic ard preliminary efficacy study of temotigina in patients with resistant partital seizures. Cin Muticenter, doublablind, placobo-controded, add-on, crossover study of tamotrigine (Lamicta), in epileptic outpatients with partial

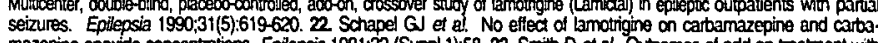

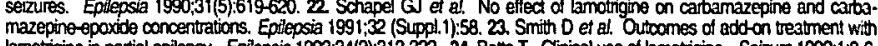
lamothigine in partial epilepsy. Eplepsia 1993;34(2):3123232. 24. Betts T. Clrical use of lamotigine. Seizura 1992;1:36. 25. Binnie CO. The eficacy of lamourigine. Rev Contemp Phamacother 1994;5:115-122. 26. Cohen AF et al. Lamotrigine (BW430C), a potential anticomutsant. Effects on the central nervous system in comparison with phenyoin and diazepam. BrJ Clin Phamacol 1985:20:619-629.

\section{Glaxo Wellcome}

\section{Giano Wellcome inc.}

Mississauga, Ontario. Canada L5N 6L 4
90995 LAM $\left[\begin{array}{l}\text { PAAB } \\ \text { CCPP }\end{array}\right]$

${ }^{\Theta}$ Registered trademark of The Wellcome Foundation Limited, Glaxo Wellcome Inc, licensed use. 


\section{VIMITREX}

\section{$100 \mathrm{mg}$ Tablet}

$6 \mathrm{mg}$ Subcutaneous Injection and Autoinjector

\section{SSIFICATION}

\section{Migraine Therapy}

\section{CLINICAL PHARMACOLOGY}

IMITREX (sumatriptan succinate) is a selective 5-hydroxyrryptamine, like $\left(5-\mathrm{HT}_{1}\right.$-like) receptor agonist which has been shown to be effective in relieving migraine headache. The activity of sumatriptan at the 5 $\mathrm{HT}_{1}$-like receptor mediates a selective vasoconstriction within the carotid arterial circulation supplying the intracranial and extracranial tissues such as the brain and meninges. The dilatation of cranial blood vessels is thought to play an important role in the underlying mecha. nism of migraine. Sumatriptan $(0.01-100 \mu \mathrm{M})$ caused a dose-dependent vasoconstriction in human isolated perfused dura mater as judged by vasoconstriction in human isolated perfused dura mater as judged by by sumatriptan suggests the possibility that the mechanism of the antimigraine action of sumatriptan could involve vasoconstriction of dural blood vessels. Sumatriptan has no effect at either $5-\mathrm{HT}_{2}$ or $5-\mathrm{HT}_{3}$ receptor subtypes. Clinical response begins $10-15$ minutes following subcutaneous injection and around $\mathbf{3 0}$ minutes following oral administration.

Cordiovascular Effects: In vitro studies in human isolated epicardial coronany arteries suggest that the predominant contractile effect of $5 . \mathrm{HT}$ is mediated via $5-\mathrm{HT}_{2}$ receptors. However, $5-\mathrm{H} \mathrm{T}_{1}$-like receptors also contribute to some degree to the contractile effect seen. Transient increases in systolic and diastolic blood pressure (up to $20 \mathrm{mmHg}$ ) of rapid onset (within minutes), have occurred after intravenous administration of up to $64 \mu \mathrm{g} / \mathrm{kg}$. $[3.2 \mathrm{mg}$ tor $50 \mathrm{~kg}$ subject) to healthy volunteers. These changes were not dose related and returned to normal within $10-15$ minutes. Following oral administration of $200 \mathrm{mg}$, however, mean peak increases in blood pressure were smaller and of slower onset than after intravenous or subcutaneous administration.

Pharmacokinetics: Sumatriptan is rapidly absorbed after oral and sub. cutaneous administration with a mean bioavailability of $96 \%$ atter subcutaneous dosing and $14 \%$ after oral dosing. The low oral bioavailability is mainly due to hepatic metabolism and, to a lesser extent, to incomplete absorption. The oral absorption of sumatriptan is not significantly affected either during migraine attacks or by food. Following an oral dose of $100 \mathrm{mg}$, a mean $\mathrm{C}_{\operatorname{mex}}$ of $54 \mathrm{ng} / \mathrm{mL}$ was attained, while the time to peak plasma level was variable $\{0.5$. 5 hours $\}$. However, $70 \%$ to $80 \%$ of $\mathrm{Cmax}_{\mathrm{m}}$ values were attained within 30-45 minutes of oral dosing. The mean plasma half-life was approximately 2 hours (range $1.9 \cdot 2.2$ hours). region of the arm or thigh or autoinjection into the thigh, a mean C region of the arm of thigh or autoinjection into the thigh, a mean Cmax value of $60 \mathrm{ng} / \mathrm{mL}$ was attained at approximately 15 minutes. Mean plasma half-life was approximately 2 hours (range $1.7 \cdot 2.3$ hours). lesser extent by renal excretion. The major metabolite, the indole acetic acid analogue of sumatriptan is mainly excreted in the urine where it is present as a free acid $(35 \%)$ and the glucuronide conjugate $(11 \%)$. It has no known5.HT, or $5 \cdot H T_{2}$ activity. Minor metabolites have not been identified. Plasma protein binding of sumatriptan in humans is low $(14 \%-21 \%)$. No differences have been observed between the pharmacokinetic parameters in healthy elderly votunteers compared with younger volunteers (less than 65 vears old).

INDICATIONS AND CLINICAL USES: IMITREXX (sumatriptan succinate) is indicated for the relief of migraine attacks with or without aura. the management of hemiplegic or basilartic therapy

the management of hemiplegic or basilar migraine.
CONTRAINDICATIONS: IMITREX (sumatriptan succinate) is contraindicated in patients with known hypersensitivity to any of the components of cated in patients with known hypersensitivity to any of the components of is ischaemic heart disease, angina pectoris including Prinzmetal angina hypertension. Sumatriptan is also contraindicated in patients taking ergotamine-containing preparations. Until further data are available, the use of sumatriptan is contraindicated in patients with hemiplegic migraine,
basilar migraine and in patients receiving treatment with MAOI's, selective 5-HT reuptake inhibitors and lithium.

WARNINGS

There is no experience in patients with recent cerebrovascular
accidents or cardiac arrhythmiss (especially tachycardias).
Therefore, the use of IMITREX (sumatriptan succinate) in these
patients is not recommended.

Sumatriptan has been sssociated with transient chest pain and tightness which may mimic angina pectoris and may be intense. Only in rare cases have the symptoms been identified as the result of coronary vasospasm. The vasospasm may result in arrythmia, ischaemia or myocardial infarction. If the patient experiences symptoms which are severe or persistent and are consistent with angina, appropriate investigations should be carried oul to check for the possibility of ischaemic changes. A careful medical history should be taken before sumatriptan is prescribed to exclude pre-existing cardiovascular disease. Sumatriptan should be used with caution in patients in whom there is a concern of ischaemic heart disease, as well as in patients with arteriosclerotic diseases such as peripheral and/or cerebral vascular disease. There have been rare reports of serious and/or life-threatening archythmias, including atrial fibrillation, ventricular fibrillation, ventricuarthythmias, including atrial fibrillation, ventricular fibrillation, ventricular tachycardia and myocardial infarction, as well as transient
ischaemic ST wave elevations associated with IMITREX injection. Consideration should be given to administering the first dose of Imitrex injection in the physician's office to patients in whom unrecognised coronary artery disease is comparatively likely: postmenopausal wornen, males over 40, patients with risk factors tor CAD (hypertension,
hypercholesterolaemia, obesity, diabetes, smoking, or strong family history of CAD). Sumatriptan injection should never be given intravenously. The recommended dose of sumatriptan should not be exceeded. PRECAUTIONS

Cluster Headache: There is insufficient information on the efficacy and safery of sumatriptan in the treatment of cluster headache, which is present in an older, predominantly male population. The need for prolenged use and the demand for repeated medication in this condition renders the dosing information inapplicable for cluster headache. General: Prolonged vasospastic reactions have been reported with ergotamine. As these effects may be additive, 24 hours should elapse before sumatripten can taken following any ergotamine-containing preparation. Conversely. have elapsed following sumatriptan administration. Chest jaw or neck tightness is relatively common (3.5\% in controlled clinical trials) after IMITREX injection, but has only been rarely associated with ischaemic ECG changes. Sumatriptan may cause a short-lived elevation of blood pressure (see Clinical Pharmacology and Contraindications). Patients should be cautioned that drowsiness may occur as a result of treatment with sumatriptan. They should be advised not to perform skilled tasks with sumatriptan. They should be advised not to perform

Hepatic and Renal Impairment: The effects of renal and hepatic impairment on the efficacy and safety of sumatriptan have not been evaluated. Therefore sumatriptan is not recommended in this patient population.

Use in Elderly (>65 years): Experience of the use of sumatriptan in patients aged over 65 years is limited. Therefor

Use in Children (<18 years): The safety and efficacy of sumatriptan in children has not been established and its use in this age group is not recommended.

Use in Pregnancy: Reproduction studies, performed in rats, have not revealed any evidence of impaired fertility, teratogenicity or post-natal development due to sumatriptan. Reproduction studies, performed in rabbits by the oral route, have shown increased incidence of variations in cervico-thoracic blood vessel configuration in the fetuses. These effects were only seen at the highest dose tested, which affected weight gain in the dams, and at which blood levels were in excess of 50 times those seen in humans atter therapeutic doses. A direct association with sumatriptan treatment is considered unlikely but cannot be excluded. Therefore, the use of sumatriptan is not recommended in pregnancy.

Lactation: Sumatriptan is excreted in breast milk in animals. No data exists in humans, therefore, caution is advised when administering sumatriptan to nursing women.

Orug Interactions: Single dose pharmacokinetic drug interaction studies have not shown evidence of interactions with propanolol, flunar-
izine, pizotifen or alcohol. Multiple dose interaction studies have not izine, pizotifen or

ADVERSE REACTIONS: The most common adverse reaction associated with IMITREX (sumatriptan succinate) administered subcutaneously is transient pain (local erythema and burning sensation) at the site of injection. Other side effects which have been reported for both the oral and subcutaneous routes, but were more common for the subcuta. neous route, include sensations of tingling, heat, heaviness, pressure and feelings of weakness. Transient increases in blo ing coronary vasospasm in patients with a history of coronary artery discoronary vasospasm in patients with a history of coronary artery disrarely, without prior history suggestive of coronary artery disease. There have been rare reports of serious and/or life-threatenin arrhythmias, including atrial fibrillation, ventricular fibrillation, ventricu. lar tachycardia, myocardial infarction, and transient ischaemic ST elevation associated with IMITREX injection (see WARNINGS)

Incidence of Drug Related Adverse Events in Controlled Clinical Trials

\begin{tabular}{|c|c|c|c|c|}
\hline Event & \begin{tabular}{|l} 
Tablets \\
$N=1456$
\end{tabular} & $\begin{array}{l}\text { Placebo } \\
\mathrm{N}=296\end{array}$ & \begin{tabular}{|c|c|} 
S.C. \\
njection \\
$\mathrm{N}=2665$ \\
\end{tabular} & \begin{tabular}{|} 
Placebo \\
$\mathrm{N}=868$
\end{tabular} \\
\hline \begin{tabular}{l|} 
Gastrointestinal: \\
nausea/vomiting \\
gastric symptoms, \\
abdominal discomfort \\
dysphagia \\
gastro-oesophageal reflux, \\
diarrhea and abnormal stools \\
\end{tabular} & $\begin{array}{r}12 \% \\
1 \% \\
1 \% \\
<1 \% \\
\end{array}$ & $\begin{array}{r}4 \% \\
\leq 1 \% \\
0 \% \\
\leq 1 \% \\
\end{array}$ & $\begin{array}{r}8 \% \\
1 \% \\
1 \% \\
<1 \% \\
\end{array}$ & $\begin{array}{r}4 \% \\
<1 \% \\
0 \% \\
0 \% \\
\end{array}$ \\
\hline $\begin{array}{l}\text { Neurological: } \\
\text { tingling } \\
\text { malaise/fatigue } \\
\text { dizziness/vertigo } \\
\text { warm/hot sensation } \\
\text { burning sensation } \\
\text { numbress } \\
\text { drowsiness/sedation } \\
\text { paresthesia } \\
\end{array}$ & $\begin{array}{r}1 \% \\
8 \% \\
5 \% \\
1 \% \\
1 \% \\
<1 \% \\
1 \% \\
3 \% \\
1 \% \\
\end{array}$ & $\begin{array}{r}<1 \% \\
2 \% \\
2 \% \\
<1 \% \\
0 \% \\
<1 \% \\
1 \% \\
0 \% \\
0 \%\end{array}$ & $\begin{array}{l}9 \% \\
2 \% \\
8 \% \\
8 \% \\
5 \% \\
3 \% \\
2 \% \\
1 \% \\
\end{array}$ & $\begin{array}{r}2 \% \\
<1 \% \\
3 \% \\
3 \% \\
3 \% \\
1 \% \\
1 \% \\
<1 \% \\
<1 \% \\
\end{array}$ \\
\hline $\begin{array}{l}\text { Cardiovascular: } \\
\text { flushing } \\
\text { hypertension, tachycardia } \\
\text { bradycardia } \\
\text { palpitations } \\
\text { hypotension } \\
\text { pallor } \\
\text { pulsating sensation } \\
\end{array}$ & $\begin{array}{l}<1 \% \\
<<\% \\
<1 \% \\
<1 \% \\
<1 \% \\
<1 \% \\
<1 \% \\
<1 \% \\
\end{array}$ & $\begin{array}{l}1 \% \\
0 \% \\
0 \% \\
<1 \% \\
0 \% \\
0 \% \\
0 \% \\
\end{array}$ & $\begin{aligned} 5 \% \\
<1 \% \\
<1 \% \\
<1 \% \\
<1 \% \\
<1 \% \\
<1 \% \\
<1 \% \\
\end{aligned}$ & $\begin{array}{l}2 \% \\
<1 \% \\
0 \% \\
0 \% \\
<1 \% \\
<1 \% \\
0 \% \\
<1 \% \\
\end{array}$ \\
\hline 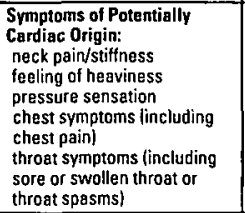 & $\begin{array}{l}2 \% \\
3 \% \\
1 \% \\
3 \%\end{array}$ & $\begin{array}{r}0 \% \\
<1 \% \\
<1 \% \\
<1 \% \\
<\% \\
0 \%\end{array}$ & $\begin{array}{l}3 \% \\
8 \% \\
6 \% \\
4 \% \\
2 \% \\
\end{array}$ & $\begin{array}{l}<1 \% \\
1 \% \\
1 \% \\
<1 \%\end{array}$ \\
\hline $\begin{array}{l}\text { Musculoskeletal: } \\
\text { weskness } \\
\text { myalgia } \\
\text { feeling of tightness } \\
\text { joint symptoms, backache. } \\
\text { muscle stittness or cramp }\end{array}$ & $\begin{array}{r}3 \% \\
2 \% \\
<1 \% \\
<1 \% \\
\end{array}$ & $\begin{array}{l}<1 \% \\
0 \% \\
0 \% \\
0 \% \\
\end{array}$ & $\begin{array}{l}3 \% \\
1 \% \\
3 \% \\
0 \% \\
\end{array}$ & $\begin{array}{l}<1 \% \\
<1 \% \\
<1 \% \\
0 \% \\
\end{array}$ \\
\hline $\begin{array}{l}\text { Miscellaneous: } \\
\text { sweatiting } \\
\text { disorder of mouth and tongue } \\
\text { disturbance of hearing } \\
\text { visual disturbance }\end{array}$ & $\begin{aligned} 2 \% \\
2 \% \\
<1 \% \\
<1 \%\end{aligned}$ & $\begin{array}{l}<\% \\
<1 \% \\
0 \% \\
0 \%\end{array}$ & $\begin{array}{l}2 \% \\
4 \% \\
<1 \% \\
<1 \%\end{array}$ & $\begin{array}{l}<1 \% \\
2 \% \\
0 \% \\
<1 \%\end{array}$ \\
\hline
\end{tabular}

Fatigue and drowsiness have been reported at slightly higher rates for the oral route, as were nausea and vomiting; the relationship of the latter adverse reactions to sumatriptan is not clear. The preceding table ints the incidence of adverse reactions reported in clinical trials undertaken with the oral formulation and the subcutaneous injection. Most of the events were transient in nature and resolved within 45 minMinor disturbances of liver function tests have occasionally been observed. There is no evidence that clinically significant abnormalities occurred more frequently with sumatriptan than with placebo. SYMPTOMS AND TREATMENT OF OVERDOSE

There have been no reports of overdosage with IMITREX (sumatriptan I Experience with doses outside of the recommended

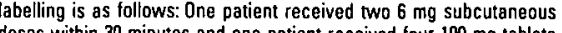
doses within 30 minutes and one patient received four $100 \mathrm{mg}$ tablets within 24 hours, with no adverse events. If overdosage with sumatriptan occurs, the patient should be monitored and standard supportive effect of haemodialysis or peritoneal dialysis on the serum concentra. tion of sumatriptan is unknown.

\section{DOSAGE AND ADMINISTRATION}

General: IMITREX (sumatriptan succinate) is indicated only for the intermittent treatment of migraine headache with or without aura. Sumatriptan should not be used prophybactically. Sumatriptan may be given orally or subcutaneously. Sumatriptan is equally effective when administered at any stage of a migraine attack, however, it is recomof aura or headache. Clinical response begins $10-15$ minutes following subcutaneous injection and around 30 minutes following oral administration. Further doses of sumatriptan should not be taken if the patient shows no response to the initial treatment of a single attack. However, shows no response to the initial treatment of a single attack. However, may be used for further pain relief. Sumatriptan may be taken for subsequent attacks. Twenty-four hours should elapse before sumatriptan is taken following any ergotamine-containing preparation. Converselv, ergotamine-containing preparations should not be taken until 6 hours have elapsed following sumatripten administration.

TABLETS: The recommended adult dose of IMITREX Tablets is a single $100 \mathrm{mg}$ tablet. Clinical trials have shown that approximately $50.75 \%$ of patients have headache relief within two hours after oral dosing, and that a further $15.25 \%$ have headache relief by 4 hours. If a patient has not responded within 4 hours, he/she is considered to be a nonresponder. Rescue medication excepting ergotamine-containing preparations may be used. Patients who have had a successful response (ie. no pain or mild pain) may treat a later recurrence of headache with an additional $100 \mathrm{mg}$ dose of sumatriptan. The maxiheadache with an additional $100 \mathrm{mg}$ dose of sumatriptan. The maxi-
mum dose in 24 hours is $3 \times 100 \mathrm{mg}$ tablets $(300 \mathrm{mg})$. Patients who do mum dose in 24 hours is $3 \times 100 \mathrm{mg}$ tablets $(300 \mathrm{mg})$. Patients who do not respond to the first dose should not take a second dose of sumaattacks. The tablet should be swallowed whole with water, not crushed or chewed

INJECTION: IMITREX Injection should be injected subcutaneously (on the outside of the thigh) using an autoinjector. The recommended adult dose of sumatriptan is a single $6 \mathrm{mg}$ subcutaneous injection. Clinical trials have shown that patients continue to improve for at least $120 \mathrm{~min}$ utes after a single subcutaneous injection of sumatriptan. If a patient has not responded within 2 hours, he/she is considered to be a nonresponder. Rescue medication excepting ergotamine-containing preparations may be used. Patients who have had a successful response (ie. no pain or mild pain) may treat a later recurrence of hour has elapsed since the first dose. This I hour interval is based on the knowled of the pharmakinetics of the drug. The maximum in 24 hours is in 24 hours is two $6 \mathrm{mg}$ injections $(12 \mathrm{mg}$ ). Patients who do not respond to the first dose should not take a second dose of sumatriptan for the same attack. But, sumatriptan may be taken for subsequent attacks.
STABILITY AND STORAGE RECOMMENDATIONS: IMITREX Tablats STABILITY AND STORAGE RECOMMENDATIONS: IMITREX Tablets
should be stored at $15^{\circ} \mathrm{C}$ to $30^{\circ} \mathrm{C}$. IMITREX Injection should be stored should be stored at $15^{\circ} \mathrm{C}$ to $30^{\circ} \mathrm{C}$. IMITREX Inje
between $22^{\circ} \mathrm{C}$ and $30^{\circ} \mathrm{C}$ and protected from light.

AVAILABILITY OF DOSAGE FORMS: IMITREX (sumatriptan succinat $\theta$ ) Tablets are pink, film-coated tablets available in blister packs containing 6 tablets, packed in a cardboard carton. Each tablet contains 100
mg sumatriptan (base) as the succinate salt. IMITREX Injection is available in prefilled syringes containing $6 \mathrm{mg}$ of sumatriptan base, as the succinate salt, in an isotonic solution (total volume $=0.5 \mathrm{~mL}$ ). Syringes are placed in a tamper-evident carning/disposal case. Two prefilled syringes plus an autoinjector are packed in a patient starter kit. A refill pack is available containing 2 prefilled syringes in a carton. dose vial (total volume $=0.5 \mathrm{~mL}$ ) containing $6 \mathrm{mg}$ of sumatriptan base, as the succinate salt.

Imitrex is a registered trade mark of Glaxo Group Limited, Glaxo Canada Inc. licensed use. Product Monograph available to physicians and pharmacists upon request. Please contact Glaxo Canada Inc. and pharmacists upon request. Please contact Glaxo
7333 Mississauga Road N, Mississauga, Ontario, L5N 6L4.

References: 1. Edmeads $\mathbf{J}$ et al. Impact of migraine and tension-type headache on lifestyle, consulting behaviour, and medication use. A Canadian population survey. Can J Neurol Sci 1993;20:131-137. 2. Schoenen $J$ et al. Self-treatment of acute migraine with subcutaneous sumatriptan using an auto-injector device: Comparison with customary treatment in an open, longitudinal study. Cephalalgia
1994:14:55-63 3. Product Monograph of IMITREX). Glaxo Canada Inc. 1994; 14:55-63 3. Product Monograph of IMITREX, Glaxo Canada Inc., Evaluation of a multiple-dose regimen of oral sumatriptan for the acut treatment of migraine. Eur Neurol 1991:31:306-313. 5. The Subcutaneous Sumatriptan international Study Group. Treatment of migraine attacks with sumatriptan. N Engl J Med 1991;325:316-321. 6. Sands $\mathrm{GH}$. A protocol for butalbital, aspirin and caffeine (BAC) detoxification in headache patients. Headache 1990;30:491-496. 7. Tansey MJB et al. Long-term experience with sumatriptan in the treatment of migraine. Eur Neurol 1993;33:310-315. B. Sullivan JT et al. Psycho1992:52:635-642. 9. Salonen $R$. The time to onset and duration of adverse events reported after the acute treatment of migraine with sumatriptan. The 2nd International Conference European Headache Federation. June $15-18$, 1994. Abstract from papers presented. Liege Federation. June 15-18, 1994. Abstract trom papers presented. Liege,
Belgium. 10. Data on file. Glaxo Canada inc., 1994. 11. Angus Reid Belgium. 10. Data on file. Glaxo Canada inc., 1994. 11. Angus Reid
Research, 1994. 12. Variation in Migraine Severity. Data on fite. Glaxo Canada Inc., 1994.

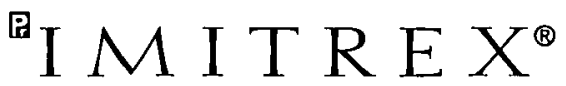

SUMATRIPTAN SUCCINATE

See pages vi, vii. 


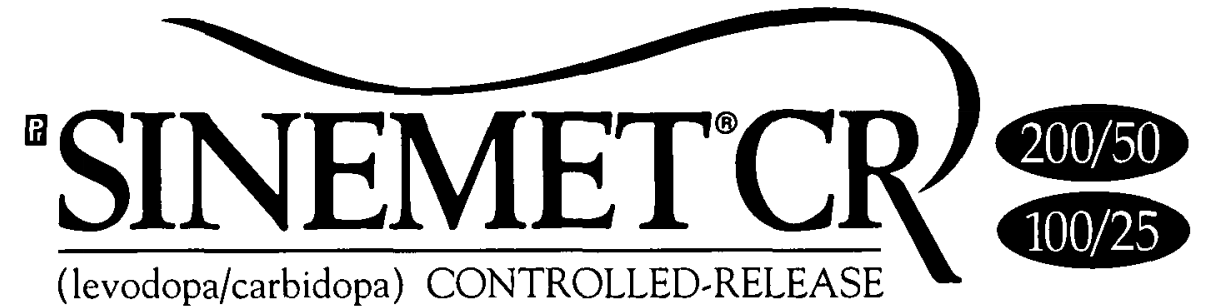

Controlled-Aelease Tablets

Antiparkinson Agent

Indications and Clinical Use: SINEMET@ CR (levodopa and carbidopa)

is indicated for the treatment of Parkinson's disease

At this time, experience in patients nol previously treated with levodopa/decarboxylase inhibitors or levodopa alone is limited.

SINEMET $\leftrightarrow$ CR is not recommended for the treatment of drug-induced extrapyramidal reaclions.

Contraindications: Monoamine oxidase inhibitors (except low doses of selective MAO-B inhibitors) and SINEMET ${ }^{\Theta}$ CA (levodopa and carbidopa) should not be given concomilantly. These inhibitors must be discontinued at least two weeks prior to initiating therapy with SINEMET $\otimes C R$

SINEMET(i) CR should not be administered to patients with clinical or laboratory evidence of uncompensated cardiovascular, endocrine, hematologic, hepatic, putmonary (including bronchial asthma). or renal disease; or to patients with narrow angle glaucoma.

As with levodopa. SINEMET $\Theta C R$ should not be given when administration of a sympathomimelic amine is contraindicated.

SINEMET $A$ CR is contraindicated in patients with known hypersensitivity to any component of this medication.

Because levodopa may activate a malignant melanoma, SINEMET@ CR should not be used in patients with suspicious undiagnosed skin lesions or a history of melanoma.

Warnings: When patients are receiving levodopa monotherapy or SINEMET $\Leftrightarrow$ (levodopa and carbidopa), this medication must be discontinued at least 8 hours betore therapy with SINEMET $\Theta$ CR is started. (For appropriate dosage substitulions, see DOSAGE AND ADMINISTRATION

As with levodopa or SINEMET@. SINEMET ${ }^{\otimes}$ CR may cause involuntary movements and mental disturbances. These reactions are thought to be due to increased brain dopamine following administration of levodopa. These adverse reactions may be more prolonged with SINEMETB CR than with SINEMET Al All patients should be observed carefully for the development of depression with concomilant suicidal tendencies. Patients with past or current psychoses should be treated with caution.

A symptom complex resembling the neuroleptic malignant syndrome including muscular rinidity elevated body remperature, mental changes. and increased serum creatine phosphokinase has been reported when antiparkinsonian agents were withdrawn abruptly. Therelore, patients should be observed carefully when the dosage of SINEMET $\otimes$ CA is reduced abruptly or discontinued, especially if the patient is receiving neuroleptics.

Care should be exercised in administering SINEMET $Q$ CR to patients with a history of recent myocardial infarction who have residual atrial, nodal, or ventricular arthythmias. In such patients, cardiac function should be monitored with particular care during the period of initial dosage administration and tiltation, in a lacility with provisions for intensive cardiac care.

SINEMET $\oplus$ CR should be administered cautiously to patients with a history of peptic ulcer disease or of convulsions

Precautlons: General: Periodic evaluations of hepatic, hematopoietic, cardiovascular and renal function are recommended during extended therapy (see ADVERSE REACTIONS)

Patients with chronic wide angle glaucoma may be treated cautiously with SINEMET $\otimes$ CR (levodopa and carbidopa), provided the intraocular pressure is well controlled and the patient monitored carefully for changes in intraocular pressure during therapy.

Use in Children: Safety of SINEMET(S) CR in patients under 18 years of age has not been established.

Use in Pregnancy and Lactation: Although the effects of SINEMET@ CR on human pregnancy and lactation are unknown, both levodopa and combinations of carbidopa and levodopa have caused visceral and skeletal mallormations in rabbits (see TERATOLOGIC AND REPRODUCTIVE STUDIES in Product Monograph). Therefore, use of SINEMET $\otimes$ CR in women of child-bearing potential requires that the anticipated benefits of the drug be weighed against possible hazards to the mother and to the fetus. SINEMET\& CR should nol be given to nursing mothers.

Drug interactions: Caution should be exercised when the following drugs are administered concomitantly with SINEMET® CR:

Antihypertensive drugs: Symptomatic postural hypotension has occurred when levodopa/decarboxylase inhibitor combinations were added to the Ireatment of patients receiving antihypertensive disgs. Theretore, when therapy with SINEMET $\otimes$ CR is started, dosage adjustment of the antihypertensive drug may be required.

Psychoactive drugs: Phenothiazines and butyrophenones may reduce the therapeutic elfects of levodopa. The beneficial effects of levodopa in Parkinson's disease have been reported to be reversed by phenyloin and

(s) Trademark ol Merck \& Co., Inc./Merck Frosst Canada Inc.,

and Du Pont Merck Pharma, R.U. papaverine. Patients taking these drugs with SINEMET@ CR should be observed carefully for loss of therapeutic response.

There have been rare reports of adverse reaclions, including hypertension and dyskinesia, resulting from the concomitant use of tricyclic antidepressants and carbidopa-levodopa preparations. (For patients receiving monoamine oxidase inhibitors, see CONTRAINDICATIONS.) Other drugs: Although specitic interaction studies were not perforned with other concomitant drugs, in clinical trials of SINEMETS CR patients were allowed to receive tricyclic antidepressants, benzodiazepines, propranolol thiazides, digoxin, $\mathrm{H}_{2}$ antagonists, salicylates and other nonsteroidal antiinflammatory drugs. SINEMET ${ }^{*} \mathrm{CR}$ was also used with other antiparkinson agents (see DOSAGE and ADMINISTRATION)

Adverse Reactions: In controlled clinical lrials involving 748 patients with moderate to severe motor fluctuations, SINEMET $\Leftrightarrow$ CR (levodopa and carbidopa) did not produce side elfects which were unique to the controlled-release tormulation. occasionally, prolonged, and at times, severe atternoon dyskinesias have occurred in some patients.

Other adverse reactions that were reported frequently were: nausea $(5.5 \%)$, hallucinations $(5.3 \%)$, confusion $(4.9 \%)$, dizziness $(3.5 \%)$. headache $(2.5 \%)$, depression $(2.5 \%)$, chorea $(2.5 \%)$, dry mouth $(2.3 \%)$ somnolence $(2.1 \%)$, dream abnormalities $(2.1 \%)$, dystonia $(2.0 \%)$ and asthenia $(2.0 \%)$

Adverse reactions occurring less irequently (less than $2 \%$ ) were: System $/ \%$ : Body as a uhole: Chest pain 1.7\%, Fatigue 0.9\%. Weight loss $0.8 \%$. Cardiovascular: Orthostatic hypotension $0.8 \%$. Palpitation $0.8 \%$, Hypotension 0.5\%

Nervous System / Psychiatric: Insomnia 1.7\%, Falling 1.6\%, On-off phenomenon $1.2 \%$, Paresthesia $0.9 \%$, Disorientation $0.8 \%$, Anxiety disorders $0.8 \%$. Decreased mental acuity $0.7 \%$. Extrapyramidal disorder $0.7 \%$ Gait abnormalities $0.7 \%$, Agitation $0.5 \%$, Memory impairment $0.5 \%$ Gastrointestinal: Anorexia 1.9\%. Constipation 1.5\%, Vomiting 1.3\% Diarrhea $1.2 \%$, Gastrointestinal pain $0.9 \%$. Dyspepsia $0.8 \%$. Musculoskeletal: Muscle cramps $0.9 \%$

Respiratory: Dyspnea 1.6\%

Special Senses; Blurred vision $1.1 \%$

Other adverse reactions that have been reported with levodopa or SINEMET $\Theta$ and may be potential side eflects with SINEMETQ CR are listed bolow:

Nervous System: Ataxia, numbness, increased hand tremor, muscle twitching, blepharospasm, trismus, activation of latent Horner's syndrome. Psychiatric: Sleepiness, euphoria, paranoid ideation and psychotic episodes. and dementia.

Cardiovascular: Arrhythmias, non-specific ECG changes, flushing, phlebitis. Gastrointestinal: Bitter taste, sialorrhea, dysonagia, bruxism, hiccups, gastrointestinal bleeding, flatulence, burning sensation of tongue, development of duodenal ulce

Integumentary: Increased sweating, dark sweat, rash, hair loss.

Genitourinary: Urinary frequency, retention, incontinence, hematuria, dark urine, nocluria and priapism.

Special Senses: Diplopia, dilated pupils, oculogyric crises.

Hematologic: Leukopenia, hemolytic and non-hemolytic anemia, thrombocytopenia, agranulocytosis.

Miscellaneous: Weakness, faintness, hoarseness, malaise, hot flashes, sense of stimulation, bizarre breathing patterns. hypertension, neuroleptic malignant syndrome, malignant melanoma (see CONTRAINDICATIONS)

Convulsions have occurred; however, a causal relationship with levodopa of levodopa/carbidopa combinations has not been established.

Dosage and Administration: SINEMET $\Leftrightarrow$ CR (levodopa and carbidopa) Tablets contain a 4:1 ratio of levodopa to carbidopa. SINEMET $\Theta$ CR 200/50 contains levodopa $200 \mathrm{mg} / \mathrm{carbidopa} 50 \mathrm{mg}$ per tablet. SINEMET $\otimes C R 100 / 25$ contains levodopa $100 \mathrm{mg} /$ carbidopa $25 \mathrm{mg}$ per tablet. The daily dosage of SINEMET $\omega$ CR must be deternined by caretul titration. Patients should be monitored closely during the dose adjustment period particularly with regard to appearance or worsening of nausea or abnormal involuntary movements, including dyskinesias, chorea and dystonia.

SINEMET $B$ CR 200/50 may be administered as whole or as hali tablets. SINEMET ${ }^{\circ}$ CR 100/25 should only be adrinistered as whole tablets. To maintain the controlled-release properties of the product, tablets should not be chewed or crushed.

Standard antiparkinson drugs, other than levodopa alone, may be continued while SINEMET@ CR is being administered, although their fosage may have to be adjusted. The delayed onset of aclion with SINEMET $B$ CR may require the supplemental use of conventional SINEMET $\odot$ Tablets tor optimal control in the mornings.

Intial Dosage and Titration lor Patients Currently Treated with Conventional Levodopa/Decarboxylase inhibitor Combinations: Dosage with
The adverse reaction reported most frequently was dyskinesia (12.8\%).
SINEMET $\Theta$ CR 200/50 should be substituted at an amount that eventually provides approximately 101030 percent more tevodopa per day. The interval between doses should be prolonged by 30 to 50 percent. Initially, patients should receive SINEMET' 'CR 200/50 at a dosage that provides the same amount of levodopa but with a lonoes dosing interal. Dapending on clinical response, the dosage may be increased.

A guide for the initiation of treatment with SINEMET. CR 200/50 is shown in the tollowing table.

Guideline for Intial Conversion ITOM SINEMET (o) to SINEMET W) CR 200/50

\begin{tabular}{|c|c|}
\hline $\begin{array}{l}\text { SINEMETO } \\
\text { Total Daily Dose } \\
\text { Levodopa (mg) }\end{array}$ & $\begin{array}{c}\text { SINEMET CR 200:50 } \\
\text { (levodopa } 200 \mathrm{mg} \\
\text { carbidopa } 50 \mathrm{mg} \text { ) } \\
\text { Suggested Dasage Regums }\end{array}$ \\
\hline $300-400$ & 1 tablet bid. \\
\hline $500-600$ & $\begin{array}{l}11 / 2 \text { lablets bi.d. } \\
\text { or } 1 \text { tablet ti.d. }\end{array}$ \\
\hline $700-800$ & $\begin{array}{l}\text { A total of } 4 \text { tablets in } \\
3 \text { or more divided doses } \\
\text { (e.g., } 11 / 2 \text { tablets a.m. } \\
11 / 2 \text { tablets early } p m \text {. } \\
\text { and } 1 \text { tablet later } p . m .)\end{array}$ \\
\hline $900-1000$ & $\begin{array}{l}\text { A total of } 5 \text { lablels in } \\
3 \text { or more divided doses } \\
\text { (e. } ., 2 \text { tablets a m. } \\
2 \text { tablets earty p.m. } \\
\text { and } 1 \text { tablet later } p . m \text {.) }\end{array}$ \\
\hline
\end{tabular}

* For dosing ranges not shown in the table, see DOSAGE AND ADMINISTRATION.

SINEMET $\otimes C R ~ 100 / 25$ is availabte to tacilitate titration when $100 \mathrm{mg}$ steps are required and as an atternative to the hall tablet of SINEMET w CR 200550 Initial Dosage for Patients Currenlly Trested with Levodops Alora: Levodop3 must be discontinued at least eight hours betore therapy with SINEMETE CR 200/50 is started. SINEMETw) CR should be substituted at a dosage that will provide approxinately $25 \%$ of the previous levodopa dosage. In patients with mild to moderate disease, the intilal dose is usunlly 1 tablet of SINEMET $\backsim$ CR 200/50 two times daily.

Patients Without Prior Levodopa Therapy: Experience with SINEMET " CR is limiled in the de novo parkinsonian patients.

SINEMET C CR 1CO/25 may be used in early slage pattents who have ned had prior levodopa therapy or to tacililate titration when necessary in pattents receiving SINEMET(E) CR 200/50. the initial recommended dose is 1 lablet of SINEMET $\Theta$ CR 100/25 twice daiy. Fos patients who require more levodops, a daily dose of 1 to 4 tab!ets ol SINEMEET $₫$ CR 100/25 twice a day is gererally well-tolerated.

When appropriate, levodopa therapy may also bo initiated with SINEMET 6 CR 200/50. The initial recommended dose in patients with mild to moderate disease is 1 lablet of SINEMET:; CR 200/50 wo times daily. Initial dosages should not exceed $600 \mathrm{mg}$ per day of levodopa or be given at intervals of less than 6 houts.

Tliration: Doses and dosing intervals must be adjusted on an individual basis, depending upon therapeutic response. An interval of at least 3 days between dosage adjustments is recommended. Most patients have been adequately treated with 2 to 8 tablets of SINEMET(w) CR 200/50 per day, administered as divided doses at intervals ranging from 4 to 12 hours during the waking day.

If the divided doses of SINEMET: CR 200/50 are not equal, it is recommended that the smaller doses be given at the end of the day

Maintenance: Because Parkinson's disease is progressive, periodic clinical evaluations are recommended and adjusiment of the dosage regimen of SINEMET $\omega$ CR may be required.

Addition ot Other Antiparkinson Medicatlons: Anticholinergic agents, dopamine agonists, amantadine and lower doses of selective MAO-B inhibilors can be given with SINEMET: $C R$. When combinng therapies, dosage adjustments may be necessary.

Interruption of Therapy: Patients should be observed casefully it abrup reduction or discontinuation of SINEMET CR is requred, especially it the patient is receiving neuroleptics (see PRECAUTIONS)

It general anesthesia is required, SINEMETW CR may be continued as long as the patient is permilted to take oral medication. It therapy is interrupted temporarily. the usual dosage should be administered as soon as the patient is ab!e to take oral medication

Availability of Dosage Form: No. 2042 - SINEMETw CR 100/25 is a pink-colored, oval-shaped, biconvex, compressed tablet, engraved SINEMET CR on one side and 601 an the other Avaitable in botlles of 100

No. 2041 - SINEMET: CR is peach-colored, oval-shaped, biconvex scored compressed tablet, engraved SINEMET CR on one side and $521 / 521$ on the other. Available in bottles of 100

Product Monograph Available on Request

$(364-\mathrm{a}, 4,93)$

04-94-SCR-93-CDN-0040-JA

$\begin{array}{lll}2655 \text { North Sheridan Way } & \text { Mississauga, Ontario } \\ \text { L5K 2P8 } & \text { DUPON B }\end{array}$

See page ix. 


\section{PARKF-DAVS} WEURONTIN (Gabapentin)

$100 \mathrm{mg}, 300 \mathrm{mg}, 400 \mathrm{mg}$ Capsules Antiepileptic Agent

\section{ACTION AND CUNICAL PHARMACOLOGY}

Gabapentin exhibits antiseizure activity in mice and rats both in the maximal electroshock and in the pentylenetetrazol seizure models.

Gabapentin is structurally related to the neurotransmitter GABA (gamma-aminobutyric acid) but does not interact with GABA receptors, it is not metabolized to GABA or to GABA agonists, and it is not an inhibitor of GABA uptake or degradation. Gabapentin at concentrations up to $100 \mu \mathrm{M}$ did not demonstrate affinity for other receptor sites such as benzodiazepine, glutamate, glycine or $\mathrm{N}$-methyl-D-aspartate receptors nor does it interact with neuronol sodium channels or L-type calcium channels.

The mechanism of action of gabapentin has not yet been established, however, it is unlike that of the commonly used anticonvulsant drugs.

In vitro studies with radiolabelled gabapentin have revealed o gabapentin binding site in rat brain tissues including neocortex and hippocampus. The identity and function of this binding site remain to be elucidated.

\section{Pharmacokinetics}

Adults:

Following oral administration of Neurontin (gabapentin), peak plasma concentrations are observed within 2 to 3 hours. Absolute bioavailability of a $300 \mathrm{mg}$ dose of Neurontin capsules is approximately $59 \%$. At doses of 300 and $400 \mathrm{mg}$, gabapentin bioavailability is unchanged following multiple dose administration. Gabapentin elimination from plasma is best described by linea pharmacokinetics. The elimination half-life of gabapentin is independent of dose and averages 5 to 7 hours in subjects with normal renal function.

Plasma gabapentin concentrations are dose-proportional at doses of 300 to $400 \mathrm{mg}$ q8h, ranging between $1 \mu \mathrm{g} / \mathrm{mL}$ and $10 \mu \mathrm{g} / \mathrm{mL}$, but are less than dose-proportional above the clinical range $(>600 \mathrm{mg}$ q8h). There is no correlation between plasma levels and efficacy. Gabapentin pharmacokinetics are not affected by repeated administration, and steady state plasma concentrations are predictable from single dose data.

Gabapentin is not appreciably metabolized in humans, is eliminated solely by renal excretion, and can be removed from plasma by hemodialysis.

Gabapentin does not induce or inhibit hepatic mixed function oxidase enzymes responsible for drug metabolism, does not interfere with the metabolism of commonly coadministered antiepileptic drugs, and is minimally bound to plasma proteins.

Food has no effect on the rate or extent of absorption of gabapentin.

Table 1 summarizes the mean steady-state pharmacokinetic parameters of Neurontin capsules.

Table 1: Summary of Neurontin (gabapentin) Mean Steady-State Pharmacokinetic Parameters in Adults Following Q8H Administration

\begin{tabular}{|l|c|c|}
\hline $\begin{array}{c}\text { Pharmacokinetic } \\
\text { Parameter }\end{array}$ & $\begin{array}{c}300 \mathrm{mg} \\
(\mathbf{N}=7)\end{array}$ & $\begin{array}{c}400 \mathrm{mg} \\
(\mathbf{N}=11)\end{array}$ \\
\hline $\mathrm{C}_{\max }(\mu \mathrm{g} / \mathrm{mL})$ & 4.02 & 5.50 \\
${ }^{\dagger} \max (\mathrm{hr})$ & 2.7 & 2.1 \\
$\mathrm{t}^{1} / 2(\mathrm{hr})$ & 5.2 & 6.1 \\
$\mathrm{AUC}(0-\alpha)(\mu \mathrm{g} \bullet \mathrm{hr} / \mathrm{mL})$ & 24.8 & 33.3 \\
$\mathrm{AE}{ }^{1}$ & $\mathrm{NA}$ & 63.6 \\
\hline
\end{tabular}

'Amount excreted in urine (\% of dose)

NA $=$ Not available

In patients with epilepsy, gabapentin concentrations in cerebrospinal fluid are approximately $20 \%$ of corresponding steady-state trough plasma concentrations.

Elderly:

Apparent oral clearance (CL/F) of gabapentin decreased as age increased, from about $225 \mathrm{~mL} / \mathrm{min}$ in subjects under 30 years of age to about $125 \mathrm{~mL} / \mathrm{min}$ in subjects over 70 years of age. Renal clearance (CLr) of gabapentin also declined with age; however, this decrease can largely be explained by the decline in renal function. Reduction of gabapentin dose may be required in patients who have age-related compromised renal function (See Dosage and Administration).

\section{Renal Impairment}

In patients with impaired renal function, gabapentin clearance is markedly reduced and dosage adjustment is necessary (See Table 5 in Dosage and Administration).

\section{Hemodialysis:}

In a study in anuric subjects ( $N=11$ ), the apparent elimination halflife of gabapentin on non-dialysis days was about 132 hours; dialysis three times a week ( 4 hours duration) lowered the apparent half-life of gabapentin by about $60 \%$, from 132 hours to 51 hours. Hemodialysis thus has a significant effect on gabapentin elimination in anuric subjects.

Dosage adjustment in patients undergoing hemodialysis is necessary (See Table 5 in Dosage and Administration).

\section{Pediatric:}

There are no pharmacokinetic data available in children under 18 years of age.

\section{Hepatic Impairment}

Because gabapentin is not appreciably metabolized in humans, no study was performed in patients with hepatic impairment.

\section{Clinical Irials}

In placebo-controlled trials in patients not satisfactorily controlled with current antiepileptic drugs, Neurontin (gabapentin), when added to current antiepileptic therapy, was superior to placebo in reducing the frequency of both simple and complex partial seizures and secondarily generalized tonic-clonic seizures. Further analysis of data indicated a higher efficacy for complex partial seizures and secondarily generalized tonic-clonic seizures as compared to all seizure types. Doses ranged from 900 to $1800 \mathrm{mg} /$ day, with a median dose of $1200 \mathrm{mg} / \mathrm{day}$.

Long-term, open, uncontrolled studies in drug-resistant patients for periods of up to 18 months demonstrated that doses up to $2400 \mathrm{mg} /$ day did not result in anything unusal in the type or frequency of adverse events.

\section{INDICATIONS AND CUNICAL USE}

Neurontin (gabapentin) is indicated as adjunctive therapy for the management of patients with epilepsy who are not satisfactorily controlled by conventional therapy.

\section{CONTRAINDICATIONS}

Neurontin (gabapentin) is contraindicated in patients who have demonstrated hypersensitivity to the drug or to any of the components of the formulation.

\section{PRECAUTIONS}

General

Neurontin (gabapentin) is not considered effective in the treatment of absence seizures and should therefore be used with caution in patients who have mixed seizure disorders that include absence seizures.

\section{Tumorigenic Potential}

Gabapentin produced an increased incidence of acinar cell adenomas and carcinomas in the pancreas of male rats, but not female rats or in mice, in oncogenic studies with doses of $2000 \mathrm{mg} / \mathrm{kg}$ which resulted in plasma concentrations 14 times higher than those occurring in humans at the maximum recommended dose of $2400 \mathrm{mg} /$ day. The relevance of these pancreatic acinar cell tumours in male rats to humans is unknown, particularly since tumours of ductal rather than acinar cell origin are the predominant form of human pancreatic cancer.

\section{Drug Discontinuation}

As with other anticonvulsant agents, abrupt withdrawal is not recommended because of the possibility of increased seizure frequency. When in the judgement of the clinician there is a need for dose reduction, discontinuation or substitution with alternative medication, this should be done gradually over a minimum of one week.

\section{Occupational Hazards}

Patients with uncontrolled epilepsy should not drive or handle potentially dangerous machinery. During clinical trials, the most common adverse reactions observed were somnolence, ataxia, fatigue and nystagmus. Patients should be advised to refrain from activities requiring mental alertness or physical coordination until they are sure that Neurontin does not affect them adversely.

\section{Drug Interactions}

Antiepileptic Agents:

There is no interaction between Neurontin and phenytoin, valproic acid, carbamazepine, or phenobarbital. Consequently, Neurontin may be used in combination with other commonly used antiepileptic drugs without concern for alteration of the plasme concentrations of gabapentin or the other antiepileptic drugs.

Gabapentin steady-state pharmacokinetics are similar for healthy subjects and patients with epilepsy receiving antiepileptic agents.

\section{Oral Contraceptives:}

Coadministration of Neurontin with the oral contraceptive NorlEstrin * does not influence the steady-state pharmacokinetics of norethindrone or ethinyl estradiol.

\section{Antacids:}

Coadministration of Neurontin with an aluminum and magnesium based antacid reduces gabapentin bioavailability by up to $24 \%$. Although the clinical significance of this decrease is not known, coadministration of similar antacids and gabapentin is not recommended.

Probenecid:

Renal excretion of gabapentin is unaltered by probenecid

Cimetidine:

A slight decrease in renal excretion of gabapentin observed when it is coadministered with cimetidine is not expected to be of clinical importance.

\section{Use in Pregnancy}

No evidence of impaired fertility or harm to the fetus due to gabapentin administration was revealed in reproduction studies in mice at doses up to 62 times, and in rats and rabbits at doses up to 31 times the human dose of $2400 \mathrm{mg} /$ day

There are, however, no adequate and well-controlled studies in pregnant women. Because animal reproduction studies are not always predictive of human response, this drug should only be used during pregnancy if the potential benefit to the mother justifies the potential risk to the fetus.

\section{Use in Lactation}

It is not known if gabapentin is excreted in human milk, and the effect on the nursing infant is unknown. However, because many drugs are excreted in human milk, and because of the potential for serious adverse reactions in nursing infants from gabapentin, breast-feeding is only recommended if the potential benefit outweighs the potential risks.

\section{Use in Children}

Systematic studies to establish safety and efficacy in children have not been performed. Data in 39 patients between the ages of 12 and 18 years included in the double-blind, placebo-controlled trials showed that gabapentin was superior to placebo in reducing seizure frequency. Safety data showed that the incidence of adverse events in this group of patients were similar to those observed in older individuals.

\section{Use in the Elderly}

Systematic studies in geriatric patients have not been conducted. Adverse clinical events reported among 59 patients over the age of 65 years treated with Neurontin did not differ from those reported for younger individuals. The small number of individuals evaluated and the limited duration of exposure limits the strength of any conclusion reached about the influence of age, if any, on the kind and incidence of adverse events associated with the use of Neurontin

As Neurontin is eliminated primarily by renal excretion, dosage adjustment may be required in elderly patients because of declining renal function (See Dosage and Administration).

\section{Use in Renal Impairment}

Gabapentin clearance is markedly reduced in this patien population and dosage reduction is necessary (See Table 5 in Dosage and Administration).

\section{Laboratory Tests}

Clinical trials data do not indicate that routine monitoring of clinica laboratory parameters is necessary for the safe use of Neurontin. Neurontin may be used in combination with other commonly used antiepileptic drugs without concern for alteration of the blood concentrations of gabapentin or other antiepileptic drugs.

For urinary protein determination the sulfosalicylic acid precipitation procedure is recommended, as false positive readings were reported with the Ames N-Multistix SG* dipstick test, when gabapentin or placebo was added to other anticonvulsant drugs. 


\section{ADVERSE REACTIONS}

\section{Incidence in Controlled Clinical Irials}

Table 2 lists treatment-emergent signs and symptoms that occurred in at least $1 \%$ of patients with partial seizures participating in placebo-controlled studies. In these studies, either Neurontin lat doses of $600,900,1200$ or $1800 \mathrm{mg} /$ day) or placebo were added to the patient's current antiepileptic drug therapy.

The most commonly observed adverse events associated with the use of Neurontin in combination with other antiepileptic drugs, not seen at an equivalent frequency in placebo-treated patients, were somnolence, dizziness, ataxia, fatigue, nystagmus and tremor

Among the treatment-emergent adverse events occurring in Neurontin-treated patients, somnolence and ataxia appeared to exhibit a positive dose-response relationship. Patients treated with $1800 \mathrm{mg} /$ day ( $\mathrm{n}=54$, from one controlled study) experienced approximately a two-fold increase, as compared to patients on lower doses of 600 to $1200 \mathrm{mg} /$ day $(\mathrm{n}=489$, from several controlled studies), in the incidence of nystagmus (20.4\%), tremor (14.8\%), rhinitis (13\%), peripheral edema (7.4\%), abnormal coordination, depression and myalgia (all at 5.6\%). Adverse events were usually mild to moderate in intensity, with a median time to resolution of 2 weeks.

Since Neurontin was administered most often in combination with other antiepileptic agents, it was not possible to determine which agent(s) was associated with adverse events.

Table 2: Treatment-Emergent Adverse Event Incidence in PlaceboControlled Add-On Trials (Events in at Least 1\% of Neurontin Patients and Numerically More Frequent than in the Placebo Groupl

\begin{tabular}{|c|c|c|}
\hline $\begin{array}{l}\text { BODY SYSTEM/ } \\
\text { ADVERSE EVENT (AE) }\end{array}$ & $\begin{array}{c}\begin{array}{c}\text { Neurontin } \\
N=543 \\
\%\end{array} \\
\end{array}$ & $\begin{array}{c}\text { Placebo }{ }^{a} \\
N=378 \\
\%\end{array}$ \\
\hline $\begin{array}{l}\text { BODY AS A WHOLE: } \\
\text { Fatigue } \\
\text { Weight Increase } \\
\text { Back Pain } \\
\text { Peripheral Edema }\end{array}$ & $\begin{array}{r}11.0 \\
2.9 \\
1.8 \\
1.7\end{array}$ & $\begin{array}{l}5.0 \\
1.6 \\
0.5 \\
0.5\end{array}$ \\
\hline $\begin{array}{l}\text { CARDIOVASCULAR: } \\
\text { Vasodilatation }\end{array}$ & 1.1 & 0.3 \\
\hline $\begin{array}{l}\text { DIGESTIVE SYSTEM: } \\
\text { Dyspepsia } \\
\text { Dry Mouth or Throat } \\
\text { Constipation } \\
\text { Dental Abnormalities } \\
\text { Increased Appetite }\end{array}$ & $\begin{array}{l}2.2 \\
1.7 \\
1.5 \\
1.5 \\
1.1\end{array}$ & $\begin{array}{l}0.5 \\
0.5 \\
0.8 \\
0.3 \\
0.8\end{array}$ \\
\hline $\begin{array}{l}\text { HEMATOLOGIC AND } \\
\text { IYMPHATIC SYSTEMS: } \\
\text { Leukopenia }\end{array}$ & 1.1 & 0.5 \\
\hline $\begin{array}{l}\text { MUSCULOSKELETAL SYSTEM: } \\
\text { Myalgia } \\
\text { Fracture }\end{array}$ & $\begin{array}{l}2.0 \\
1.1\end{array}$ & $\begin{array}{l}1.9 \\
0.8\end{array}$ \\
\hline $\begin{array}{l}\text { NERVOUS SYSTEM: } \\
\text { Somnolence } \\
\text { Dizziness } \\
\text { Ataxia } \\
\text { Nystagmus } \\
\text { Tremor } \\
\text { Nervousness } \\
\text { Dysarthria } \\
\text { Amnesia } \\
\text { Depression } \\
\text { Abnormal Thinking } \\
\text { Twitching } \\
\text { Abnormal Coordination }\end{array}$ & $\begin{array}{r}19.3 \\
17.1 \\
12.5 \\
8.3 \\
6.8 \\
2.4 \\
2.4 \\
2.2 \\
1.8 \\
1.7 \\
1.3 \\
1.1\end{array}$ & $\begin{array}{l}8.7 \\
6.9 \\
5.6 \\
4.0 \\
3.2 \\
1.9 \\
0.5 \\
0.0 \\
1.8 \\
1.3 \\
0.5 \\
0.3\end{array}$ \\
\hline $\begin{array}{l}\text { RESPIRATORY SYSTEM: } \\
\text { Rhinitis } \\
\text { Pharyngitis } \\
\text { Coughing }\end{array}$ & $\begin{array}{l}4.1 \\
2.8 \\
1.8\end{array}$ & $\begin{array}{l}3.7 \\
1.6 \\
1.3\end{array}$ \\
\hline $\begin{array}{l}\text { SKIN AND APPENDAGES: } \\
\text { Abrasion } \\
\text { Pruritus }\end{array}$ & $\begin{array}{l}1.3 \\
1.3\end{array}$ & $\begin{array}{l}0.0 \\
0.5\end{array}$ \\
\hline $\begin{array}{l}\text { UROGENITAL SYSTEM: } \\
\text { Impotence }\end{array}$ & 1.5 & 1.1 \\
\hline $\begin{array}{l}\text { SPECIAL SENSES: } \\
\text { Diplopia } \\
\text { Amblyopia }\end{array}$ & $\begin{array}{l}5.9 \\
4.2\end{array}$ & $\begin{array}{l}1.9 \\
1.1\end{array}$ \\
\hline $\begin{array}{l}\text { LABORATORY DEVIATIONS: } \\
\text { WBC Decreased }\end{array}$ & 1.1 & 0.5 \\
\hline
\end{tabular}

a Plus background antiepileptic drug therapy

Data from long-term, open, uncontrolled studies shows that Neurontin treatment does not result in any new or unusual adverse events.
Withdrawal From Treatment Due to Adverse Events

Approximately $6.4 \%$ of the 543 patients who received Neurontin in the placebo-controlled studies withdrew due to adverse events. In comparison, approximately $4.5 \%$ of the 378 placebo-controlled participants withdrew due to adverse events during these studies. The adverse events most commonly associated with withdrawal were somnolence (1.2\%), ataxia $(0.8 \%)$, fatigue, nausea and/or vomiting and dizziness (all at $0.6 \%$ ).

\section{Other Adverse Events Observed in All Clinical Trials}

Adverse events that occurred in at least $1 \%$ of the 2074 individuals who participated in all clinical trials are described below, except those already listed in the previous table:

Body As a Whole

Cardiovascular System

aesthenia, malaise, facial edema

Digestive System

hypertension

Hematologic and

Lymphatic System

anorexia, Alatulence, gingivitis

Musculoskeletal System

purpura; most often described as bruises resulting from physical trauma

Nervous System

\section{arthralgia}

vertigo, hyperkinesia

parasthesia, anxiety, hostility decreased or absent reflexes

Respiratory System

pneumonia

Special Senses

abnormal vision

\section{SYMPTOMS AND TREATMENT OF OVERDOSAGE}

Acute, life-threatening toxicity has not been observed with Neurontin (gabapentin) overdoses of up to 49 grams ingested at one time. In these cases, double vision, slurred speech, drowsiness, lethargy and diarrhea were observed. All patients recovered with supportive care.

Gabapentin can be removed by hemodialysis. Although hemodialysis has not been performed in the few overdose cases reported, it may be indicated by the patients clinical state or in patients with significant renal impairment.

Reduced absorption of gabapentin at higher doses may limit drug absorption at the time of overdosing and, hence, reduce toxicity from overdoses.

An oral lethal dose of gabapentin was not identified in mice and rats given doses as high as $8000 \mathrm{mg} / \mathrm{kg}$. Signs of acute toxicity in animals included ataxia, laboured breathing, ptosis, hypoactivity, or excitation.

\section{DOSAGE AND ADMINISTRATION}

Adults

The usual effective maintenance dose is 900 to $1200 \mathrm{mg} /$ day Treatment should be initiated with 300 to $400 \mathrm{mg} /$ day. Titration to an effective dose, in increments of $300 \mathrm{mg}$ or $400 \mathrm{mg} /$ day, can progress rapidly and can be accomplished over three days (see Table 3). Neurontin is given orally with or without food.

Table 3. Titration Schedule

\begin{tabular}{|c|c|c|c|}
\hline DOSE & Day 1 & Day 2 & Day 3 \\
\hline $900 \mathrm{mg} /$ day & $300 \mathrm{mg}$ OD & $300 \mathrm{mg}$ BID & $300 \mathrm{mg}$ TID \\
$1200 \mathrm{mg} /$ day & $400 \mathrm{mg}$ OD & $400 \mathrm{mg}$ BID & $400 \mathrm{mg}$ TID \\
\hline
\end{tabular}

Data from clinical trials suggest that doses higher than $1200 \mathrm{mg} /$ day may have increased efficacy in some patients; however, higher doses may also increase the incidence of adverse events (See Adverse Reactions).

Daily maintenance doses should be given in three equally divided doses (See Table 4), and the maximum time between doses in a three times daily schedule should not exceed 12 hours. It is not necessary to monitor gabapentin plasma concentrations in order to optimize Neurontin therapy. Further, as there are no drug interactions with commonly used antiepileptic drugs, Neurontin may be used in combination with these drugs without concern for alteration of plasma concentrations of either gabapentin or other antiepileptic drugs.

Table 4. Maintenance Dosage Schedule

\begin{tabular}{|c|r|}
\hline Total Daily Dose (mg/day) & Schedule \\
\hline 900 & $300 \mathrm{mg}$ TID \\
1200 & $400 \mathrm{mg}$ TID \\
1800 & $2 \times 300 \mathrm{mg}$ TID \\
2400 & $2 \times 400 \mathrm{mg}$ TID \\
\hline
\end{tabular}

Dosage adjustment in elderly patients due to declining renal function and in patients with renal impairment or undergoing hemodialysis is recommended as follows:

Table 5: Maintenance Dosage of Neurontin in Adults With Reduced Renal Function

\begin{tabular}{|c|c|c|}
\hline $\begin{array}{c}\text { Renal Function } \\
\text { Creatinine Clearance } \\
\text { (mL/min) }\end{array}$ & $\begin{array}{c}\text { Tolal } \\
\text { Daily Dose } \\
\text { (mg/day) }\end{array}$ & $\begin{array}{c}\text { Dose Regimen } \\
\text { (mg) }\end{array}$ \\
\hline$>60$ & 1200 & 400 Three times a day \\
$30-60$ & 600 & 300 Twice a Day \\
$15-30$ & 300 & 300 Once a Day \\
$<15$ & 150 & 300 Once Daily Every \\
& & Other Day \\
Hemodialysis $^{a}$ & - & $200-300^{b}$ \\
\hline
\end{tabular}

a Loading dose of 300 to $400 \mathrm{mg}$

b Maintenance dose of 200 to $300 \mathrm{mg}$ Neurontin following each 4 hours of hemodialysis

\section{Children Over 12 Years of Age}

The dosage used in a limited number of patients in this age group was $900-1200 \mathrm{mg} /$ day. Doses above $1200 \mathrm{mg} /$ day have not been investigated.

\section{AVAILABILITY OF DOSAGE FORMS}

Neurontin (gabapentin) capsules are supplied as follows:

100-mg capsules;

Hard gelatin SUPRO" capsules with white opaque body and cap printed with "PD" on one side and "Neurontin/100 mg" on the other. Bottles of 100 capsules.

\section{0-mg capsules;}

Hard gelatin SUPRO' capsules with yellow opaque body and cap printed with "PD" on one side and "Neurontin/300 mg" on the other. Bottles of 100 capsules.

\section{0-mg capsules;}

Hard gelatin SUPRO" capsules with orange opaque body and cap printed with "PD" on one side and "Neurontin/ $400 \mathrm{mg}$ " on the other. Bottles of 100 capsules.

\section{Composition}

Capsules contain gabapentin, lactose, corn starch, and talc. Capsule shells may contain gelatin, titanium dioxide, silicon dioxide, sodium lauryl sulfate, yellow iron oxide, red iron oxide, and FD\&C Blue No. 2.

\section{Stability and Storage Recommendations}

Store at controlled room temperature $15-30^{\circ} \mathrm{C}$
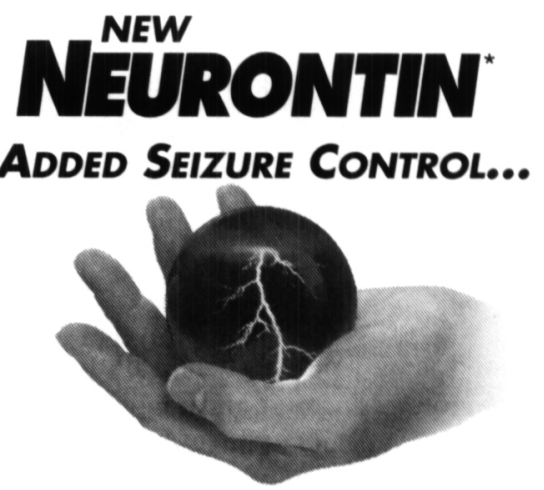

Easy To Handle

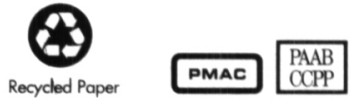

PARKE-DAVIS

Scarborough, Ontario, M1L 2N3

- T.M. Warner-Lambert Company, Parke-Davis 
PRESCRIBING INFORMATION

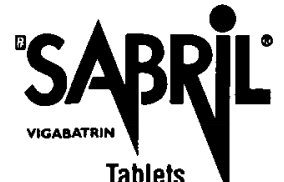

Tablets

$500 \mathrm{mg}$
Antiepileptic

ACTION AND CLINICAL PHARMACOLOGY

SABRIL (vigabatrin) is an irreversible inhibitor of gamma-aminobutyric acid transaminase (GABA-T), the enzyme responsible for the catabolism of the inhibitory neurotransmitter gamma-aminobutyric acid (GABA) in the brain. The mechanism of action of vigabatrin is attributed to irreversible enzyme inhibition of GABA-T, and consequent increased levels of the inhibitory neurotransmitter, GABA. Decreased serum levels of SGOT (ALT) and SGPT (AST) have been observed during treatment with vigabatrin and may be the result of inhibition of these transaminases by vigabatrin. The clinical significance of these findings is unknown.

The duration of effect of vigabatrin is thought to be dependent on the rate of GABA-T resynthesis rather than on the plasma concentration of vigabatrin.

Clinical Trials

In clinical trials, including double-blind, placebo-controlled studies involving 354 patients with drug-resistant complex partial seizures, vigabatrin reduced seizure frequency by $50 \%$ or more in approximately half of the patients studied.

In clinical trials involving children, the efficacy of vigabatrin was similar to that seen in adult patients with refractory partial seizures. In one study of 70 children with intractable infantile spasms, approximately $70 \%$ of the patients had a greater than $50 \%$ reduction in spasms. In this study, long-term response was observed in $75 \%$ of the children with symptomatic infantile spasms and $36 \%$ of the children with cryptogenic infantile spasms.

Pharmacokinetics

Vigabatrin is rapidly absorbed following oral administration and peak plasma concentrations are reached within two hours. Vigabatrin is widely distributed with an apparent volume of distribution slightly greater than total body water. The primary route of elimination is via the kidney, with little metabolic transtormation occurring. Following a single dose, approximately $70 \%$ is excreted in the urine as unchanged drug within the first 24 hours post-dose The plasma elimination half-life is approximately $5-8$ hours in young adults and 12-13 hours in the elderly. In renat impairment the elimination is prolonged and the rate of renal clearance is directly related to creatinine clearance (see PRECAUTIONS and DOSAGE AND ADMIN ISTRATION). Vigabatrin does not induce the hepatic cytochrome P450 system nor is it extensively metabolized or plasma-protein bound. Administration of vigabatrin with food slightly reduces the rate, but not the extent of absorption.

INDICATIONS AND CLINICAL USE

SABRIL (vigabatrin) is indicated for the adjunctive management of epilepsy which is not satisfactorily controlled by conventional therapy. There is insufficient data on the usefulness of vigabatrin in monotherapy at this time.

Vlgabatrin should be used under close monitoring by a neurologist. CONTRAINDICATIONS

SABRIL. (vigabatrin) is contraindicated in pregnancy and lactation (see WARNINGS) and in patients with a known hypersensitivity to vigabatrin or to any components of the product.

\section{WARNINGS}

\section{Neurotoxicity in Animals}

Rat, Mouse and Dog: Safety studies carried out in the rat, mouse and dog at doses of 30 to $50 \mathrm{mg} / \mathrm{kg} /$ day and higher, caused doseand time-dependent micro-vacuolation within certain white matter tracts of the brain (the cerebellum, reticular formation and thalamus in rodents and the columns of the fornix and optic tracts in dogs were most affected). The microvacuolation was caused by the separation of the outer lamellar sheath of myelinated fibres, a change characteristic of non-inftammatory intramyelinic edema.

In both the rat and dog (mouse was not tested), the intramyelinic edema was reversible after stopping the administration of vigabatrin; however, in the mouse and rat, residual changes consisting of swollen axons and mineralised microbodies were observed.

Monkey: In monkeys, the oral administration of $300 \mathrm{mg} / \mathrm{kg} / \mathrm{day}$ for 16 months produced minimal microvacuolation with equivocal differences between treated and control animals. Low oral absorption of vigabatrin in the monkey resulted in an actual absorbed dose of $75 \mathrm{mg} / \mathrm{kg} /$ day. In spite of the poor absorption, cerebrospinal fluid (CSF) levels of vigabatrin in the monkeys were comparable to those seen in rats treated with $300 \mathrm{mg} / \mathrm{kg} /$ day; however, GABA levels in the CSF and the brain cortex in treated monkeys were not significantly different from untreated monkeys. This finding may explain the reason for the equivocal effects, since the intramyelinic edema associated with vigabatrin treatment appears to be related to increased brain GABA levels.

Evoked Potentials

Evoked potentials in animals: In the dog, studies indicate that intramyelinic edema is associated with increased latencies in somatosensory and visual evoked potentials. Magnetic resonance imaging (MRI) changes also correlated with intramyelinic edema in the fornix, thalamus and hypothalamus.

Evoked potentials in man: No increased evoked potential latencies have been observed in man. Two hundred and twenty-one patients treated for 4-5 months showed no significant evoked potential latency changes at the end of treatment as compared to aseline. MRI results in man did not show the changes observed in sho had intramyelinic edema.

We were treated with vigabatrin (mean duration of treatment was 28 months, and the longest treatment was 6 years) showed no myelin vacuolation in the white matter that was considered to be outside of the control range.

Although clinical trials have not revealed the type of neurotoxicity seen in animal studies, because of increased CSF GABA levels observed in humans, it is recommended that patients treated with vigabatrin be closely observed for adverse effects on neurological function, with special attention to visual disturbance.

Use in Pregnancy and Lactation In a teratology study in the rabbit a dose-related incidence, $2 \%$ and $9 \%$, of cleft palate was observed at doses of 150 and $200 \mathrm{mg} / \mathrm{kg} /$ day, respectively.

In animal reproductive studies neurohistopathology was not performed on the fetuses, therefore it is not known whether microvacuolation occurred in utero. The possibility that microvacuolation or other neurotoxicity may occur in human fetuses cannot be discarded. PRECAUTIONS

Use in Patients with a History of Psychosis Behavioural disturbances such as aggression and psychotic episodes have been reported following initiation of vigabatrin therapy. A history of abnormal behaviour or psychosis appears to be a predisposing factor for such reactions, therefore treatment in such patients should be initiated cautiously at low doses and with frequent monitoring.

Use in the Elderly and in Patients with Renal Impairment Vigabatrin is eliminated via the kidney and caution should be exercised when administering the drug to elderly patients and to patients with renal impairment (see DOSAGE AND ADMINISTRATION).

Use in Patients with Myoclonic Seizures As with other antiepileptic drugs, some patients may experience an increase in seizure frequency with vigabatrin. Patients with myoclonic seizures may be particularly liable to this effect.

Discontinuation of Therapy As with other antiepileptic drugs, abrupt discontinuation may lead to rebound seizures. If a patient is to be withdrawn from vigabatrin treatment, it is recommended that this be done gradually by reducing the dose over a 2 to 4 week period if possible. Drug Interactions A gradual reduction of about $20 \%$ in plasma phenytoin concentration has been observed following add-on therapy with vigabatrin. The mechanism whereby this occurs is unknown. Limited data from clinical trials suggest that increasing the phenyloin dose to compensate may not be necessary.

Occupational Hazards Patients with uncontrolled epilepsy should not drive or handle potentially dangerous machinery. During clinica trials, the most common adverse reactions observed were drowsness and fatigue. Patients should be advised to refrain from activities requiring mental alertness or physical coordination until they are sure that vigabatrin does not affect them adversely.

\section{ADVERSE REACTIONS}

AABRIL (vigabatrin) is generally well tolerated in epileptic patients. Adverse events are mainly CNS-related and probably a secondary consequence of increased GABA levels caused by vigabatrin. The safety of vigabatrin was evaluated in 2081 epileptic patients treated in clinical trials. The relationship of adverse events to vigabatrin therapy was not clearly established as patients were taking other antiepileptic drugs concomitantly. The most frequently reported adverse events were somnolence $(12.5 \%)$, fatigue $(9.2 \%)$, and weight gain $(5.0 \%)$ The following adverse events were observed in more than $1 \%$ of patients:

\begin{tabular}{|c|c|c|}
\hline \multicolumn{3}{|c|}{$\begin{array}{l}\text { Adverse Events Reported } \\
\text { By More Than } 1 \% \text { of Patients }\end{array}$} \\
\hline $\begin{array}{l}\text { Body System/ } \\
\text { Adverse Event }\end{array}$ & $\begin{array}{l}\text { Number of } \\
\text { Patients }\end{array}$ & $\begin{array}{c}\text { Incidence } \\
n=2081\end{array}$ \\
\hline $\begin{array}{l}\text { Nervous } \\
\text { somnolence } \\
\text { headache } \\
\text { dizziness } \\
\text { nervousness } \\
\text { depression } \\
\text { memory disturbances } \\
\text { diplopia } \\
\text { aggression } \\
\text { ataxia } \\
\text { vertigo } \\
\text { hyperactivity } \\
\text { vision abnormal } \\
\text { confusion } \\
\text { insomnia } \\
\text { impaired concentration } \\
\text { personality disorder } \\
\text { agitation }\end{array}$ & $\begin{array}{r}261 \\
80 \\
79 \\
56 \\
52 \\
47 \\
46 \\
42 \\
39 \\
39 \\
37 \\
34 \\
29 \\
26 \\
25 \\
23 \\
21\end{array}$ & $\begin{array}{r}12.5 \\
3.8 \\
3.8 \\
2.7 \\
2.5 \\
2.3 \\
2.2 \\
2.0 \\
1.9 \\
1.9 \\
1.8 \\
1.6 \\
1.4 \\
1.3 \\
1.2 \\
1.1 \\
1.0\end{array}$ \\
\hline $\begin{array}{l}\text { Digestive } \\
\text { abdominal pain } \\
\text { constipation } \\
\text { vomiting } \\
\text { nausea }\end{array}$ & $\begin{array}{l}34 \\
29 \\
28 \\
28\end{array}$ & $\begin{array}{l}1.6 \\
1.4 \\
1.4 \\
1.4\end{array}$ \\
\hline $\begin{array}{l}\text { Body as a Whole } \\
\text { fatigue } \\
\text { weight gain } \\
\text { asthenia }\end{array}$ & $\begin{array}{r}192 \\
104 \\
23\end{array}$ & $\begin{array}{l}9.2 \\
5.0 \\
1.1\end{array}$ \\
\hline
\end{tabular}

Adverse events reported with a frequency of less than $1 \%$ include: anxemotional lability, behavioural disturbances including psychosis, rritability, tremor, abnormal gait, speech disorder, increased appetite, and dyspepsia.

As with other antiepileptic drugs, some patients may experience an increase in seizure frequency with vigabatrin treatment (see PRECAUTIONS)

Laboratory data indicate that vigabatrin treatment does not lead to renal or hepatic toxicity. Chronic treatment with vigabatrin may be associated with a slight decrease in hemoglobin, which rarely attains clinical significance.

Pediatric Safety Safety data is available in 299 children, aged 2 months to 16 years (1 patient was 18 years of age), participating in clinical trials with vigabatrin. Relationship of adverse events to vigabatrin therapy was not clearly established as children were taking other antiepileptic drugs concomitantly.

The most frequent adverse event observed in children was "hyperactivity" (reported as hyperkinesia $7.7 \%$, agitation $2.3 \%$, excitation $0.3 \%$ or restlessness $0.7 \%$ ), which was observed in $11.0 \%$ of children, an incidence higher than that seen in adults. Other commonly reported adverse events were somnolence $(8.0 \%)$ and weight gain $(3.0 \%)$.

The following adverse events were reported in children with a frequency greater than $1 \%$ :

Adverse Events Reported By More Than 1\% of Pediatric Patients

\begin{tabular}{|l|c|c|}
\hline $\begin{array}{l}\text { Body System/ } \\
\text { Adverse Event }\end{array}$ & $\begin{array}{c}\text { Number of } \\
\text { Patients }\end{array}$ & $\begin{array}{c}\text { Incidence } \\
\mathbf{n = 2 9 9}\end{array}$ \\
\hline Nervous & & \\
Somnolence & 24 & 8.0 \\
hyperkinesia & 23 & 7.7 \\
aggression & 8 & 2.7 \\
insomnia & 8 & 2.7 \\
agitation & 7 & 2.3 \\
ataxia & 7 & 2.3 \\
emotionat lability & 3 & 1.0 \\
headache & 3 & 1.0 \\
increased seizures & 3 & 1.0 \\
\hline Digestive & & \\
vomiting & 6 & 2.0 \\
nausea & 3 & 1.0 \\
increased saliva & 3 & 1.0 \\
\hline Body as a Whole & & \\
weight gain & 9 & 3.0 \\
fatigue \\
hypotonia & 8 & 2.7 \\
& 3 & 1.0 \\
\hline
\end{tabular}

SYMPTOMS AND TREATMENT OF OVERDOSAGE

There is no specific antidote. The usual supportive measures should be employed.

Two cases of SABRIL (vigabatrin) overdose have been reported. In the first case, the patient accidentally took a dose of $14 \mathrm{~g}$ daily for 3 days and transient vertigo and tremor were reported. in the second case an 18-year old female $100 \mathrm{k} 30 \mathrm{~g}$ of vigabatrin and $250 \mathrm{mg}$ of chlorazepate in a suicide attempt. The patient was admitted to hospital in a state of coma which lasted four days; however, the coma was considered to be due to the chlorazepate rather than vigabatrin. The patient recovered without sequelae.

\section{DOSAGE AND ADMINISTRATION}

SABRIL (vigabatrin) is intended for oral administration once or twice daily and may be taken with or without food. Sabril should be added to the patient's current antiepileptic therapy.

Instructions to the patient on the use of SABRIL are provided in the INFORMATION FOR THE CONSUMER Section.

Adults The recommended starting dose is $1 g$ /day, although patients with severe seizure manifestations may require a starting dose of up to $2 \mathrm{~g} /$ day. The daily dose may be increased or decreased in increments of $0.5 \mathrm{~g}$ depending on clinical response and tolerability. The optimal dose range is between $2.4 \mathrm{~g} /$ day. Increasing the dose beyond $4 \mathrm{~g}$ /day does not usually result in improved efficacy and may increase the occurrence of adverse reactions.

Children The recommended starting dose in children is $40 \mathrm{mg} / \mathrm{kg} / \mathrm{day}$ increasing to $80-100 \mathrm{mg} / \mathrm{kg} /$ day depending on response. Therapy may be started at $0.5 \mathrm{~g} /$ day, and raised by increments of $0.5 \mathrm{~g} /$ day weekly depending on clinical response and tolerability.

\begin{tabular}{|r|c|c|}
\hline Bodyweight & Daily Dose & No. Tablets/Day \\
\hline $10-15 \mathrm{~kg}$ & $0.5-1 \mathrm{~g} /$ day & $1-2$ tablets/day \\
$16-30 \mathrm{~kg}$ & $1-1.5 \mathrm{~g} /$ day & $2-3$ tablets/day \\
$31-50 \mathrm{~kg}$ & $1.5-3 \mathrm{~g} /$ day & $3-6$ tablets/day \\
$>50 \mathrm{~kg}$ & $2-4 \mathrm{~g} /$ day & $4-8$ tablets/day \\
\hline
\end{tabular}

Elderly and Renally Impaired Patients Vigabatrin is almost exclusively eliminated via the kidney and, therefore, caution should be exercised when administering the drug to the elderly, and more particularly to patients with creatinine clearance less than 60 $\mathrm{mL} / \mathrm{min}$. It is recommended that such patients be started on a lower dose of vigabatrin and observed closely for adverse events such as sedation and contusion. 


\section{AVAILABILITY OF DOSAGE FORMS}

Tablets Each SABRIL (vigabatrin) $500 \mathrm{mg}$ tablet is white to offwhite film-coated, oval biconvex, and imprinted "SABRIL" on one side. SABRIL is available in HDPE bottles containing 100 tablets.

Product Monograph available upon request.

References:

1. Drugs Reprint. Adis International: June 1991, Vol. 41 No. 6. pQ. 882.

2. Riekkinen et al. Cerebrospinal fluid GABA and seizure control with vigabatrin. Br. J. Clin. Pharmac. (1989).27-87S-94S

3. Reynotds, $E H$ et al. A controlled trial of gamma-vinyl-GABA (vigabatrin) in drug-resistant epilepsy. Br. J. of Clin. Pract. Suppl. 61.

4. Remy C. \& Beaumont D. Efficacy and safety of vigabatrin in the long-term treatment of refractory epilepsy. Br. J. Clin. Pharmac. (1989).27,125S-129S.

5. Browne, TR, Mattson, RH et al. Vigabatrin for refractory complex partial seizures: Multicenter single-blind study with long-term follow-up. Neurology 1987: 37: 184-189.

6. The Belgian Vigabatrin Evaluation Group' and A. Lhoir": Vigabatrin in uncontrolled seizures: Belgian clinical experience. Clinical Neurotogy and Neurosurgery. 96 (1994) 42.46.

Clinical Neurotogy and Neurosurgery. 96 (1994)

7. Data on file, Marion Merrell Dow Canada 1994.

9. Livingston, JH, Beaumont $\mathrm{D}$. et al. Vigabatrin in the treatment of epilepsy in children. Br. J. Clin. Pharmac. (1989).27.109S-112S.

10. Dijkstra, JB, MCGuire, AM, \& Trimble, MR. The effect of vigabatrin on cognitive function and mood. Human Psychopharmacology, vol. 7,000-000 01992

11. Dodrill, $C B, A$ rnett, JL et al. Evaluation of the effects of vigabatrin on cognitive abilities and quality of life in epilepsy. Neurology 1993;2501-2507.

12. McGuire, AM, Duncan, JS, Trimble, MR. Effects of vigabatrin on cognitive function and mood when used as add-on therapy in patients with intractable epilepsy. Epilepsia. 33(1):128-134, 1992.

13. Schecter, BJ, Hanke, NFJ et al. Biochemical and clinicat effects of $y$-vinyl GABA in patients with epilepsy. Neurology $34: 182-86$ (1984).

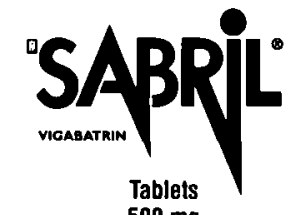

$500 \mathrm{mg}$

Antiepileptic

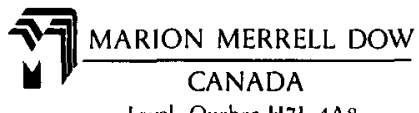

Laval, Quebec H7L 4A8

SABR94-020E

See page xii.

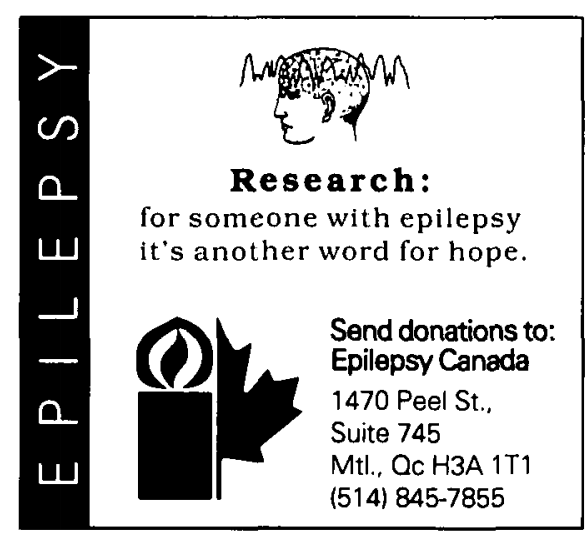

WHEN THE GOAL IS TOTAL CONTROL, ADD

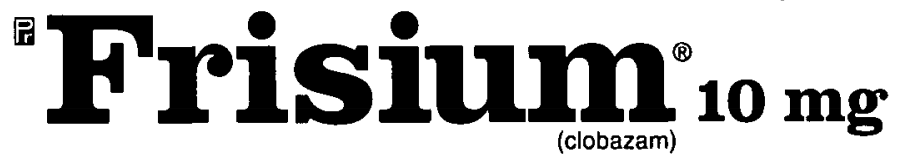

FOR A COMPREHENSIVE APPROACH TO SEIZURE CONTROL
Frisium (clobazam) Tablets $10 \mathrm{mg}$

THERAPEUTIC CLASSIFICATION Anticonvulsant for adjunctive therapy. INDICATIONS Frisium (clobazam) has been found to be of value as adjunctive therapy in patients vith epilepsy who are not adequately stabilized with their current anti-convutsant therapy. CONTRAINDICATIONS Hypersensitivity to clobazam, severe muscle weakness (myasthenia gravis) and narrow angle glaucoma. WARNINGS Use in the elderly: Frisium (clobazam) should be used with caution in elderly and debilitated patients, and those with organic brain disorders, with treatment initiated at the lowest possible dose. [See Precautions]. Potentiation of drug effects: Patients should be cautioned about the possibility of additive effects when Frisium is combined with alcohol or other drugs with central nervous system depressant effects. Patients should be advised against consumption of alcohol during treatment with Frisium. [See Precautions]. Physica and psychological dependence: Physical and psychological dependence are known to occur in persons taking benzodiazepines. Caution must be exercised if it is at all necessary to administer increase the dose on their own initiative. Such patients must be placed under careful surveillance. Signs and symptoms of withdrawa may follow discontinuation of use of Frisium; thus it should not be abruptly discontinued after prolonged use. [See Precautions]. Use in pregnancy: Frisium should not be used in the first trimester of pregnancy and thereafter only if strictly indicated. Nursing mothers in whom therapy with Frisium is indicated should cease breast-teeding since clobazam passes into breast milk. Several studies have suggested an increased risk of congenital malformations associated with the use of minor tranquilizers (chlordiazepoxide, diazepam and meprobamate) during the first trimester of pregnancy. If Frisium is prescribed to a woman of child-bearing potential she should be warned to consult her physician regarding the discontinuation of the drug if she intends to become, or suspects she might be, pregnant. Anterograde amnesia: Anterograde amnesia is known to occur afte administration of benzodiazepines. Use in patlents with depression of psychosis: Frisium is not recommended for use in patients vith depressive disorders or psychosis. PRECAUTIONS Driving and Hazardous Activities: Frisium (clobazam) possesses a mild central nervous system depressant effect, therefore patients should be cautioned against driving, operating dangerous machinery of engaging in other hazardous activities, particularly in the dos adjustment period, or until it has been established that they do not become drowsy or dizzy. Use in the Elderly: Elderly and debilitated patients, or those with organic brain syndrome, have been found to be prone to the CNS depressant activity of benzodiazepines even after low doses. Manifestations of this CNS depressant activity includ ataxia, oversedation and hypotension. Therefore, medication should be administered with caution to these patients, particularly if a drop in blood pressure might lead to cardiac complications. Initial doses should be low and increments should be made gradually, depending on the response of the patient, in order to avoid oversedation. Dependence Liabih chould not be administered to individuals prone to drug abuse. Caution should be observed in al patients who are considered to have potential for psychologica dependence. Withdrawal symptoms have been observed after abrupt discontinuation of benzodiazepines. These include irritability, nervousness, insomnia, agitation, tremors, convulsions, diarrhea, abdominal cramps, vomiting and mental impaiment. As with other benzodiazepines, Frisium should be withdrawn gradually. Tolerance: Loss of part or all of the anti-convulsant effectiveness of clobazam has been described in patients who have been receiving the drug for some time. There is no absolute or universal definition for the ohenomenon and reports vary widely on its development. The reported success of clobazam in intermittent therapy in catamenial epitepsy implies that tolerance may be minimized by intermitten treatment but long-term follow-up is unreported. No studies have identified or predicted which patients are likely to develop tolerance or precisely when this might occur. Use in Mental and Emotional Disorders: It shoutd be recognized that suicidal tendencies may be present in patients with emotional disorders; particularly thos depressed. Protective measures and appropriate treatment may be necessary and should be instituted without delay. Since excitement and other paradoxical reactions can result from the use of benzodiazepines in psychotic patients. Clobazam should not be used in patients suspected of having psychotic tendencies. Use in Patients with Impaired Renal or Hepatic Function: Clobazam requires deallylation and hydroxylation before conjugation. Usual precaution should be taken if frisium is used in patients who may have some impairment of renal or hepatic function. It is suggested that the dose in such cases be carefully titrated. In patients for whom prolonged Frisium to individuals with a history of drug misuse or those who may neurological impairment and other possible adverse reactions. therapy with Frisium is indicated, blood counts and liver function should be monitored periodicalty. Use in Palients with Acute, Severe Respiratory Insufficiency: In patients with acute, severe respiratory insufficiency, respiratory function should be monitored. Laboratory Tests: If Frisium is administered for repeated cycles of therapy, periodic blood counts and liver and thyroid function tests are advisable. Drug Interactions: Most studies of the potential interactions of clobazam vith other anti-epileptic agents have failed to demonstrate significant interactions with phenytoin, phenobarbital, or carbamazepine. However, one study noted that the addition of clobazam caused a $25 \%$ increase in serum drug tevels in $29 \%$ of patients taking carbamazepine, $63^{\circ}$; of patients taking phenytoin. $13 \%$ of those taking valproate and $14 \%$ of those on phenobarbital. The contradictory findings in different studies are presumably due to variations in patient susceptibility, and although clinically significan interactions are unusual, they may occur. Alcohol may also significantly increase plasma clobazam lovels. Several of the ostablished gnti-epileptic agents: carbamazepine diphenythydantoin, phenobarbital, valproic acid, cause the blood levels of clobazam to decrease slightly. Findings are less consistent with regard to $\mathrm{N}$-desmethylclobazam: serum levels are lower with concurrent valproic acid, but higher with carbamazepine and diphenylhydantoin. Toxicologic Studies: In mouse, clobazam was associated with hepatomas in high-dose males. In rat, an increased incidence of thyroid adenomas was seen in males. There were three malignancies: two (male and female) in the thyroid and one (temale) in the fiver. The relevance of these findings to man has not been established. ADVERSE REACTIONS From 19 published studies of Frisium (clobazam) use in epileptic patients, the overall incidence of side-effects was 33\% of which drowsiness, dizziness and fatigue were most frequently reported. Canadian experience provides a similar overall incidence (32\%) with drowsiness reported in $17.3 \%$ of patients, and 12\% of patients terminating treatment because of sideeffects. The incidence of side-effects was lower in patients under 16 years of age $(23.7 \%)$ than the incidence in adults $(43.1 \%): p<0.05$ whereas treatment discontinuation incidences were similar across age groups: $10.6 \%$ and $13.8 \%$ respectively. The following sido-effects occurred at incidences of greater than $1 \%$ (ataxia [3.9\%], weight gain [2.2\%] dizziness $[1.8 \%$, nervousness [1.6\%) behaviour disorder $[2.2 \%]$, dizziness $[1.8 \%]$, nervousness $[1.6 \%]$, behaviour disorder
$[1.4 \%]$, hostility and blurred vision $[1.3 \%$,$) while other effects$ occurred at a less than $1 \%$ incidence. Symptoms of tiredness may sometimes appear, especially at the beginning of treatment with Frisium and when higher doses are used. Also in rare instances and usually only temporarily, the patient may experience dryness of the mouth, constipation, loss of appetite, nausea, dizziness, musclo weakness, disorientation, tiredness, or a fine tremor of the fingers, but also paradoxical reactions, e.g., restiessness and irritability. After prolonged use of benzodiazepines, impairment of consciousness combined with respifatory disorders has been reported in very rare cases, particularly in elderly patients; it sometimes persisted for some length of time. Under experimental conditions, impairment of alertness has been observed to be less pronounced after therapeutic doses of clobazam than after other benzodiazepines. Nevertheless, even when used as directed, the drug may alter reactivity to such an extent as to impair driving performance or the ability to operate machinery, especially when it is taken in conjunction with alcohol. A with other drugs of this type (benzodiazepines), the therapeutic benefit must be balanced against the risk of habituation and dependence durino prolonged use Isolated cases of skin reactions such as rashes or urticaria tave been observed. DOSAGE AND ADMINISTRATION As with other benzodiazepines, the possibility of a borne in mind. In patients vith impaired liver and kidney function Frisium (clobazam) should be used in reduced dosage. Adults: Small doses, $5 \cdot 15 \mathrm{mg} / \mathrm{day}$, should be used initially, gradually increasing to a maximum daily dose of $80 \mathrm{mg}$ as necessary. Chitdren: In infants ( 2 years), the initial daily dose is $0.5-1 \mathrm{mo} / \mathrm{kg} /$ day. The initial dose in children (2-16 years) should be $5 \mathrm{mg} /$ day, which may be increased at 5 -day intervals to a maximum of $40 \mathrm{mg} / \mathrm{day}$. As with all benzodiazepines, abrupt withdrawal may precipitate seizures. It is therefore recommended that Frisium be gradually reduced in dose before treatment is discontinued. Administration: If the daily dose is divided, the higher portion should be taken at night. Daily doses up to $30 \mathrm{mg}$ may be taken as a single dose at night. AVALABILITY Frisium tablets of $7 \mathrm{~mm}$ ' obverse and the Hoechst 'Tower and Bridge' logo on the reverse. Frisium $10 \mathrm{mg}$ tablets are packaged in blisters of PVC film and aluminium foil and are distributed in packs of 30 [3×10] tablets. Product Monograph available on request. decrease in anticonvulsant efficacy in the course of treatment must be

References: 1. Schmidt D. Clobazam for treatment of intractable epilepsy: A critical assessment. Ep.'epsia 1994;35(Suppl.5):S92-S95. 2. Canadian Clobazam Cooperative Group. Clobazam in the treatment of refractory epilepsy. The Canadian Experience. A retrospective study. In: Epilapsia 1990:1-10. 


\section{CLAUDE BERTRAND \\ FELLOWSHIP IN NEUROSURGICAL RESEARCH}

The division of Neurosurgery at Notre-Dame Hospital affiliated with the University of Montreal is offering one year fellowship to conduct independent clinical and/or basic sciences investigation in neurosurgery. The fellowship will start on January 1st, 1997.

-Pre-requisites: completion of training in neurology, neurosurgery or advanced degree in neurosciences. The applicant must submit a detailed abstract of his research project as well as a Curriculum Vitae.

Stipend \$C35,000.

Application deadline: June 30th, 1996.

Send applications to:

Michel W. Bojanowski, MD, FRCS(C)

Claude Bertrand

Fellowship in Neurosurgical Research

Division of Neurosurgery

Notre-Dame Hospital

1560 Sherbrooke Street East

Montreal, Quebec H2L 4M1
DEPARTMENT OF SURGERY, UNIVERSITY OF OTTAWA UNIVERSITY DIVISION CHAIR - NEUROSURGERY

The Department of Surgery at the University of Ottawa is currently seeking a University Division Chair, for the Division of Neurosurgery. This division is distributed over two adult hospitals and one pediatric hospital. There are seven Geographical Full-time (GFT) faculty. There are a considerable number of resources for academic achievement available in the faculty. These include two major research institutes with significant funding in the Neuroscience area. The opportunities for expansion in recruitment are significant in the Ottawa-Carlton region with a population of one million.

The ideal candidate would be a mature, experienced individual with proven leadership skills. The University of Ottawa is limiting the probe to a Tier One Level Canadian search.

For further information interested candidates should contact Dr. Hartley S. Stern, Professor and Chairman, Department of Surgery, University of Ottawa, and Chair of the Search Committee at the Ottawa Civic Hospital, Suite 105, CPC Bldg., 1053 Carling Avenue, Ottawa, ON K1Y 4E9. Tel: (613)761-5413, Fax: (613)761-5424 by February 29, 1996

\title{
ADVERTISERS INDEX
}

\author{
Abbott \\ Epival - ifc, xvii, xviii \\ Berlex \\ Betaseron - xiii, xxi, xxii \\ Ciba/Geigy \\ Tegretol - obc, xvi, xix, xx \\ Dupont \\ Sinemet - ix, xxvi \\ Glaxo Wellcome \\ Imitrex - vi, vii, xxv \\ Lamictal - iv, v, x, xi, xxiii, xxiv \\ Hoescht \\ Frisium - ibc, iii, xxx \\ Marion Merrell Dow \\ Sabril - xii, xxix, $x x x$ \\ Parke Davis \\ Neurontin - viii, xv, xxvii, xxviii \\ Classified Ads \\ $-\mathrm{xxxi}$
}




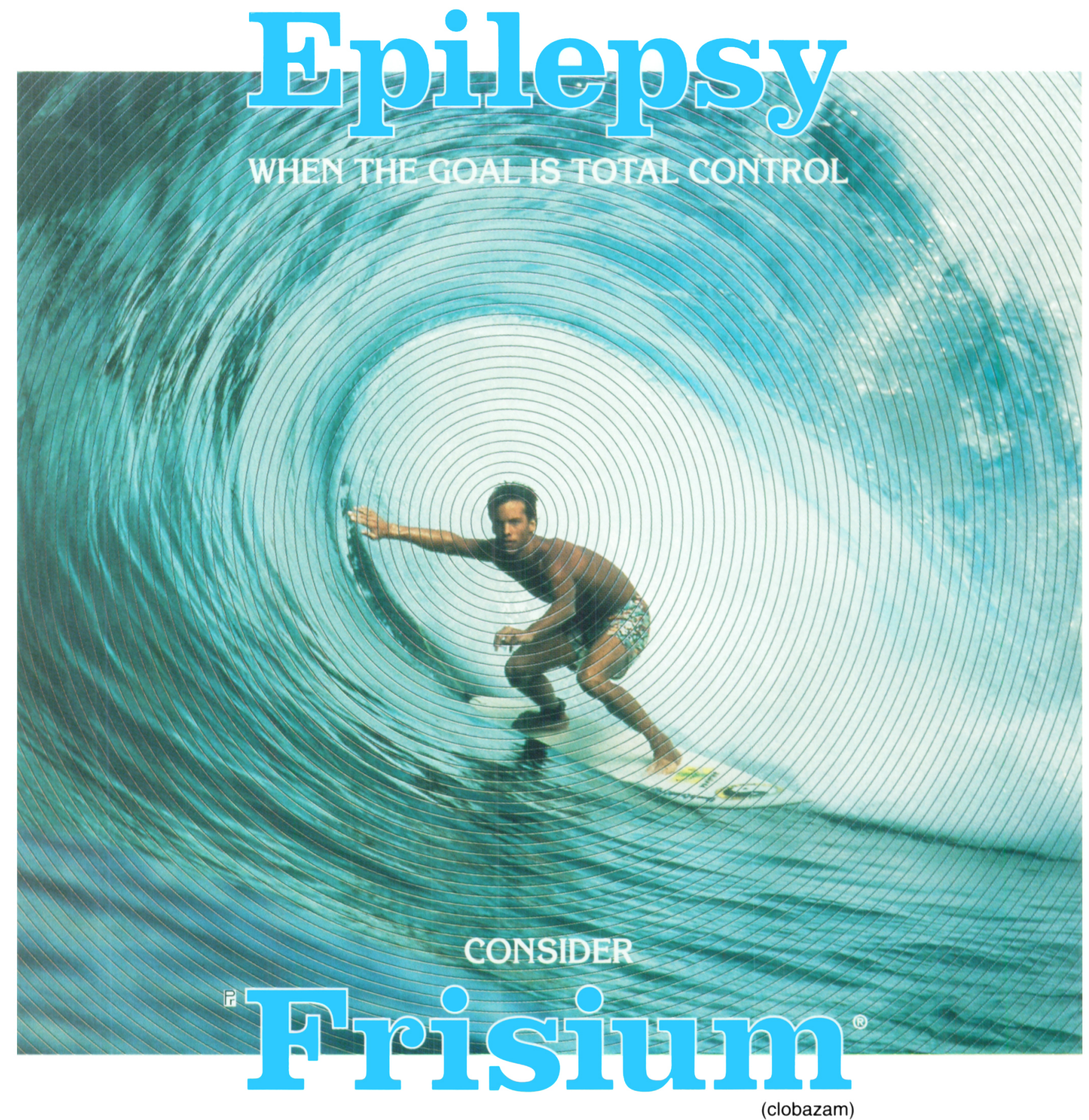

- Impressive degree of complete seizure control.'

- Effective in all seizure types in pediatric and adult patients. ${ }^{2}$

- Frisium is a "remarkably effective and [generally] safe add-on anti-epileptic drug".

- Once-daily dosage, preferably at bedtime.

\section{For a comprehensive approach to seizure control}

*Daily dose can be divided for some patients.

Frisium is indicated as adjunctive therapy in epileptic patients not adequately stabilized with their current anticonvulsant therapy. As with all benzodiazepines, patients (particularly geriatrics) should be cautioned accordingly. Most frequent adverse effects (> $1 \%$ ) include ataxia, weight gain, dizziness and nervousness. 


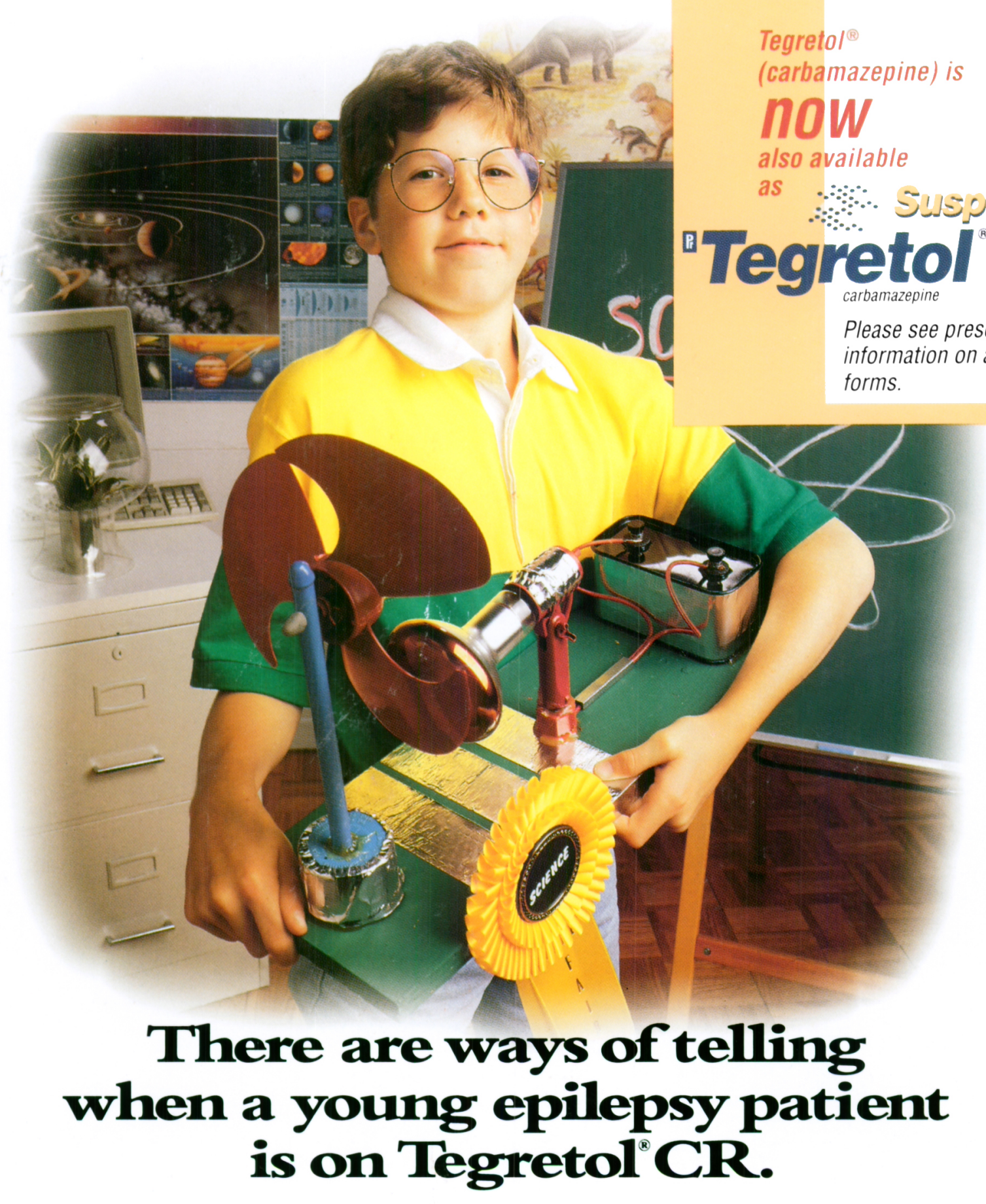

\section{Excellent Seizure Control.}

QTegretol ${ }^{*}$ CR (controlled-release carbamazepine) controls seizures in many patients-with little impact on cognitive function. ${ }^{12}$ Tegretol CR can leave many patients free to think clearly and do their best.'

\section{Consistent Blood Levels.}

Tegretol CR delivers fewer "peaks and valleys" in blood levels than conventional Tegretol. That means fewer side effects and a more stable pattern of cognitive functioning.

The most commonly reported side effect with carhamazepine

drowsiness. This reaction usually occurs only during the initia

phase of therapy $y^{4}$ and can he minimized by using controlled

release carbamazepine (TEGRETOL"CR) "

\section{Convenient B.I.D. Dosing.}

When initiating or switching therapy, consider Tegretol CR. It comes in easyto-break $200 \mathrm{mg}$ and $400 \mathrm{mg}$ tablets for dosage flexibility, and offers B.I.D. dosing to enhance patient compliance.

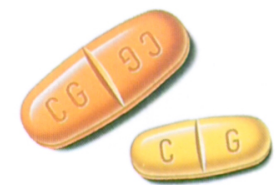

\section{TEGRETOL CR.}

Helping epilepsy patients reach their full potential. 